\title{
Hurricanes: Intertemporal Trade and Capital Shocks
}

\author{
John C. Bluedorn ${ }^{\dagger}$ \\ Dept. of Economics, University of Oxford \\ Manor Road Building, Manor Road \\ Oxford OX1 3UQ \\ United Kingdom \\ Email: john.bluedorn@economics.ox.ac.uk \\ Tel.: +44 (0) 1865-281-483 \\ Fax: +44 (0) 1865-271-094
}

May 2005

\begin{abstract}
Hurricanes in the Caribbean and Central America represent a natural experiment to test the intertemporal approach to current account determination. The intertemporal approach allows for the possibility of intertemporal trade, via international borrowing. Previous tests of intertemporal current account (ICA) models have typically relied upon the identification of shocks in a VAR framework with which to trace the current account response. Hurricane shocks represent exactly the kind of temporary, country-specific shock required by the theory, allowing for the intertemporal current account response to be estimated without recourse to a VAR shock decomposition. Using data on the economic damages attributable to a hurricane, I estimate the economy's response to a hurricane-induced capital shock within a fixed effects panel model. The current account response qualitatively conforms to the S-shaped response predicted by the theory, indicating that countries are engaging in intertemporal trade. However, the exact timing and magnitude of the response differs from a standard ICA model's smooth behavior. A hurricane which destroys capital valued at one year's GDP pushes the current account over GDP into deficit by 5 percentage points initially. 3-8 years after such a hurricane, the current account over GDP moves into surplus at 2.7 percentage points.
\end{abstract}

JEL Classification: F320, F410

Keywords: hurricanes, natural experiment, current account dynamics

\footnotetext{
${ }^{\dagger}$ This paper is a greatly revised version of the first chapter of my dissertation. Special thanks to David Romer, Maurice Obstfeld, Andrew Rose, and Michael Jansson for their guidance and comments. I would also like to thank Björn Brügemann, Elizabeth Cascio, Paola Guiliano, Rebecca Hellerstein, and Hui Tong for their feedback. All errors are mine.
} 


\section{Introduction}

In the 1970s, the OPEC oil price shocks generated large current account imbalances. Oil-consuming countries borrowed extensively on the international capital market to pay higher oil prices, while oil-producing nations sought out investment opportunities for their revenue windfall. Traditional Keynesian models did not provide much insight into the long-run consequences of such shocks for external debt sustainability, as they failed to account for the intertemporal budget constraint. Around the same time, Lucas (1976) argued that reliable macroeconomic policy analysis needed a firm grounding in theoretical models explicitly based on economic agents' forward-looking behavior. The intertemporal approach to the current account emerged in the early 1980s as an attempt to understand the consequences of external shocks for an open economy within a forward-looking dynamic optimization framework. ${ }^{1}$ Following models such as the Ramsey-Cass-Koopmans and Diamond models, an intertemporal current account (ICA) model describes the open macroeconomy's dynamics as the solution to a representative agent's optimization problem, subject to an intertemporal budget constraint. Its fundamental innovation is the introduction of forward-looking intertemporal trade which occurs through international borrowing. Intertemporal trade allows the agent to save and borrow in response to country-specific shocks in order to smooth the evolution of the marginal utility of consumption, while maximizing returns. ${ }^{2}$ An ICA model thus predicts a specific empirical relationship between movements in a country's current account and country-specific shocks.

Although presenting an intuitive framework to understand current account dynamics, most empirical tests have rejected the intertemporal approach to the current account. I

\footnotetext{
${ }^{1}$ For a good account of the basic history and origins of the intertemporal approach, see Obstfeld and Rogoff [1995] and Obstfeld and Rogoff [1996]. Intellectually, the intertemporal approach is a precursor in the development of the New Open Economy Macroeconomics. New Open Economy models enhance a standard intertemporal current account model by introducing imperfect competition and nominal rigidities [Lane, 2001].

${ }^{2}$ When everyone is subject to the same shock, there is no differential across countries to make risk-sharing through borrowing and lending desirable. Formally, the world real interest rate changes to eliminate the gains from borrowing and lending in response to a global shock. Thus, the current account does not generally respond to global shocks.
} 
suggest that many of the documented empirical rejections of ICA models may be due to violations of the auxiliary assumptions required in structural tests (detailed later) and the failure to properly identify country-specific shocks.

I argue that hurricanes represent a natural experiment in which to test the predictions of an ICA model. Hurricanes are large, temporary, exogenous, negative country-specific capital shocks. In this paper, I evaluate the responses of the small, open economies of the Caribbean and Central America to large hurricane shocks. Some of these economies are exceptionally small. For example, St. Kitts and Nevis and Antigua and Barbuda both have populations under a hundred thousand. In the markets in which they participate, they clearly take world economic conditions as given. They do not influence world prices or interest rates. Such economies are real world counterparts to the theoretical construct of small, open economies.

Using economic damages attributable to a storm, I find evidence that countries do engage in intertemporal trade in response to hurricane shocks, thus broadly supporting the key prediction of an ICA model. In response to an unanticipated, negative capital shock, an ICA model predicts that the country experiences an immediate fall in output. Accompanying the fall in output is a fall in saving (from consumption smoothing) and a rise in investment (to replace the capital destroyed). In sum, these responses imply a fall in the current account, identical to a fall in net foreign assets or a rise in international borrowing. After the initial shock, output is predicted to recover and investment to fall back to its steady state level. The exact predicted future current account and saving responses depend on the relationship between a country's rate of time preference and the world interest rate, as this determines how the intertemporal budget constraint binds. For a relatively impatient country, both saving and the current account are predicted to rise in the future. If the country is relatively patient, then saving and the current account remain below what they would have been in the absence of the capital shock. ${ }^{3}$ Deaton

\footnotetext{
${ }^{3}$ An economy's degree of patience is related to its long-run propensity to be a debtor (impatient) or a creditor (patient). Notice how this is potentially related to Kraay and Ventura's [2000] observation that debtor and creditor economies may exhibit different current account responses.
} 
[1990] argued that impatience is the more realistic assumption in modelling developing countries. I follow him by focusing on the impatient case. When capital adjustment costs are introduced into the model, the responses of all the variables are slowed. Furthermore, the response magnitudes are reduced, as adjustments are spread over a greater period of time.

Corresponding to the primary variables of the standard ICA model, I investigate the effect of a hurricane shock on: the current account over GDP, the national saving rate, capital investment rate, real per capita output growth, and real per capita consumption growth. I also consider the effect of a hurricane shock on a set of additional variables which may be significant drivers of current account behavior in light of a large capital shock, but about which the standard ICA model is silent. These include: net transfers from abroad over GDP, foreign aid over GDP, worker remittances over GDP, and the government budget deficit over GDP.

I estimate a heteroskedasticity and autocorrelation robust panel model for each of the macroeconomic variable's listed above, including both country and time fixed effects. The country fixed effect captures the country-specific trend in a macroeconomic variable, while the time fixed effect captures any global shocks experienced by the region. Hurricane economic damages and its lags are the explanatory variables in the baseline regression. I then allow for different responses across countries by introducing various country-specific characteristics interacted with the damages measure. The coefficients on hurricane economic damages, its lags and interactions thus embody the reduced form impulse response of the macroeconomic variable to a hurricane shock, allowing the response to be unrestricted.

The empirical results support an ICA model's qualitative predictions. There is clear evidence of intertemporal trade taking place in response to the large, country-specific, negative capital shocks caused by hurricanes. This manifests as a current account response that is similar to that described above: the current account falls initially, as output falls and investment rises; the current account then rises, as saving rises and in- 
vestment falls. The results indicate a 5 percentage point decline in the current account to GDP ratio in the year after a large hurricane shock. ${ }^{4} \quad 3-8$ years after a hurricane shock, the current account to GDP ratio rises approximately 2.7 percentage points above its long-run trend. Such an S-shaped intertemporal response is consistent with an ICA model, but not with an atemporal model. However, the estimated current account response's timing and magnitude differs from the predictions of a standard ICA model. This suggests several modifications to a standard ICA model, all of which influence the rate at which the intertemporal budget constraint binds.

The paper proceeds as follows. In Section 2, I discuss the empirical record of ICA models, examining how previous tests might generate false rejections. In Section 3, I present more information regarding hurricanes as a natural experiment, generating random changes in the size of a country's physical capital stock. In Section 4, I present a standard ICA model and discuss its predictions. In Section 5, I describe the hurricane economic damages' measure and the macroeconomic data used in the analysis. In Section 6, I discuss the panel data model I employ to estimate the macroeconomic response to a hurricane. In Section 7, the empirical results of the analysis are presented. In Section 8, I discuss the economic significance of the findings and their implications for intertemporal models. In Section 9, I conclude by summarizing and interpreting my findings more broadly.

\section{The Empirical Record of Intertemporal Current}

\section{Account Models}

Two broad approaches have developed to test ICA models. They employ different strategies to achieve the identification of shocks and thus ensure proper statistical inference on the current account response.

\footnotetext{
${ }^{4} \mathrm{~A}$ large hurricane shock is one which inflicts capital stock damages equal to a year's GDP. The changes in the current account to GDP ratio are relative to trend.
} 
The first research approach is structural. Inspired by Campbell's 1987 innovation in testing present-value models, the structural approach exploits the information structure implied by a forward-looking rational expectations model to establish identification. ${ }^{5}$ Under certain assumptions, an ICA model implies a simple formulation of the current account, as the negative expectation of the present-value of net output. The identification assumption effectively allows for the current account response to shocks to be recovered in a VAR framework. Applications of present-value tests to an ICA model include Sheffrin and Woo [1990], Otto [1992], Ghosh [1995], and Ghosh and Ostry [1995].

The second research approach is nonstructural. Political and natural events that are plausibly exogenous are used to achieve the identification of temporary country-specific shocks, which can then be directly used to estimate the current account response. Ahmed [1987] follows such an approach. Arguing that wars are exogenous and temporary, he examines the relationship between public military spending (government budget deficits) and the trade balance in the United Kingdom from 1723 to $1913 .{ }^{6}$ He then compares the observed responses of economic variables to the predictions of an ICA model. The "natural experiment" afforded by wartime public spending thus generates identification in the analysis.

Each approach presents its own advantages and disadvantages for proper inference. There are three main drawbacks to empirical testing of ICA models using structural present-value tests. First, a rejection of the model could be due to any one of the auxiliary assumptions required for the formulation of the present-value test. These include: (1) quadratic period utility; (2) a rate of time preference that is equal to the world real interest rate; and (3) shocks that follow a martingale difference process. ${ }^{7}$ The model is thus an open economy version of the permanent income (PI) model. Second,

\footnotetext{
${ }^{5}$ Specifically, an unobserved components structure is assumed for choice variables. The unobserved components capture information available to the agent, but not to the econometrician. Observed choices by agents under rational expectations then become sufficient statistics for the unobserved components (or shocks). This allows for the expectation of future net output flows to be evaluated, which determines the current account under the null.

${ }^{6}$ Ahmed [1986] used a similar approach to investigate crowding out and Ricardian equivalence.

${ }^{7}$ The last assumption means that conditional expectations are linear projections on past information, yielding a standard VAR prediction framework.
} 
a present-value test fails to differentiate between global and country-specific shocks. An ICA model predicts a current account response to country-specific shocks, whereas global shocks (which affect all countries) result in no current account response. ${ }^{8}$ Glick and Rogoff [1995] demonstrated the importance of the global versus local shock distinction in their study of the effect of productivity shocks on the current account and investment. Present-value tests implicitly treat all shocks as country-specific, potentially leading to over-rejection of the ICA model. Third, even if all shocks are in fact country-specific, Kasa [2003] demonstrates that present-value tests are not necessarily revelatory about the underlying shocks. Temporary (or transitory) and permanent shocks will generally have different effects, and thus distinguishing between these two types of shocks when testing is important. Considering an ICA PI model with additive net output shocks, Kasa demonstrates that Campbell's method will lead to erroneous inference in certain regions of the parameter space. When the moving average representation with respect to the true shocks is non-invertible, Campbell's method will extract "transitory" shocks that are in fact a combination of the true transitory and permanent shocks. When the measured current account response does not react fully to the "transitory" shock, a present-value test will tend to reject the model. ${ }^{9}$ This can occur for a variety of reasonable parameter values. Taken together, these caveats cast doubt on the generally negative statistical results found in most present-value tests of ICA models. In fact, Kasa remarks that the focus on present-value tests of the ICA model has arguably lead to a "technological regress" in the effective decomposition and identification of shocks, which is necessary for empirical tests of ICA models.

The structural approach using present-value tests makes strong, unambiguous quantitative predictions under the null. It implies that the parameters of the VAR must satisfy certain restrictions. ${ }^{10}$ In contrast, testing under the non-structural approach does not

\footnotetext{
${ }^{8}$ See footnote 2 .

${ }^{9}$ The failure to adequately differentiate between transitory and permanent shocks could also result in a false acceptance of the model.

${ }^{10}$ See Obstfeld and Rogoff [1995, 1996] for a clear exposition of these restrictions.
} 
typically make such clear quantitative predictions. ${ }^{11}$ If one is interested in measuring quantitatively how closely an ICA model predicts the actual current account response, the empirical response of the current account must be compared with the quantitative predictions from a calibrated theoretical model. However, the qualitative predictions of an intertemporal model of the current account differ from the qualitative predictions of an atemporal model, such as the classic Mundell-Fleming model. The difference in qualitative predictions between intertemporal and atemporal models arises from the lack of an intertemporal budget constraint in an atemporal model. The intertemporal budget constraint implies that the current account must exhibit long-run convergence. Thus, a qualitative comparison of the predicted response with the actual response can distinguish the intertemporal and atemporal models. ${ }^{12}$

There have been several attempts to rehabilitate present-value tests of ICA models, by making various modifications to the canonical present-value ICA model (described above). These include introducing time non-separable preferences (via habit formation in consumption), country-specific fiscal policy shocks, world real interest rate shocks, and imperfect international capital mobility (via an upward-sloping supply curve for international debt). Nason and Rogers [2003] review this literature and present a model which nests all of these modifications. Using an interesting Bayesian framework, they test how closely the estimated response from synthetic data generated by the modified ICA model matches the estimated response from actual data. ${ }^{13}$ They find that world real interest rate shocks do the most to move the model predictions closest to the actual response, perhaps highlighting the importance of the global versus country-specific shock

\footnotetext{
${ }^{11}$ A notable exception is related to the classic Feldstein-Horioka 1980 regression, which soundly rejected the intertemporal prediction that investment and saving are contemporaneously unrelated. However, the endogeneity of investment and saving means that a proper test of this prediction requires that a windfall change in income or wealth be used to instrument saving, as only such a windfall change would leave capital returns unchanged. Clearly, a physical capital shock, such as a hurricane, does not fulfill this requirement, meaning that it cannot be used to instrument for saving.

${ }^{12}$ Of course, with sufficient ad hoc assumptions, an atemporal model can exactly replicate the current account predictions of an intertemporal model, rendering the two models observationally equivalent. In an unpublished appendix (Appendix A.2), I present a standard atemporal model which generates predictions different from those of an intertemporal model. It imposes a set of limited but plausible assumptions.

${ }^{13}$ The estimated response from actual data is derived from the standard present-value test.
} 
distinction. While attending to some of the concerns regarding the auxiliary theoretical assumptions of present-value tests, these modifications to structural present-value tests of the ICA still fail to truly distinguish between country-specific and global shocks, and to identify temporary and permanent shocks. ${ }^{14}$

Employing the shock decompositions implied by various econometric models, other work has improved shock identification. Exploiting the long-run budget constraint, Corsetti and Konstantinou [2004] use a cointegration framework to quantify temporary and permanent innovations to net output flows for the United States. Although unable to distinguish between country-specific and global shocks, their findings are generally supportive of an ICA model. ${ }^{15}$ Giannone and Lenza [2004] use a generalized dynamic factor model to allow for country-specific responses to global shocks. With the resulting identification of country-specific shocks, they show that the Feldstein-Horioka puzzle vanishes after the 1970s, thus supporting an ICA model. However, it is difficult to interpret what exactly the identified statistical global shocks are.

Recently, Gournichas and Rey [2005] have presented another explanation for empirical rejections of ICA models, in particular for developed economies. By failing to consider the portfolio composition of net foreign assets (the stock counterpart of the current account), potentially important valuation effects are neglected. ${ }^{16}$ They present results for the United States which support this interpretation, indicating that valuation effects may aid the US in eventually achieving external balance. ${ }^{17}$ However, such valuation effects are likely not as relevant for developing economies, as Obstfeld [2004] explains. A rough

\footnotetext{
${ }^{14}$ Kasa [2003] notes that identifying temporary and permanent additive net output shocks is feasible in the framework of a present-value test, if one uses the moving-average representation of the process directly. Hansen and Sargent [1991] present other possible remedies.

${ }^{15}$ In related work, Hoffmann [2001, 2003] decomposes temporary and permanent, country-specific and global shocks in a VAR framework by employing various orthogonality assumptions.

${ }^{16}$ In related work emphasizing a portfolio-based interpretation of the current account, Kraay and Ventura [2000, 2003] show that if investment risk is high and diminishing returns to capital are weak, current account behavior differs across debtor and creditor economies. In the presence of capital adjustment costs, the short-run behavior of the current account emphasizes movements in net foreign assets as a shock-absorber, while the long-run behavior of the current account reflects portfolio concerns. In regressions of the current account on portfolio-adjusted saving, they demonstrate that their model effectively addresses the Feldstein-Horioka puzzle and thus supports an intertemporal model. However, as with all Feldstein-Horioka type regressions, endogeneity is an issue.

${ }^{17}$ Tille [2004] forcefully demonstrates the potential size of the valuation effect for the US.
} 
decomposition of net foreign assets into development finance (intertemporal trade) and diversification finance (intra-temporal portfolio asset trades) reveals that diversification finance is significantly less operative in developing economies.

In the current paper, I revive the non-structural approach to testing an ICA model, arguing that hurricanes are the temporary, country-specific shocks required by the theory. With a natural experiment research design, it will not be necessary to infer the size or quality of shocks via a VAR-type decomposition. The natural experiment generates the appropriate shock identification.

\section{$3 \quad$ Hurricanes as Natural Experiments}

Each year, the Atlantic basin experiences an average of 9.8 named storms (storms with maximum wind speeds of at least 18 meters per second). ${ }^{18}$ Figure 1 shows the quintennial distribution of named storms since 1960. It includes information on their relative strength. There is substantial interannual variation in storm activity [Landsea et al., 1999]. Of storms affecting the Caribbean and Central America, only a few each year are destructive enough to significantly impact a country's macroeconomy. Pictures of the size of such devastating storms can be seen in Figure 2. These storms can completely engulf an unfortunate island country. The damage wrought by a storm can include home and building destruction, severe beach erosion, and crop and agricultural capital destruction, such as banana trees (see Elsner and Kara [1999]). From an economic perspective, a strong hurricane manifests primarily as a large negative capital shock. ${ }^{19}$

Do such hurricane shocks need to be completely unanticipated in order for a current account effect to manifest, under a standard ICA model? An unanticipated shock causes a deterioration of the current account in an ICA model, as the representative agent attempts to smooth consumption and maximize returns to domestic capital by borrowing

\footnotetext{
${ }^{18}$ Hurricanes are the strongest of named storms.

${ }^{19}$ Although there can be terrible human losses from a storm, the effect on the size of the labor force is typically small.
} 
from abroad (reducing net foreign assets). Later, the current account is expected to improve, as the representative agent recovers and attempts to bring their saving back into line with their desired steady-state path of net foreign assets.

On the other hand, if shocks are anticipated, the agent should undertake measures before the shock to minimize the consequences of the shock, thus leading one to expect that there might be little current account effect with an anticipated shock. To the extent that the agent undertakes local mitigation measures, such as improved building and zoning practices, this is correct. However, an ICA model still predicts that an anticipated shock will generate current account effects similar to an unanticipated shock, if local mitigation measures are unable to entirely prevent or offset damages from a storm. This is due to the standard ICA model assumption of incomplete international markets, in the sense that there is not a complete set of internationally tradeable contingent claims. Complete insurance against hurricanes shocks is not possible, thus generating a bufferstock saving motive. Saving is then accomplished by increasing holdings of foreign assets. In the event of a hurricane shock, buffer-stock savings falls and the current account deteriorates, just as it would in response to an unanticipated shock. Later current account effects depend upon how completely the size of the shock is anticipated. If the size of the shock is known, then there should be no future current account effect, as buffer-stock saving is undertaken only to the extent required to exactly offset the shock. However, if there is some uncertainty about the size of the shock, then the future current account effect could be either positive or negative, depending on the difference between the expected size of the shock and the actual size of the shock. If the actual shock is larger than expected, then the future current account effect is positive, as in the unanticipated case. Conversely, if the actual shock is smaller than expected, then the future current account effect is negative.

Thus, an ICA model predicts a similar decline in the contemporaneous current account response for both unanticipated and anticipated hurricane shocks. An atemporal model of current account dynamics generates a similar prediction for the contemporaneous cur- 
rent account response. It is only the ex ante and ex post current account responses that distinguish intertemporal and atemporal models. A true intertemporal model introduces an active response to a shock or news of a forthcoming shock, as delineated above.

How unanticipated are hurricanes? Although meteorologists can give some predictions on the degree of storm activity in a season, there is as yet no way to infer the amount of damage that might occur. Franklin et al. [2001] note that:

While certainly progress has been made in anticipating certain measures of overall seasonal activity, there remains no way to accurately predict the corresponding impact of that activity. Indeed, the correlations between tropical cyclone activity and either damage or deaths in the United States are very small [Landsea et al., 1999].

Even using today's best forecasting techniques, there is an average storm track forecast error of around 400 miles at horizons of only 72 hours [Pielke, Jr. and Pielke, Sr., 1997]. There is still a large degree of unpredictability in storm paths. Although there may be a constant expectation of a hurricane in the region in a given year, a particular hurricane strike's damage is effectively random and unanticipated. It is thus a prime example of a temporary, country-specific shock.

\section{Physical Capital Shocks and the Current Account: A Small, Open Economy Model}

Let Home's small, open economy be characterized by a representative agent, who faces the following problem:

$$
\begin{gathered}
\max _{C_{s}, I_{s}} U=E_{t}\left[\sum_{s=t}^{\infty} \beta^{s-t} u\left(C_{s}\right)\right] \\
\text { s.t. } C_{s}=(1+r) B_{s}+Y_{s}+N_{s}-I_{s}-C\left(I_{s}, K_{s}\right)-G_{s}-B_{s+1} \text { for all } s, \\
K_{s+1}=\left(1-\varepsilon_{s+1}\right)\left[K_{s}+I_{s}\right], \tilde{K}_{s+1}=K_{s}+I_{s}, Y_{s} \equiv F\left(A_{s}, K_{s}\right) \text { and } A_{s+1}=(1+g) A_{s} .
\end{gathered}
$$


Assume that the government budget is balanced (expenditures equal lump-sum tax receipts). The components of the problem are:

1. $\beta$ is the time preference discount factor and $\beta \in(0,1)$.

2. $u(\cdot)$ is a concave, period utility function.

3. $C$ is period consumption.

4. $B$ is net foreign asset holdings.

5. $r$ is the exogenous constant foreign rate of return on foreign assets.

6. $Y$ is output.

7. $N$ is exogenous net transfers from abroad.

8. $A$ is exogenous total factor productivity, which grows at rate $g$.

9. $F(\cdot)$ is a concave, linearly homogenous production function with $F_{A}>0, F_{K}>0$, $F_{A K}>0, F_{A A}<0, F_{K K}<0$.

10. $K$ is the physical capital stock (which is non-tradeable).

11. $I$ is physical capital investment.

12. $\tilde{K}$ is next period's planned physical capital stock.

13. $\varepsilon$ is the proportion of the planned physical capital stock that is destroyed in a period, before it can be used in production. Let $\delta=1-\varepsilon$ denote the proportion of the planned physical capital stock that remains for use in production.

14. $C(I, K)$ is a convex, linearly homogenous physical capital adjustment cost function with $C_{I}>0, C_{K}<0, C_{I I}>0, C_{K K}>0, C\left(0, K_{s}\right)=0$.

15. $G$ is exogenous government spending. 
The above represents the most general formulation of the intertemporal current account model I will investigate. The general model implicitly assumes that international asset markets are incomplete (a complete set of state-contingent assets does not exist), while the domestic asset market is complete, in the sense that a representative agent exists for the domestic economy. Preferences are time-additive and separable (habit formation in consumption is not considered here). Discounting is exponential and the risk-free world real interest rate is assumed to be constant. Expectations are formed rationally. After exploring the implications of the above ICA model, I will impose some assumptions on particular functional forms of the components of the model to generate sharper predictions.

\subsection{ICA Model's Implications in the Time Prior to a Shock}

The resulting bond Euler equation is: ${ }^{20}$

$$
u^{\prime}\left(C_{t}\right)=\beta(1+r) E_{t}\left[u^{\prime}\left(C_{t+1}\right)\right]
$$

What does the Euler equation imply for the time path of consumption? To build some intuition, I will make some assumptions to simplify the possible pattern of shocks. Suppose that in any given period there is a constant probability $p$ that a negative physical capital shock will occur. ${ }^{21}$ If a shock does occur, it has a know magnitude, such that $\delta_{s}=\delta \in[0,1]$, some constant. Let superscript $S$ denote that a shock has occurred and superscript $N S$ denote that no shock has occurred. In this case, the bond Euler equation implies:

$$
u^{\prime}\left(C_{t}\right)=\beta(1+r)\left\{p u^{\prime}\left(C_{t+1}^{S}\right)+(1-p) u^{\prime}\left(C_{t+1}^{N S}\right)\right\},
$$

where $C_{t}=(1+r) B_{t}+Y_{t}+N_{t}-\left(\tilde{K}_{t+1}-K_{t}\right)-C\left(\left(\tilde{K}_{t+1}-K_{t}\right), K_{t}\right)-G_{t}-B_{t+1}$.

\footnotetext{
${ }^{20}$ Full details of the derivation are given in Appendix A (not for publication).

${ }^{21}$ The occurrence of shocks follows a Bernoulli distribution. The limiting distribution for a given shock path in this case is Poisson, while a shock path of finite length follows a Binomial distribution.
} 
How will the time path of consumption change with the size of the shock? The shock does not influence $C_{t+1}^{N S}$ directly, and hence $\frac{\partial C_{t+1}^{N S}}{\partial \delta}=0$. Notice that:

$$
\begin{aligned}
\frac{\partial C_{t+1}^{S}}{\partial \delta} & =\frac{\partial\left[(1+r) B_{t+1}+Y_{t+1}^{S}+N_{t+1}-G_{t+1}-I_{t+1}^{S}-C\left(I_{t+1}^{S}, K_{t+1}^{S}\right)-B_{t+2}^{S}\right]}{\partial \delta} \\
& =\frac{\partial Y_{t+1}^{S}}{\partial \delta}+\frac{\partial N_{t+1}}{\partial \delta}-\frac{\partial G_{t+1}}{\partial \delta}-\frac{\partial C\left(I_{t+1}^{S}, K_{t+1}^{S}\right)}{\partial \delta}
\end{aligned}
$$

since $B$ and $I$ are either predetermined or control variables.

$$
\begin{aligned}
= & \frac{\partial Y_{t+1}^{S}}{\partial K_{t+1}^{S}} \frac{\partial K_{t+1}^{S}}{\partial \delta}+\frac{\partial N_{t+1}}{\partial \delta}-\frac{\partial G_{t+1}}{\partial \delta}-\frac{\partial C\left(I_{t+1}^{S}, K_{t+1}^{S}\right)}{\partial K_{t+1}^{S}} \frac{\partial K_{t+1}^{S}}{\partial \delta} \\
= & F_{K}\left(A_{t+1}, K_{t+1}^{S}\right) \tilde{K}_{t+1}+\frac{\partial N_{t+1}}{\partial \delta}-\frac{\partial G_{t+1}}{\partial \delta}-C_{K}\left(I_{t+1}^{S}, K_{t+1}^{S}\right) \tilde{K}_{t+1}, \\
& \text { since } K_{t+1}^{S}=\delta \tilde{K}_{t+1} .
\end{aligned}
$$

Suppose that the time paths of $N$ and $G$ do not respond to the shock. Then, $\frac{\partial C_{t+1}^{S}}{\partial \delta}=$ $\tilde{K}_{t+1}\left[F_{K}\left(A_{t+1}, K_{t+1}^{S}\right)-C_{K}\left(I_{t+1}^{S}, K_{t+1}^{S}\right)\right]>0$, since $F_{K}>0$ and $C_{K}<0$. This implies that the smaller $\delta$ (i.e., the larger the shock), the smaller will be consumption, and thus the higher will be the marginal utility of consumption when there is a shock. The agent can mitigate this possibility by either investing in physical capital or by purchasing foreign bonds today. The other option would be to wait and reduce investment next period (when the return to physical capital will have risen from the shock) and/or to increase borrowing next period (reduce net foreign bond holdings), which will depend upon the patience of the agent. The exact mix of their choice between foreign bonds and physical capital will depend on their relative rates of return in each state of the world, weighted by their probability of occurrence and each state's marginal utility of consumption. Regardless, saving today will increase. ${ }^{22}$

An implication of the above analysis is that increasing exposure to shocks (either through higher $p$ or lower $\delta$ ) should generate greater saving. However, if expected net transfers from abroad offset the capital shock, there are reduced incentives to saving. The rest of the world supplies costless insurance to the agent. This will manifest itself as falls

\footnotetext{
${ }^{22}$ Recall that national saving can be written as $S_{t}=C A_{t}+I_{t}=B_{t+1}-B_{t}+I_{t}$.
} 
in the current account net of transfers from abroad when a shock occurs. The agent uses transfers from abroad to smooth consumption and increase physical capital investment. Furthermore, to the extent that net transfers are anticipated, saving behavior prior to the shock is diminished.

Government consumption spending reductions (reductions in $G$ ) can also mitigate the shock If there is a temporary increase in government spending and it is not accompanied by an offsetting increase in taxes, then international borrowing will increase and there should be a decrease in the current account. ${ }^{23}$

Notice that the presence of capital adjustment costs increases the effect on consumption of a physical capital shock, since a fall in the physical capital stock increases adjustment costs. Capital adjustment costs thus increase the need for buffer stock savings in order to follow the bond and capital Euler equations. ${ }^{24}$

What are appropriate empirical tests for the ex ante implications of the model? The bond Euler equation implies that the representative agent chooses a time path for net foreign assets so that the marginal utility of present consumption is set equal to the probability-weighted average of the marginal utilities of future consumption. The higher is $p$ (the probability of a shock), the larger will be the expected difference between present consumption and future consumption (for a given $\delta$ ). The lower is $\delta$, the larger will be the expected difference between present consumption and future consumption (for a given $p$ ). Essentially, higher $p$ and lower $\delta$ generate greater saving. Hence, changes in $p$ and $\delta$ should be correlated with changes in saving behavior. This suggests that saving should increase in response to a greater predicted frequency and severity of storm shocks in a region. For example, greater building and population along the coastline of countries

\footnotetext{
${ }^{23}$ There will be a small decline in domestic consumption associated with such a policy in the current model, as Ricardian equivalence (which holds in this model) implies that the agent will take account of the fact that government debt must be repaid by higher taxes in the future. However, any decline in domestic consumption will be smaller than the corresponding rise in government spending, generating an increase in international borrowing. Tax revenues here are assumed to be generated through lump-sum taxes.

${ }^{24}$ Buffer stock saving can take the form of increased net foreign asset acquisition or increased physical capital investment, or some mixture of the two. The attractiveness of physical capital investment as buffer stock saving will depend upon the size of the capital adjustment cost reduction from the capital stock size.
} 
increases the severity of storm shocks. It has further been postulated that global warming may increase the frequency and severity of storm shocks. The economic model above suggests that these trends should be accompanied by increasing net foreign asset holdings and/or greater physical capital investment by those countries most affected.

Although intriguing, I set aside these general ex ante predictions in the current paper and focus instead on the ex post predictions of an ICA model for testing. I will return briefly to the ex ante predictions in the conclusion.

\subsection{ICA Model's Implications in the Time After a Shock}

Sharper predictions require sharper assumptions. Accordingly, I consider a specific set of functional forms for the general ICA model and observe the consequences for the current account in light of physical capital shocks. The following functional forms are assumed:

1. the production function is Cobb-Douglas, with $F\left(A_{t}, K_{t}\right)=A_{t}^{1-\alpha} K_{t}^{\alpha}$, where $\alpha \in$ $(0,1)$.

2. the capital adjustment cost function is linearly homogenous, with $C\left(I_{t}, K_{t}\right)=$ $\frac{\chi}{2}\left(\frac{I_{t}^{2}}{K_{t}}\right)$, where $\chi>0$.

3. the period utility function is isoelastic, with $u\left(C_{t}\right)=\frac{C_{t}^{1-\frac{1}{\sigma}}}{1-\frac{1}{\sigma}}-1$, for $\sigma>0$, and $u\left(C_{t}\right)=\ln \left(C_{t}\right)$, for $\sigma=1 . \quad \sigma$ is the elasticity of intertemporal substitution of consumption.

For tractability reasons, I will look at the consequences of physical capital shocks for the ICA model under perfect foresight. The physical capital shock will be an unforeseen event, creating a temporary deviation from the optimal path for the economy to which the agent must adapt. Although implying a different response timing pattern than a full rational expectations ICA model, the intertemporal character of the response is maintained. As discussed earlier, where foreseen and unforeseen shocks differ in their effects upon the current account are in the ex ante phase (prior to the shock) and in 
the ex post phase (after the shock). A foreseen shock generates a movement in the current account opposite in sign to the upcoming shock during the ex ante phase, with the current account moving to its long-run level in the ex post phase. On the other hand, an unforeseen shock is predicted to have no effect in the ex ante phase (it is unforeseen), while it does generate a movement of the current account opposite in sign to the shock in the ex post phase. Regardless, the ICA model predicts countervailing movements in the current account, with the timing of these movements dependent upon the degree of uncertainty about the shock. Movements in the current account will be more dramatic in the case of a partially or completely unforeseen shock than in the perfectly foreseen case, as the agent scrambles to adapt to the surprise. In what follows, I focus on the case where the hurricane shock is unforeseen, since the exact time of a hurricane strike is never known for certain ex ante. ${ }^{25}$

The ICA model implications for the current account are most easily demonstrated if capital adjustment costs are set to zero $(\chi=0)$. Let $v=1-\beta^{\sigma}(1+r)^{\sigma}$; this is a measure of the agent's impatience. If an unforeseen capital shock occurs at time $t$ when the economy is on its balanced growth path (BGP), the contemporaneous response of the current account over output is:

$$
\begin{aligned}
\frac{\partial\left(\frac{C A_{t}}{Y_{t}}\right)}{\partial K_{t}}= & \frac{\frac{\partial C A_{t}}{\partial K_{t}}}{Y_{t}}-\frac{C A_{t}}{Y_{t}} \frac{\frac{\partial Y_{t}}{\partial K_{t}}}{Y_{t}} \\
= & \left(1-\frac{r+v}{1+r}\right)\left(\alpha \frac{1}{K_{t}}+\frac{1}{Y_{t}}\right)-\frac{C A_{t}}{Y_{t}}\left[\alpha \frac{1}{K_{t}}\right] \\
= & \left(1-\frac{r+v}{1+r}-\frac{C A_{t}}{Y_{t}}\right)\left[\alpha \frac{1}{K_{t}}\right]+\left(1-\frac{r+v}{1+r}\right)\left(\frac{1}{Y_{t}}\right)>0, \\
& \text { since } \frac{C A_{t}}{Y_{t}}<\left(1-\frac{r+v}{1+r}\right) .
\end{aligned}
$$

The future response of the current account over output is:

$$
\frac{\partial\left(\frac{C A_{t+s}}{Y_{t+s}}\right)}{\partial K_{t}}=\frac{\frac{\partial C A_{t+s}}{\partial K_{t}}}{Y_{t+s}}-\frac{C A_{t+s}}{Y_{t+s}} \frac{\frac{\partial Y_{t+s}}{\partial K_{t}}}{Y_{t+s}}
$$

\footnotetext{
${ }^{25}$ The full model solution is given in Appendix A (not for publication).
} 


$$
\begin{gathered}
=-v(1-v)^{s}\left(1-\frac{r+v}{1+r}\right)\left(\alpha \frac{1}{K_{t}} \cdot \frac{Y_{t}}{Y_{t+s}}+\frac{1}{Y_{t+s}}\right)<0, \\
\text { for } s>0 \text { and } v>0 \text { (impatient case). }
\end{gathered}
$$

Thus, the magnitude of the response of the current account over output depends on $\frac{d K_{t}}{Y_{t+s}}$ and $\frac{Y_{t}}{K_{t}}$.

The current account response thus follows an S-shaped pattern, relative to its BGP. Capital adjustments costs of the form considered here do not change this basic qualitative result, but do result in slowing of the current account response and a reduction in the magnitude of its response (not surprisingly). Figure 3 shows the simulated current account over output response under various levels of capital adjustment costs. When capital adjustment costs are extremely high, the ex post response of the current account to a negative capital shock is small but positive (it is difficult to see this on the graph), as expected. The simulated time paths of output and consumption growth relative to their BGP are given in figure 4. Notice how consumption growth falls with the negative shock, but then grows at its BGP value. Output growth on the other hand falls, but then grows faster than it does on its BGP. In a simple atemporal model, consumption growth would be expected to track output growth. The lack of a later consumption growth response to output growth demonstrates the consumption-smoothing properties of the intertemporal model.

\section{Description of the Hurricane Damage Measure and the Macroeconomic Data}

The hurricane damage measure employed in the analysis is the ratio of a country's economic damages due to hurricanes in a given year divided by last year's GDP. It is thus a relative measure of the severity of hurricane shocks experienced by a country in a given year. Figure 5 shows the geographic distribution of the hurricane damage measure, with 
each circle area indicative of the size of hurricane damages. Notice how the largest hurricane shocks mostly occur in the small island economies of the Lesser Antilles. The empirical cumulative distribution function for the hurricane damage measure is in figure 6. It shows how large hurricane shocks are relatively uncommon events.

The economic damage figures (all in current US\$), primarily come from one of two sources: annual articles on the Atlantic hurricane season in the American Meteorological Society's Monthly Weather Review; or, the Emergency Events Database (EM-DAT) of the World Health Organization's Collaborating Centre for Research on the Epidemiology of Disasters (CRED). In both cases, I compiled annual data on damages for the period 1960 to 2002. Further data on economic damages were taken from a variety of sources, including: the United Nations' Economic Commission for Latin America and the Caribbean (ECLAC), the US National Climatic Data Center (NCDC), the US Agency for International Development's Office of US Foreign Disaster Assistance (USAID OFDA), the Inter-American Development Bank (IADB), the Meteorological Service of the Netherlands Antilles and Aruba (MDNAA), Swiss Re, Grenada's Ministry of Foreign Affairs and International Trade, the Caribbean Disaster Emergency Response Agency (CDERA), Guy Carpenter and Company Incorporated, and the United Nations' Department of Humanitarian Affairs (UNDHA). ${ }^{26}$

For those events for which no economic damage figure was available, I compared the quality of damages in a country due to the storm event to other countries' with a similar damage pattern from other storm events, for which economic damage data exists. ${ }^{27}$ I then inferred that the relative economic damage (described above) inflicted is likely similar for these events. For example, in 1979, Hurricane David struck Dominica, leaving $80 \%$ of the population homeless. Unfortunately, no valuations of the aggregate damage are available. However, St. Lucia, a near neighbor of Dominica, also experienced a destruction of around

\footnotetext{
${ }^{26}$ Details on the exact construction of the dataset (e.g., which observations come from which source, etc.) are available upon request.

${ }^{27}$ Examples of measures of the quality of damages due to a hurricane include the death rate, proportion of the housing stock or buildings destroyed, proportion of the agricultural sector damaged and the size of the agricultural sector, infrastructure damage estimates, etc.
} 
80\% of its housing stock, when it was struck by Hurricane Allen in 1980 [Granger, 1990]. Economic damages for St. Lucia were 2.3 times annual GDP. Dominica likely had a similar level of economic damages from Hurricane David. Accordingly, I use St. Lucia's relative economic damage measure from Hurricane Allen as a proxy for Dominica's relative economic damage from Hurricane David. Excluding such observations from the analysis does not affect the estimated responses substantially.

Annual economic data are drawn from the World Development Indicators (WDI) 2003 dataset of the World Bank. ${ }^{28}$ The WDI is generally acknowledged to contain the most reliable macroeconomic data for developing countries. The economic variables I look at are:

1. the current account over GDP;

2. the gross national saving rate (inclusive of all income and transfers);

3. the gross investment rate (gross capital formation over GDP);

4. the log difference of per capita real GDP (measured in constant local currency units);

5. the log difference of per capita real final consumption expenditures (measured in constant local currency units);

6. the current account minus net transfers over GDP;

7. net unilateral transfers over GDP;

8. foreign aid over GDP;

9. worker remittances over GDP;

10. the overall government budget deficit over GDP.

\footnotetext{
${ }^{28}$ As far as I know, the data do not exist for the countries in my sample at a higher frequency.
} 
The ICA model presented in Section 4 implies that the pure levels of all of the relevant variables are nonstationary. Hence, stationary transformations (such as log differences or ratios relative to GDP) of the pure levels are used in the analysis. In the empirical analysis, all variables are converted to their percentage point equivalents for legibility (viz., they have all been multiplied by 100).

I also investigated the effects of including various country-specific characteristics as explanatory variables into the analysis. These are:

1. real GDP in the year prior to a shock (measured in constant 1995 US dollars);

2. bank-owned net foreign assets over GDP in the year prior to a shock (inclusive of private and central bank deposits abroad);

3. external debt over GDP in the year prior to a shock;

4. agricultural value-added over GDP in the year prior to a shock (measuring the size of the agricultural sector).

Countries included in the analysis are in the Caribbean and Central America. Essentially, these are small countries which have some probability of experiencing a hurricane strike. A list and description of the sample is found in Table 1. The time period covers 1960 to 2002, all the years for which WDI data exist. Data availability is the primary restriction for inclusion in the sample. As evinced by the table, the number of observations available for each country (and variable) varies widely. The sample is thus unbalanced.

\section{Econometric Methodology - Panel Data Model}

To uncover the response to a hurricane, I estimate a fixed effects panel regression models for each of the macroeconomic variables, delineated above. The general regression 
equation is:

$$
Y_{i, t}=\alpha_{i}+\beta_{t}+\sum_{m=0}^{M} \gamma_{m} L^{m} H_{i, t}+\sum_{m=0}^{M} L^{m}\left[H_{i, t} X_{i, t-1}^{\prime}\right] \delta_{m}+\varepsilon_{i, t}
$$

where $i$ indexes countries, $t$ indexes year, $Y$ denotes the macroeconomic variable of interest, $H$ denotes the relative economic damages due to a hurricane (defined earlier), $X$ is a $(K \times 1)$ vector of country-specific characteristics, and $L$ is the standard lag operator. $\varepsilon$ is a mean zero disturbance term, which may be heteroskedastic and/or autocorrelated. The country fixed effects, denoted $\alpha_{i}$, allow for country-specific trends in each of the dependent variables. They also absorb any direct effects of time-invariant characteristics of the countries considered. The time fixed effects, denoted $\beta_{t}$, allow for a common region-wide macroeconomic shock each year. The coefficient on the relative economic damage measure $\gamma_{m}$ measures the direct effect of the hurricane shock at time $m$ after the shock. The term $X_{i, t-1}^{\prime} \delta_{m}$ measures the indirect effect of the hurricane shock at time $m$, which depends upon country-specific characteristics in the year prior to a hurricane shock. ${ }^{29}$ The regression is thus a distributed lag model, with lag length $M$. It measures the reduced form effect of a hurricane, as I am not modelling the simultaneity among the dependent variables. The above econometric model allows for a particularly rich impulse response to a hurricane shock.

For each dependent variable, I tested a random effects specification versus a fixed effects specification, using the heteroskedasticity/autocorrelation robust test in Wooldridge [2002]. The random effects specification is rejected for all of the variables. Furthermore, tests of heteroskedasticity and autocorrelation of the error disturbances revealed that these were present. ${ }^{30}$ Hence, I employ Newey-West heteroskedasticity and autocorrelation robust (HAC) standard errors for all of the statistical inference. This allows for arbitrary heteroskedasticity and autocorrelation, both within and across panels (coun-

\footnotetext{
${ }^{29}$ Lagged country-specific characteristics are used to mitigate endogeneity concerns.

${ }^{30}$ Formal test results for the RE vs. FE, heteroskedasticity, and autocorrelation tests are available upon request.
} 
tries).

The choice of the lag length $M$ for each equation is made using the joint hypothesis testing procedure described in Pagano and Hartley's [1981] article on fitting distributed lag models. ${ }^{31}$ The maximum lag length considered is 10 .

The empirical results presented derive from econometric models which impose various restrictions on the above general model. The baseline specification imposes the restriction that $\delta_{m}$ be equal to zero. It thus assumes that only the direct effects of the hurricane are significant. In later specifications, I included the country-specific characteristic variables (elements of $X_{i, t}$ ). They are included singularly, as the introduction of multiple characteristic variables with the lag structure rapidly burns up the degrees of freedom.

\section{$7 \quad$ Empirical Results}

Here, I discuss in greater detail the panel model results. In the first part of this section, I present the baseline results, estimated under the restriction that $\delta_{m}=0$. In the second part of this section, I introduce a set of country-specific characteristics and hurricane damage measure interactions into the analysis, thus allowing for the economy's response to a hurricane shock to vary across country characteristics. Finally, I conclude this section by considering the correspondence between the estimated response's timing and magnitude with that predicted by a standard ICA model.

\subsection{Baseline Specification - Hurricane Damages Alone}

Coefficient estimates in the baseline results may be interpreted as the dependent variable's response to a hurricane shock that destroys physical capital valued at one year's national GDP. ${ }^{32}$ The baseline results in table 2 show the expected intertemporal response of the current account. There is a 5 percentage point fall in the current account over GDP in

\footnotetext{
${ }^{31} \mathrm{Lag}$ truncation for the Newey-West HAC estimator is calculated by $\left(\frac{3}{4}\right) T_{\text {aver }}^{\left(\frac{1}{3}\right)}$, and rounding up. $T_{\text {aver }}$ is the average length of a panel. This results in a lag truncation parameter of 3 for all regressions. ${ }^{32}$ Thus, $-\frac{\Delta K_{t}}{Y_{t}}=1$.
} 
the year after a hurricane shock, as expected in both the intertemporal and atemporal CA models (significant at the 1\% level). The S-shaped current account response predicted by an ICA model is visible 3 years after a hurricane shock in the 2.7 percentage point improvement, although significant only at the $10 \%$ level. In subsequent years, the point estimates are all positive, although generally insignificant. However, they culminate eight years after the hurricane shock in a 2.7 percentage point positive response which is significant at the $5 \%$ level. Such a response is not consistent with an atemporal model. ${ }^{33}$

The gross national saving rate shows a large increase from 2 years after a hurricane shock to 5 years after a hurricane shock. The size of the increase ranges from 5 percentage points to 3.4 percentage points. Notice how the later year increases in saving are larger than any of the contemporaneous increases in investment, likely generating the later estimated positive response of the current account. Curiously, the gross saving rate in the year of a hurricane shock shows an increase of 3.8 percentage points. This may be related to a large influx of net transfers from abroad in the year of a hurricane shock. Table 3 provides evidence that is weakly supportive of this hypothesis. Although there is no significant foreign aid response contemporaneous with a hurricane shock, net transfers over GDP does show a large response of 7.3 percentage points which is significant at the $10 \%$ level. Interestingly, net worker remittances received (a component of net transfers exclusive of foreign aid) shows a 2.4 percentage point rise in the year of a hurricane shock (significant at the $10 \%$ level). The rise in the annual saving rate in the year of a hurricane shock could also reflect increased buffer-stock saving in anticipation of a hurricane shock. The Atlantic basin hurricane season is most active from August to October. Thus, higher than usual saving earlier in the year might more than offset later dissaving due

\footnotetext{
${ }^{33}$ I have not attempted to account for the possibility of insurance. If countries are insuring against storm shocks, then one might be concerned that the observed current account response merely reflects the flows of insurance claims. However, insurance claims would enter positively into the current account, mitigating the current account response. Premiums paid out to foreign insurers are counted as imports of insurance service, and thus claims received count positively into the services portion of the current account, acting similar to an income or transfer flow from abroad. In any case, it's likely the case that developing countries are underinsured against such shocks. Even in the United States, it is estimated that insurance covers at best half of the actual damage caused by hurricanes [Pielke, Jr. and Landsea, 1998].
} 
to a hurricane, since hurricane shocks typically occur late in the year (the later third to early fourth quarters of the calendar year). Quarterly data could resolve this puzzle, but they are not available for the vast majority of countries in the sample.

The gross investment rate shows a strong positive response inclusive of the year of the hurricane shock, which declines in magnitude over time. It ranges from 3.8 to 5.9 percentage points above its trend value up to 2 years after the hurricane shock, with the largest response in the year just after the shock (all significant at the $1 \%$ level). The response is smaller but positive in later years, culminating in an estimated 2 percentage point rise above trend six years after the hurricane shock (significant at the $5 \%$ level). This is consistent with a hurricane shock being a physical capital shock and not a pure income shock (e.g., such as might be expected from a fall in tourism demand or the like).

Real output and consumption growth both show significant declines due to a hurricane shock, although the declines are not synchronized. Output growth falls 5.4 percentage points in the year of a hurricane shock (significant at the $5 \%$ level). Consumption growth falls by 4.8 percentage points 2 years after a hurricane (significant at the $5 \%$ level), recovering somewhat in the third year after a hurricane to 3.9 percentage points below its trend value (significant at the $1 \%$ level. Perplexingly, the results show a 2.8 percentage point rise in real consumption growth the year after a hurricane shock (significant at the $5 \%$ level). This is likely due to the inclusion of consumer durables, which can arguably be considered investment goods, in the consumption measure. Unfortunately, the WDI does not contain non-durable consumption with which to test this assertion. There is a later real output growth increase of 3.7 percentage points above trend eight years after the hurricane shock (significant at the 10\% level), which is consistent with there being some catch-up after a negative shock. However, real consumption growth shows an unexpected rise of 4.3 and 4.9 percentage points above trend, nine and ten years after a hurricane shock (significant at the $1 \%$ level). A rise in consumption growth is also suggested by a decline in the gross national saving rate ten years after a hurricane shock (-3.1 percentage points, significant at the $5 \%$ level). 
As mentioned above, there is evidence of a net transfers' response to a hurricane shock. As seen in table 3 , in the year after a hurricane shock, net transfers over GDP shows an increase of 5.4 percentage points above trend (significant at the $5 \%$ level). This response appears to be coming partially from increases in foreign aid (3.2 percentage point increase, significant at the $5 \%$ level) and worker remittances (1.8 percentage point increase, significant at the $10 \%$ level). When net transfers are subtracted from the current account, the negative contemporaneous effect of a hurricane shock is even larger and more significant, indicating that transfers from abroad dampen the effect of a hurricane shock on the current account. However, the timing of large transfer flows does not coincide with large movements in national saving or the current account, excepting the years immediately following a hurricane shock. There is evidence of a 3.1 percentage point increase in the overall government budget deficit over GDP 3 years after a hurricane shock (significant at the 1\% level). Again though, the gross national saving rate 3 years after a hurricane shock still shows a positive significant response despite the fall in public saving. ${ }^{34}$

\subsection{Differential Responses across Country-specific Characteris- tics}

As described in the econometrics discussion, I also introduced several characteristic variables interacted with the hurricane damage measure as additional explanatory variables. The variables I considered included: (1) economic size (real GDP); (2) bank-owned net foreign assets over GDP; (3) external debt over GDP; and, (4) the size of the agricultural sector (agricultural value-added over GDP). In my discussion, I focus on the estimated current account responses.

\footnotetext{
${ }^{34}$ Although the baseline real ICA model makes no predictions about nominal prices, I also looked for a hurricane shock effect on CPI-measured inflation and the rate of foreign exchange rate depreciation. I found no significant effect on these variables. This likely reflects the fact that the small economies of the sample are price-takers in world markets. Furthermore, several of the countries in the sample are strong fixers (e.g., the members of the East Caribbean Currency Union have never devalued/revalued the EC\$).
} 
Table 4 presents the estimated marginal effects of economic size, bank-owned net foreign assets over GDP and agricultural sector size upon the current account over GDP. The effects are given for two levels (small and large; negative and positive; small and large) of each characteristic variable. The results differentiated by country-specific characteristics are more mixed than the baseline results. In part, this may reflect the loss of degrees of freedom incurred by introducing another nine parameters to estimate in the fixed effects framework. However, they do still suggest some kind of S-shaped response, with earlier negative movements in the current account, followed by later positive movements in the current account.

As seen in columns 1 and 2 of Table 4, there is little difference in the current account response magnitude between small and large economies, for a hurricane shock of similar relative size (capital destruction equal to $100 \%$ of annual GDP). The initial negative response is present, but insignificant for both economic sizes ( $\mathrm{p}$-value of 0.107 for the small economy case). Both do show a later positive move of the current account (significant at the $1 \%$ level for the small economy and $10 \%$ for the large economy).

Columns 3 and 4 show that countries with negative bank-owned net foreign assets (NFA) over GDP experience a larger negative move of the current account initially after a hurricane shock (significant at the 10\% level). Economies with negative bank-owned NFA show a more dramatic S-shaped current account response than those with positive bank-owned NFA. ${ }^{35}$ To the extent that bank-owned NFA reflect the overall economy's NFA, the results lend some support to Kraay and Ventura's [2000] ICA model with differential responses across creditor and debtor economies. However, given that the coefficients are only significant at the $10 \%$ level, it can only be suggestive.

Economies with large agricultural sectors at the time of a hurricane shock show much more dramatic negative early effects of a hurricane shock, as seen in columns 5 and 6 . This is not surprising, as extensive crop damage can appear even with storms which do not generate large capital damages. The estimated current account decline in the year after

\footnotetext{
${ }^{35}$ The levels of NFA to GDP are both equal in magnitude to $5 \%$ of annual GDP.
} 
a hurricane shock is -17.8 percentage points, significant at the $5 \%$ level. Furthermore, their recovery is much more sluggish than that of economies with small agricultural sectors. There is an eventual positive current account response for economies with large agricultural sectors, but this appears only eight years after a hurricane shock (significant at the $10 \%$ level).

External debt showed no relationship with the current account, although there are few observations available for this variable. ${ }^{36}$

Despite the generally more imprecise estimates when conditioning upon countryspecific characteristics, all of the results do appear to show a later positive move of the current account. Such an active response to a negative capital shock is required by an intertemporal model, reflecting the interaction of the intertemporal budget constraint and agent impatience.

\section{Discussion and Implications}

I now consider the the economic significance of the baseline results and their implications for ICA models.

\subsection{Economic Significance of the Baseline Estimates}

What is the economic significance of these estimates? The average current account over GDP from 1960 to 2002 is -7.45 percentage points. Thus, the estimated 5 percentage point fall of the current account over GDP due to a hurricane shock means that the current account worsens by some $70 \%$, relative to its average value. Simulations of the current account consequences of a hurricane shock generally show an even larger negative contemporaneous response (see figure 3). However, as capital adjustment costs become more important in the economy, the simulated response becomes smaller in magnitude. The smaller estimated size of the current account response may thus be indicative of

\footnotetext{
${ }^{36}$ Available upon request.
} 
significant capital adjustment costs at work in the economy. These may be either direct (for example, if public infrastructure construction is a necessary pre-condition for private capital investment to proceed), or indirect (for example, due to international capital market imperfections). The estimated future 2.7 percentage point rise above trend of the current account over GDP represents an improvement of $35 \%$ relative to its average value. The smaller magnitude of the future current account response relative to the contemporaneous response is predicted by an ICA model with adjustment costs, as illustrated by the simulated current account response mentioned above. The S-shaped intertemporal response manifests with a lower amplitude.

Given that hurricane shocks generally occur in the last third of a year, the estimated 5.4 percentage point fall in real output growth due to a capital stock fall equal to one year's GDP is actually reflective of the growth rate in the last four months of the year. The annualized real output growth rate (relative to trend) in the year's last third is thus around $-13 \%$, which is a substantial fall in income. The simulated fall in real output growth relative to its BGP of $-14 \%$ due to a $40 \%$ fall in the capital stock is remarkably close to this figure (see figure 4).

\subsection{Baseline Current Account Response Timing and Magnitude}

The general qualitative characteristics of the estimated current account response match the predictions of an ICA model. There is evidence of intertemporal trade occurring in response to a negative capital shock. However, a comparison of the estimated response's timing and magnitudes with a standard ICA model's predictions reveals some discrepancies.

As seen in figure 3 and mentioned above, a standard ICA model predicts that the current account over GDP will exhibit an extremely strong initial negative response to a hurricane shock. There is then a much smaller, but more drawn out, positive response in future periods. When there are no capital adjustment costs, the initial negative current account response is approximately 6.75 times the size of the largest future positive current 
account response. When capital adjustment costs are introduced, the size differential becomes even greater. The estimated current account response (from table 2) shows a size differential of only approximately 2. The empirical future current account response is thus much stronger than that predicted by a standard ICA model.

In the absence of capital adjustment costs, the growth rate of the future current account response is constant in a standard ICA model. The current account smoothly declines, converging to its long-run value. When capital adjustment costs are present, the growth rate of the future current account response takes on a hump-shaped pattern, increasing slowly to a peak value and then decreasing. Again, the current account smoothly converges to its long-run value. The estimated future current account response does not appear to exhibit such smooth behaviour. However, the hypothesis that the growth rate of the future current account response is constant cannot be rejected. ${ }^{37}$

The discrepancies between the estimated current account response and that predicted by a standard ICA model suggest some possible modifications to the theory. ${ }^{38}$ First, the ICA model simulated here is a perfect foresight model, where the negative capital shock is unique and completely unexpected. Explicitly incorporating a buffer-stock savings motive could help account for the stronger future current account response. Since there is some probability of being struck by a damaging hurricane again, there is an incentive to pay down debt more quickly than in the perfect foresight model. Second, there is only a single asset (foreign bonds), which must be paid back only in the limit. Allowing for a richer portfolio of assets which show a variety of maturity structures could also help account for the discrepancies outlined above. The exact portfolio available depends upon a country's degree of international capital market access. Related to this, strategic concerns on the part of either borrowers or lenders may also motivate a stronger future current account response. Third, theoretical modifications which affect the smooth

\footnotetext{
${ }^{37}$ The delta-method is used to calculate the standard errors of the implied growth rates and then test the non-linear (in parameters) hypothesis. The annual growth rates are calculated from the ex post responses from year 3 to 8 .

${ }^{38}$ The following modifications maintain the fundamental structure of the problem, assuming a representative agent and an invariant period utility function.
} 
convergence (viz., adjustment behaviour) of the economy, such as the introduction of nominal rigidities or habit formation, may help better match the estimated response. Regardless, theoretical modifications must address the rate at which the intertemporal budget constraint binds.

\section{Conclusion}

Many tests of the intertemporal approach to the current account rely upon the implicit decomposition of shocks within a VAR framework. I argued that hurricanes represent exactly the kinds of temporary, country-specific shocks required to test for an intertemporal trade response, obviating the need to extract shocks to macroeconomic variables via a VAR model. With data on hurricane economic damages in Central America and the Caribbean, I am able to quantify the size of the capital shock experienced by an economy. I then used the hurricane damage measure to investigate the response of a variety of macroeconomic variables, focusing on the behavior of the current account to GDP ratio. The presence of capital adjustment costs implies that the macroeconomic response to even a large capital shock will be somewhat muted, as costs are spread out over time. This means that very large shocks, such as major hurricanes for small economies, are likely needed to identify an intertemporal response.

The results show an S-shaped current account response which is consistent with an intertemporal model but not an atemporal model. There is clear evidence of intertemporal trade occurring. However, the response does not exhibit the smooth convergence and exact timing expected by a standard ICA model, implying that theory must be modified to address the rate at which the intertemporal budget constraint binds. In response to a hurricane shock destroying capital equal to one year's GDP, there is an initial move of the current account to deficit relative to the BGP (-5 percentage points). This is later reversed by a move to surplus relative to the BGP $(+2.7$ percentage points), which then shrinks over time as the current account converges to its BGP value. 
More broadly, the paper's empirical findings indicate that the countries in the sample are experiencing large wealth shocks from hurricanes, which entail costly reinvestment. Underinsurance against hurricane losses results in further hardship, generating substantial debt acquisition in response to a hurricane shock and reducing welfare by necessitating buffer-stock saving. Small, island economies have no hinterland upon which to draw in the event of a negative capital shock, and thus rely heavily upon the international community and international markets to aid their recovery [Fleming, 2004]. More complete international insurance markets would mitigate both ex post debt acquisition and the ex ante need for buffer-stock saving, improving welfare for these economies.

Finally, Gallup et al. [1998] argue that geography plays a large part in economic development. Developing countries may be relatively poor in large part to their geographic circumstances (for example, being landlocked or being subject to particularly malicious disease organisms). The paper lends some support to this position. Hurricanes represent large negative capital shocks which can consistently impoverish a country, potentially inhibiting its ability to develop. ${ }^{39}$ Geography has placed the countries of the Caribbean and Central America in the path of many of these damaging storms. Furthermore, the evidence suggests that the countries of the Caribbean and Central America are becoming more vulnerable to hurricane shocks as a consequence of increased coastal and mountainous regional development, poor building construction, and deforestation [Pielke, Jr. et al., 2003]. If such a trends continue, the effects of hurricanes upon development will only become larger.

\footnotetext{
${ }^{39}$ For an argument against this interpretation, see Skidmore and Toya [2002]. They argue that a high incidence of natural disasters is associated with higher total factor productivity and economic growth, by encouraging human capital investment and the adoption of new, more productive vintages of physical capital.
} 


\section{References}

Shaghil Ahmed. Temporary and permanent government spending in an open economy: Some evidence for the United Kingdom. Journal of Monetary Economics, 17:197-224, 1986.

Shaghil Ahmed. Government spending, the balance of trade, and the terms of trade in british history. Journal of Monetary Economics, 17:197-224, 1987.

John Y. Campbell. Does saving anticipate declining labor income? An alternative test of the permanent income hypothesis. Econometrica, 55:1249-1273, 1987.

Christopher Carroll. Theoretical foundations of buffer stock saving. NBER Working Paper, (10867), October 2004.

Giancarlo Corsetti and Panagiotis T. Konstantinou. The dynamics of the U.S. net foreign liabilities: an empirical characterization. photocopy, European University Institute and University of Rome III, 2004.

Angus Deaton. Saving in developing countries: Theory and review. In Proceedings of the World Bank Annual Conference on Development Economics 1989, pages 61-96, 1990.

James B. Elsner and A. Birol Kara. Hurricanes of the North Atlantic: Climate and Society. Oxford University Press, New York, NY, 1999.

Martin Feldstein and Charles Horioka. Domestic saving and international capital flows. Economic Journal, 90:314-329, 1980.

Charles Fleming. Unmatched scope of disaster delays damage estimates. Wall Street Journal, page A8, December 282004.

John Luke Gallup, Jeffrey D. Sachs, and Andrew D. Mellinger. Geography and economic development. NBER Working Paper, (6849), 1998.

Atish R. Ghosh. Capital mobility amongst the major industrialized countries: Too little or too much. Economic Journal, 105:107-128, 1995.

Atish R. Ghosh and Jonathan D. Ostry. The current account in developing countries: A perspective from the consumption-smoothing approach. World Bank Economic Review, 9:305-333, 1995.

Domenico Giannone and Michele Lenza. The Feldstein-Horioka fact. CEPR Discussion Paper, (4610), 2004.

Reuven Glick and Kenneth Rogoff. Global versus country-specific productivity shocks and the current account. Journal of Monetary Economics, 35:159-192, 1995.

Pierre-Olivier Gournichas and Hélène Rey. International financial adjustment. NBER Working Paper, (11155), 2005.

Orman E. Granger. Natural Disasters and Social Change: An Eastern Caribbean Perspective. University of California-Berkeley, Berkeley, CA, 1990. 
Lars P. Hansen and Thomas J. Sargent. Two difficulties in interpreting vector autoregressions. In Lars P. Hansen and Thomas J. Sargent, editors, Rational Expectations Econometrics, Underground Classics in Economics. Westview Press, 1991.

Mathias Hoffmann. The relative dynamics of investment and the current account in the G7-economies. Economic Journal, 111:C148-C163, May 2001.

Mathias Hoffmann. International macroeconomic fluctuations and the current account. Canadian Journal of Economics, 36(2):401-420, May 2003.

Kenneth Kasa. Testing present value models of the current account: a cautionary note. Journal of International Money and Finance, 22:557-569, 2003.

Aart Kraay and Jaume Ventura. Current accounts in debtor and creditor countries. Quarterly Journal of Economics, 115(4):1137-1166, November 2000.

Aart Kraay and Jaume Ventura. Current accounts in the long and short run. In Mark Gertler and Kenneth Rogoff, editors, 2002 NBER Macroeconomics Annual, chapter 2. MIT Press, Cambridge, MA, 2003.

Christopher W. Landsea, Roger A. Pielke, Jr., Alberto M. Mestas-Nuñez, and John A. Knaff. Atlantic Basin Hurricanes: Indices of Climatic Changes. Climatic Change, 42: 89-129, 1999.

Philip R. Lane. The new open economy macroeconomics: A survey. Journal of International Economics, 54:235-266, 2001.

James M. Nason and John H. Rogers. The present-value model of the current account has been rejected: Round up the usual suspects. Federal Reserve Board of Governors International Finance Discussion Paper, (760), 2003.

Maurice Obstfeld. External adjustment. NBER Working Paper, (10843), 2004.

Maurice Obstfeld and Kenneth Rogoff. The intertemporal approach to the current account. In Gene M. Grossman and Kenneth Rogoff, editors, Handbook of International Economics, volume 3 of Handbooks in economics, chapter 34, pages 1731-1799. Elsevier Science B.V., Amsterdam, 1995.

Maurice Obstfeld and Kenneth Rogoff. Foundations of International Macroeconomics. MIT Press, Cambridge, Massachusetts, first edition, 1996. ISBN 0262150476.

Glenn Otto. Testing a present-value model of the current account: Evidence from US and Canadian time series. Journal of International Money and Finance, 11:414-430, 1992.

Marcello Pagano and Michael J. Hartley. On fitting distributed lag models subject to polynomial restrictions. Journal of Econometrics, 16:171-198, 1981.

Roger A. Pielke, Jr. and Christopher W. Landsea. Normalized hurricane damages in the United States: 1925-1995. Weather and Forecasting, 13:621-631, 1998. 
Roger A. Pielke, Jr. and Roger A. Pielke, Sr. Hurricanes, Their Nature and Impacts on Society. John Wiley and Sons, New York, NY, 1997.

Roger A. Pielke, Jr., Jose Rubiera, Christopher Landsea, Merio L. Fernández, and Roberta Klein. Hurricane vulnerability in Latin America and the Caribbean: Normalized damage and loss potentials. Natural Hazard Review, 4(3):101-114, August 2003.

Steven M. Sheffrin and Wing Thye Woo. Present value tests of an intertemporal model of the current account. Journal of International Economics, 29:237-253, 1990.

Mark Skidmore and Hideki Toya. Do natural disasters promote long-run growth? Economic Inquiry, 40(4):664-687, October 2002.

Cédric Tille. Financial integration and the wealth effect of exchange rate fluctuations. Photocopy, Federal Reserve Bank of New York, August 2004.

Jeffrey M. Wooldridge. Econometric Analysis of Cross Section and Panel Data. MIT Press, Cambridge, Massachusetts, first edition, 2002. ISBN 0262232197. 


\section{Data Sources}

Associated Press. Damage in Dominican Republic above $\$ 1$ billion. Associated Press Wire Report, September 1998.

Lixion A. Avila and Edward N. Rappaport. Atlantic Hurricane Season of 1994. Monthly Weather Review, 124:1558-1578, 1996.

Lixion A. Avila and Edward N. Rappaport. Atlantic Hurricane Season of 1996. Monthly Weather Review, 127:581-610, 1999.

John L. Beven II, Stacy R. Stewart, Miles B. Lawrence, Lixion A. Avila, James L. Franklin, and Richard J. Pasch. Atlantic Hurricane Season of 2001. Monthly Weather Review, 131:1454-1484, July 2003.

Robert A. Case. Atlantic Hurricane Season of 1985. Monthly Weather Review, 114: 1390-1405, 1986.

Robert A. Case and Harold P. Gerrish. Atlantic Hurricane Season of 1983. Monthly Weather Review, 112:1083-1092, 1984.

Robert A. Case and Harold P. Gerrish. Atlantic Hurricane Season of 1987. Monthly Weather Review, 116:939-949, 1988.

Robert A. Case and Max Mayfield. Atlantic Hurricane Season of 1989. Monthly Weather Review, 118:1165-1177, May 1990.

Caribbean Disaster Emergency Response Agency. Tropical storm Lili situation report no. 2. Technical Report 2, Caribbean Disaster Emergency Response Agency, October 2002 .

Gilbert B. Clark. Atlantic Hurricane Season of 1982. Monthly Weather Review, 111: 1071-1079, 1983.

Centre for Research on the Epidemiology of Disasters. EM-DAT: the OFDA/CRED international disaster database. Website, 2004. URL http://www.em-dat.net.

Department of Regional Development and Environment Executive Secretariat for Economic and Social Affairs. Primer on Natural Hazard Management in Integrated Regional Development Planning. Organization of American States, Washington, D.C., 1991.

Gordon E. Dunn. The Hurricane Season of 1960. Monthly Weather Review, pages 99-108, March 1961.

Gordon E. Dunn and Staff. The Hurricane Season of 1961. Monthly Weather Review, pages 107-119, March 1962.

Gordon E. Dunn and Staff. The Hurricane Season of 1962. Monthly Weather Review, pages 199-207, April 1963. 
Gordon E. Dunn and Staff. The Hurricane Season of 1963. Monthly Weather Review, 92 (3):128-138, March 1964.

Gordon E. Dunn and Staff. The Hurricane Season of 1964. Monthly Weather Review, 93 (3):175-187, March 1965.

Economic Commission for Latin America and the Caribbean. Preliminary overview of the economies of Latin America and the Caribbean 1998. Technical report, United Nations' Economic Commission for Latin America and the Caribbean, December 1998.

Economic Commission for Latin America and the Caribbean. Costa Rica: Assessment of the damage caused by Hurricane Mitch, 1998. Technical Report LC/MEX/L.373, United Nations' Economic Commission for Latin America and the Caribbean, April 1999a.

Economic Commission for Latin America and the Caribbean. El Salvador: Assessment of the damage caused by Hurricane Mitch, 1998. Technical Report LC/MEX/L.371, United Nations' Economic Commission for Latin America and the Caribbean, April 1999b.

Economic Commission for Latin America and the Caribbean. Guatemala: Assessment of the damage caused by Hurricane Mitch, 1998. Technical Report LC/MEX/L.370, United Nations' Economic Commission for Latin America and the Caribbean, April 1999c.

Economic Commission for Latin America and the Caribbean. Honduras: Assessment of the damage caused by Hurricane Mitch, 1998. Technical Report LC/MEX/L.367, United Nations' Economic Commission for Latin America and the Caribbean, April 1999 d.

Economic Commission for Latin America and the Caribbean. Nicaragua: Assessment of the damage caused by Hurricane Mitch, 1998. Technical Report LC/MEX/L.372, United Nations' Economic Commission for Latin America and the Caribbean, April 1999 e.

Economic Commission for Latin America and the Caribbean. Belize: Assessment of the damage caused by Hurricane Keith, 2000. Technical Report LC/CAR/G.627, LC/MEX/G.4, United Nations' Economic Commission for Latin America and the Caribbean, November 2000.

Economic Commission for Latin America and the Caribbean. Jamaica: Assessment of the damage caused flood rains and landslides in association with Hurricane Michelle, october 2001. Technical Report LC/CAR/G.672, United Nations' Economic Commission for Latin America and the Caribbean, December 2001.

Economic Commission for Latin America and the Caribbean. Handbook for Estimating the Socio-economic and Environmental Effects of Disasters. Number LC/MEX/G.5, LC/L.1874. United Nations, July 2003. 
James L. Franklin, Lixion A. Avila, Jack L. Beven, Miles B. Lawrence, Richard J. Pasch, and Stacy R. Stewart. Atlantic Hurricane Season of 2000. Monthly Weather Review, 129:3037-3056, 2001.

Paul J. Hebert. Atlantic Hurricane Season of 1975. Monthly Weather Review, 104:453$465,1976$.

Paul J. Hebert. Atlantic Hurricane Season of 1979. Monthly Weather Review, 108:973990, 1980.

Paul J. Hebert and Neil L. Frank. Atlantic Hurricane Season of 1973. Monthly Weather Review, 102:280-289, 1974.

John R. Hope. Atlantic Hurricane Season of 1974. Monthly Weather Review, 103:285-293, 1975.

Miles B. Lawrence. Atlantic Hurricane Season of 1976. Monthly Weather Review, 105: 497-507, 1977.

Miles B. Lawrence. Atlantic Hurricane Season of 1977. Monthly Weather Review, 106: 534-545, 1978.

Miles B. Lawrence. Atlantic Hurricane Season of 1978. Monthly Weather Review, 107: 477-491, 1979.

Miles B. Lawrence. Atlantic Hurricane Season of 1986. Monthly Weather Review, 115: 2155-2160, September 1987.

Miles B. Lawrence, Lixion A. Avila, Jack L. Beven, James L. Franklin, John L. Guiney, and Richard J. Pasch. Atlantic Hurricane Season of 1999. Monthly Weather Review, 129:3057-3084, 2001.

Miles B. Lawrence and Gilbert B. Clark. Atlantic Hurricane Season of 1984. Monthly Weather Review, 113:1228-1237, 1985.

Miles B. Lawrence and James M. Gross. Atlantic Hurricane Season of 1988. Monthly Weather Review, 117:2248-2259, October 1989.

Miles B. Lawrence, Max Mayfield, Lixion A. Avila, Richard J. Pasch, and Edward N. Rappaport. Atlantic Hurricane Season of 1995. Monthly Weather Review, 126:11241151, May 1998.

Miles B. Lawrence and Joseph M. Pelissier. Atlantic Hurricane Season of 1980. Monthly Weather Review, 109:1567-1582, 1981.

Miles B. Lawrence and Joseph M. Pelissier. Atlantic Hurricane Season of 1981. Monthly Weather Review, 110:852-866, 1982.

Max Mayfield, Lixion A. Avila, and Edward N. Rappaport. Atlantic Hurricane Season of 1992. Monthly Weather Review, 122:517-538, 1994. 
Max Mayfield and Miles B. Lawrence. Atlantic Hurricane Season of 1990. Monthly Weather Review, 119:2014-2026, 1991.

Meteorological Service of the Netherlands Antilles and Aruba. Preliminary report Hurricane Jose October 1999. Technical report, Meteorological Service of the Netherlands Antilles and Aruba, 2000. URL http://www.meteo.an/meteo2/eng/reports/jose/jose.htm.

U.S. National Climatic Data Center. Mitch: The Deadliest Atlantic Hurricane since 1780. Technical report, U.S. National Climatic Data Center, 2004. URL http://lwf.ncdc.noaa.gov/oa/reports/mitch/mitch.html.

U.S. National Hurricane Center. Atlantic tracks file 1851-2003. Website, 2003. URL http://www.nhc.noaa.gov/tracks1851to2003_atl.txt.

Richard J. Pasch and Lixion A. Avila. Atlantic Hurricane Season of 1991. Monthly Weather Review, 120:2671-2687, 1992.

Richard J. Pasch, Lixion A. Avila, and John L. Guiney. Atlantic Hurricane Season of 1998. Monthly Weather Review, 129:3085-3123, 2001.

Richard J. Pasch, Miles B. Lawrence, Lixion A. Avila, John L. Beven, James L. Franklin, and Stacy R. Stewart. Atlantic Hurricane Season of 2002. Monthly Weather Review, 132:1829-1859, July 2004.

Richard J. Pasch and Edward N. Rappaport. Atlantic Hurricane Season of 1993. Monthly Weather Review, 123:871-886, 1995.

Edward N. Rappaport. Atlantic Hurricane Season of 1997. Monthly Weather Review, 127:2012-2026, 1999.

Robert H. Simpson and Paul J. Hebert. Atlantic Hurricane Season of 1972. Monthly Weather Review, 101:323-333, 1973.

Robert H. Simpson and John R. Hope. Atlantic Hurricane Season of 1971. Monthly Weather Review, 100:256-267, 1972.

Robert H. Simpson and Joseph M. Pelissier. Atlantic Hurricane Season of 1970. Monthly Weather Review, 99:269-277, April 1971.

Robert H. Simpson, Arnold L. Sugg, and Staff. The Hurricane Season of 1969. Monthly Weather Review, 98(4):293-306, March 1970.

Arnold L. Sugg. The Hurricane Season of 1965. Monthly Weather Review, 94(3):183-191, March 1966.

Arnold L. Sugg. The Hurricane Season of 1966. Monthly Weather Review, 95(3):131-142, March 1967.

Arnold L. Sugg and Paul J. Hebert. The Hurricane Season of 1968. Monthly Weather Review, 97(3):225-239, March 1969. 
Arnold L. Sugg and Joseph M. Pelissier. The Hurricane Season of 1967. Monthly Weather Review, 96(4):242-250, April 1968.

Swiss Re Economic Research and Consulting Sigma Series. Natural catastrophes and man-made disasters 1999: Storms and earthquakes lead to the second-highest losses in insurance history. Technical Report 2/2000, Swiss Re, Zurich, Switzerland, 2000.

Swiss Re Economic Research and Consulting Sigma Series. Natural catastrophes and man-made disasters in 2002: high flood loss burden. Technical Report 2/2003, Swiss Re, Zurich, Switzerland, 2003.

United Nations Department of Humanitarian Affairs. Dominica - Hurricane situation report No. 3. Technical Report DHAGVA - 95/0421, United Nations Department of Humanitarian Affairs, September 1995.

U.S. Agency for International Development. Caribbean, Dominican Republic, Haiti Hurricane Georges fact sheet \#3. Technical report, U.S. AID, Office of U.S. Foreign Disaster Assistance, September 1998a.

U.S. Agency for International Development. Central America - Hurricane Mitch fact sheet \#21. Technical report, U.S. AID, Office of U.S. Foreign Disaster Assistance, December 1998b.

U.S. Agency for International Development. Northeastern Caribbean Hurricane Lenny fact sheet \#1, FY 2000. Technical report, U.S. AID, Office of U.S. Foreign Disaster Assistance, November 1999.

U.S. Agency for International Development. Hurricane Lenny recovery in the Eastern Caribbean. Special objective document, U.S. AID, Office of U.S. Foreign Disaster Assistance, April 2000.

World Bank. World Development Indicators. electronic dataset, 2003. 
Table 1: Caribbean and Central American Sample Statistics (Annual Averages over 1960-2002)

\begin{tabular}{|c|c|c|c|c|c|c|c|}
\hline Country & $\begin{array}{c}\text { Real GDP } \\
\text { (Millions of } \\
\text { Cons. } 1995 \text { US } \$ \text { ) }\end{array}$ & $\begin{array}{l}\text { Real P.C. } \\
\text { GDP (Cons. } \\
1995 \text { US\$) }\end{array}$ & $\begin{array}{l}\text { Population } \\
\text { (Thousands) }\end{array}$ & $\begin{array}{l}\text { External Debt } \\
\text { over GDP }\end{array}$ & $\begin{array}{c}\text { Bank-owned Net } \\
\text { Foreign Assets } \\
\text { over GDP }\end{array}$ & $\begin{array}{l}\text { Agric. Sector } \\
\text { Size (Prop. } \\
\text { of GDP) }\end{array}$ & $\begin{array}{l}\text { Average } \\
\text { Number } \\
\text { of Obs. }\end{array}$ \\
\hline $\begin{array}{l}\text { St. Vincent and } \\
\text { the Grenadines }\end{array}$ & $\$ 155$ & $\$ 1,483$ & 98 & $28 \%$ & $18 \%$ & $15 \%$ & 27 \\
\hline St. Kitts and Nevis & $\$ 186$ & $\$ 4,355$ & 45 & $33 \%$ & $18 \%$ & $9 \%$ & 23 \\
\hline Dominica & $\$ 190$ & $\$ 2,611$ & 70 & $51 \%$ & $5 \%$ & $26 \%$ & 23 \\
\hline Grenada & $\$ 244$ & $\$ 2,590$ & 94 & $45 \%$ & $11 \%$ & $15 \%$ & 24 \\
\hline Belize & $\$ 338$ & $\$ 1,939$ & 158 & $40 \%$ & $6 \%$ & $22 \%$ & 24 \\
\hline St. Lucia & $\$ 439$ & $\$ 3,133$ & 120 & $23 \%$ & $8 \%$ & $12 \%$ & 22 \\
\hline Antigua and Barbuda & $\$ 419$ & $\$ 6,481$ & 63 & - & $4 \%$ & $5 \%$ & 23 \\
\hline Bermuda & $\$ 1,473$ & $\$ 33,008$ & 63 & - & - & - & 5 \\
\hline Barbados & $\$ 1,516$ & $\$ 5,997$ & 250 & - & $5 \%$ & $10 \%$ & 31 \\
\hline Nicaragua & $\$ 1,938$ & $\$ 673$ & 3,147 & $276 \%$ & $-118 \%$ & $26 \%$ & 35 \\
\hline Bahamas & $\$ 2,540$ & $\$ 11,774$ & 215 & - & $-3 \%$ & $2 \%$ & 24 \\
\hline Honduras & $\$ 2,648$ & $\$ 655$ & 3,926 & $74 \%$ & $3 \%$ & $27 \%$ & 33 \\
\hline Haiti & $\$ 2,734$ & $\$ 497$ & 5,667 & $29 \%$ & $2 \%$ & - & 35 \\
\hline Trinidad and Tobago & $\$ 4,285$ & $\$ 3,789$ & 1,096 & $28 \%$ & $17 \%$ & $4 \%$ & 34 \\
\hline Jamaica & $\$ 4,314$ & $\$ 1,995$ & 2,153 & $87 \%$ & $-5 \%$ & $8 \%$ & 29 \\
\hline Panama & $\$ 5,477$ & $\$ 2,607$ & 2,003 & $76 \%$ & $-3 \%$ & $8 \%$ & 29 \\
\hline El Salvador & $\$ 7,139$ & $\$ 1,577$ & 4,499 & $33 \%$ & $1 \%$ & $29 \%$ & 35 \\
\hline Costa Rica & $\$ 7,381$ & $\$ 2,828$ & 2,452 & $58 \%$ & $5 \%$ & $21 \%$ & 35 \\
\hline Dominican Republic & $\$ 8,488$ & $\$ 1,333$ & 5,874 & $37 \%$ & $-1 \%$ & $17 \%$ & 37 \\
\hline Guatemala & $\$ 10,120$ & $\$ 1,336$ & 7,325 & $21 \%$ & $4 \%$ & $26 \%$ & 33 \\
\hline Puerto Rico & $\$ 26,460$ & $\$ 7,958$ & 3,181 & - & - & $2 \%$ & 11 \\
\hline Mexico & $\$ 206,700$ & $\$ 2,841$ & 68,729 & $37 \%$ & $4 \%$ & $9 \%$ & 34 \\
\hline Aruba & - & - & 87 & - & $20 \%$ & - & 4 \\
\hline Cuba & - & - & 9,593 & - & - & $7 \%$ & 2 \\
\hline Netherlands Antilles & - & - & 177 & - & $16 \%$ & - & 4 \\
\hline US Virgin Islands & - & - & 87 & - & - & - & 2 \\
\hline
\end{tabular}

All statistics are sample annual averages by country over the period 1960-2002. The average number of observations is calculated from the total number of observations available for the dependent variables in tables 2 and 3. 
Table 2: Baseline Fixed Effects Panel Estimation Coefficients (Newey-West HAC Robust Standard Errors) Dependent Variable

\begin{tabular}{|c|c|c|c|c|c|}
\hline Explanatory Variable & $\begin{array}{c}\text { Current Account } \\
\text { over GDP }\end{array}$ & $\begin{array}{l}\text { Gross Nat'l } \\
\text { Saving Rate }\end{array}$ & $\begin{array}{l}\text { Gross Inv't } \\
\text { Rate }\end{array}$ & $\begin{array}{l}\text { Real Output } \\
\text { Growth }\end{array}$ & $\begin{array}{l}\text { Real Cons. } \\
\text { Growth }\end{array}$ \\
\hline Hurricane Damage & 0.942 & $3.837^{* *}$ & $5.134^{* * *}$ & $-5.428^{* *}$ & -0.815 \\
\hline Measure & (3.374) & $(1.652)$ & $(1.225)$ & $(2.218)$ & $(1.563)$ \\
\hline \multirow[t]{2}{*}{ Hurricane Damage L1 } & $-5.043^{* * *}$ & 0.347 & $5.916^{* * *}$ & 0.394 & $2.811^{* *}$ \\
\hline & $(1.272)$ & $(1.514)$ & $(2.096)$ & $(1.372)$ & $(1.390)$ \\
\hline \multirow[t]{2}{*}{ Hurricane Damage L2 } & -1.588 & $3.393^{* * *}$ & $3.796^{* * *}$ & -0.815 & $-4.819^{* *}$ \\
\hline & $(1.096)$ & $(1.296)$ & $(0.980)$ & $(1.794)$ & $(2.464)$ \\
\hline \multirow[t]{2}{*}{ Hurricane Damage L3 } & $2.738^{*}$ & $5.099^{* * *}$ & $1.863^{*}$ & 1.042 & $-3.903^{* * *}$ \\
\hline & (1.617) & (1.459) & $(1.132)$ & $(0.886)$ & $(1.460)$ \\
\hline \multirow[t]{2}{*}{ Hurricane Damage L4 } & 2.312 & $4.156^{* * *}$ & 1.297 & 2.233 & 4.248 \\
\hline & (1.919) & (1.517) & $(1.212)$ & (1.779) & (2.839) \\
\hline \multirow[t]{2}{*}{ Hurricane Damage L5 } & 1.636 & $4.499^{* * *}$ & $2.644^{* *}$ & -1.366 & -0.536 \\
\hline & (1.207) & $(0.917)$ & (1.336) & $(1.180)$ & $(2.659)$ \\
\hline \multirow[t]{2}{*}{ Hurricane Damage L6 } & 1.123 & 1.835 & $2.073^{* *}$ & 0.258 & 2.440 \\
\hline & (1.838) & $(1.329)$ & $(0.817)$ & $(1.534)$ & $(1.421)$ \\
\hline \multirow[t]{2}{*}{ Hurricane Damage L7 } & 1.091 & -1.915 & & -0.630 & 0.689 \\
\hline & $(1.684)$ & $(2.139)$ & & $(0.920)$ & $(1.605)$ \\
\hline \multirow[t]{2}{*}{ Hurricane Damage L8 } & $2.718^{* *}$ & 1.486 & & $3.747^{*}$ & -0.261 \\
\hline & $(1.113)$ & $(1.184)$ & & $(2.284)$ & $(1.928)$ \\
\hline \multirow[t]{2}{*}{ Hurricane Damage L9 } & & 0.548 & & & $4.306^{* * *}$ \\
\hline & & $(1.422)$ & & & $(1.612)$ \\
\hline \multirow[t]{2}{*}{ Hurricane Damage L10 } & & $-3.125^{* *}$ & & & $4.982^{* * *}$ \\
\hline & & $(1.319)$ & & & $(1.880)$ \\
\hline $\mathrm{N}$ & 541 & 500 & 644 & 711 & 526 \\
\hline$R^{2}$ & 0.543 & 0.490 & 0.626 & 0.161 & 0.192 \\
\hline
\end{tabular}

Significance levels: $\quad *: 10 \% \quad * *: 5 \% \quad * * *: 1 \%$. Standard errors are underneath coefficient estimates in parentheses. "L" (for lag) followed by a number denotes the number of years elapsed since a hurricane strike. The lag truncation parameter used is 3 . 
Table 3: Transfers and the Government - Fixed Effects Panel Estimation Coefficients (Newey-West HAC Robust Standard Errors)

\begin{tabular}{|c|c|c|c|c|c|}
\hline \multirow[b]{2}{*}{ Explanatory Variable } & \multicolumn{3}{|c|}{ Dependent Variable } & \multirow[b]{2}{*}{$\begin{array}{l}\text { Workers' Remit. } \\
\text { over GDP }\end{array}$} & \multirow[b]{2}{*}{$\begin{array}{l}\text { Overall Gov't Bud } \\
\text { Deficit over GDP }\end{array}$} \\
\hline & $\begin{array}{l}\text { Curr. Acc. minus Net } \\
\text { Transfers over GDP }\end{array}$ & $\begin{array}{c}\text { Net Transfers } \\
\text { over GDP }\end{array}$ & $\begin{array}{c}\text { Foreign Aid } \\
\text { over GDP }\end{array}$ & & \\
\hline Hurricane Damage & $-6.389^{* * *}$ & $7.331^{*}$ & 0.992 & $2.396^{*}$ & -0.833 \\
\hline Measure & $(1.775)$ & $(4.266)$ & $(0.984)$ & $(1.238)$ & $(0.865)$ \\
\hline \multirow[t]{2}{*}{ Hurricane Damage L1 } & $-10.459^{* * *}$ & $5.416^{* *}$ & $3.175^{* *}$ & $1.766^{*}$ & 0.900 \\
\hline & $(2.430)$ & $(2.554)$ & $(1.564)$ & $(0.917)$ & $(1.108)$ \\
\hline \multirow[t]{2}{*}{ Hurricane Damage L2 } & $-5.135^{* * *}$ & $3.547^{* * *}$ & 1.290 & 1.021 & -0.493 \\
\hline & $(1.485)$ & $(1.314)$ & $(1.182)$ & $(0.800)$ & $(1.260)$ \\
\hline \multirow[t]{2}{*}{ Hurricane Damage L3 } & 1.603 & 1.135 & $2.229^{*}$ & 0.776 & $3.107^{* * *}$ \\
\hline & $(1.615)$ & $(1.488)$ & $(1.283)$ & $(0.670)$ & $(0.918)$ \\
\hline \multirow[t]{2}{*}{ Hurricane Damage L4 } & 1.319 & 0.993 & 0.054 & 1.050 & \\
\hline & $(1.971)$ & $(1.240)$ & $(0.732)$ & $(0.855)$ & \\
\hline \multirow[t]{2}{*}{ Hurricane Damage L5 } & 0.132 & 1.504 & -0.421 & 0.420 & \\
\hline & $(1.531)$ & $(1.173)$ & $(1.158)$ & $(0.935)$ & \\
\hline \multirow[t]{2}{*}{ Hurricane Damage L6 } & 0.369 & 0.755 & -0.473 & $2.137^{* * *}$ & \\
\hline & $(1.791)$ & $(1.474)$ & $(1.094)$ & $(0.592)$ & \\
\hline \multirow[t]{2}{*}{ Hurricane Damage L7 } & 2.817 & -1.726 & 0.426 & & \\
\hline & $(1.810)$ & $(1.356)$ & $(0.925)$ & & \\
\hline \multirow[t]{2}{*}{ Hurricane Damage L8 } & $4.187^{* * *}$ & $-1.469^{*}$ & 1.675 & & \\
\hline & $(1.415)$ & $(0.857)$ & $(1.039)$ & & \\
\hline $\mathrm{N}$ & 541 & 541 & 663 & 455 & 393 \\
\hline$R^{2}$ & 0.654 & 0.463 & 0.493 & 0.647 & 0.394 \\
\hline
\end{tabular}

Significance levels: $\quad *: 10 \% \quad * *: 5 \% \quad * * *: 1 \%$. Standard errors are underneath coefficient estimates in parentheses. "L" (for lag) followed by a number denotes the number of years elapsed since a hurricane strike. The lag truncation parameter used is 3 . Foreign aid is official development assistance. All other transfers are non-governmental, including worker remittances. 
Table 4: Marginal Effects of Hurricane Shocks on the Current Account over GDP (Newey-West HAC Robust Standard Errors)

Characteristic Variable and its Level

\begin{tabular}{lcccccc} 
& \multicolumn{6}{c}{ Characteristic Variable and its Level } \\
\cline { 2 - 7 } Explanatory Variable & GDP & GDP & NFA & NFA & Agric. & Agric. \\
\hline Hurricane Damage & 0.098 & -1.883 & -1.896 & 0.548 & 3.421 & -6.121 \\
Measure & $(2.807)$ & $(3.724)$ & $(2.811)$ & $(2.549)$ & $(3.858)$ & $(6.700)$ \\
Hurricane Damage L1 & -4.446 & -3.194 & $-6.223^{*}$ & -3.666 & 1.193 & $-17.776^{* *}$ \\
& $(2.764)$ & $(3.687)$ & $(3.315)$ & $(2.865)$ & $(4.135)$ & $(9.014)$ \\
Hurricane Damage L2 & 0.615 & -2.899 & 1.926 & 1.768 & 0.156 & -0.812 \\
& $(2.356)$ & $(2.893)$ & $(2.990)$ & $(2.603)$ & $(3.787)$ & $(5.304)$ \\
Hurricane Damage L3 & 5.140 & -0.647 & $6.101^{*}$ & $5.976^{*}$ & 2.345 & 3.866 \\
& $(3.638)$ & $(2.689)$ & $(3.585)$ & $(3.399)$ & $(5.629)$ & $(6.733)$ \\
Hurricane Damage L4 & 3.515 & -2.204 & $6.493^{*}$ & 5.401 & 3.575 & -0.309 \\
& $(4.247)$ & $(3.803)$ & $(3.674)$ & $(3.544)$ & $(5.747)$ & $(6.985)$ \\
Hurricane Damage L5 & $6.078^{*}$ & 1.911 & 3.061 & $6.773^{*}$ & $12.383^{* *}$ & -10.365 \\
& $(3.574)$ & $(3.904)$ & $(4.112)$ & $(3.931)$ & $(5.124)$ & $(7.092)$ \\
Hurricane Damage L6 & 0.081 & 0.213 & 0.818 & 1.448 & 8.759 & $-18.058^{* *}$ \\
& $(4.418)$ & $(4.518)$ & $(5.324)$ & $(4.381)$ & $(6.495)$ & $(9.120)$ \\
Hurricane Damage L7 & 1.546 & $4.885^{*}$ & $3.272^{*}$ & 2.413 & -2.961 & 1.244 \\
& $(2.616)$ & $(2.599)$ & $(1.951)$ & $(2.529)$ & $(4.503)$ & $(1.904)$ \\
Hurricane Damage L8 & $4.269^{* * *}$ & $4.442^{*}$ & $2.741^{*}$ & $3.234^{*}$ & 2.098 & $2.492^{*}$ \\
& $(1.586)$ & $(2.617)$ & $(1.565)$ & $(1.739)$ & $(2.355)$ & $(1.355)$ \\
\hline
\end{tabular}

Significance levels: $\quad *: 10 \% \quad * *: 5 \% \quad * * *: 1 \%$. Standard errors are underneath coefficient estimates in parentheses. L" (for lag) followed by a number denotes the number of years elapsed since a hurricane strike. The characteristic variables are economic size (GDP), bank-owned net foreign assets (NFA), and size of the agricultural sector (Agric.). Small economic size corresponds to a real GDP level of $\$ 155$ million, the time average of St. Kitt's and Nevis' real GDP. Medium economic size corresponds to a real GDP level of $\$ 2.54$ billion, the time average of Guatemala's real GDP. Negative NFA corresponds to a bank-owned net foreign assets to GDP ratio of $-5 \%$, the time average of Jamaica. Positive NFA corresponds to a bank-owned net foreign assets to GDP ratio of $+5 \%$, the time average of Dominica or Costa Rica. Small agricultural sector size corresponds to $2 \%$ of GDP, the time average of the Bahamas. Large agricultural sector size corresponds to $29 \%$ of GDP, the time average of El Salvador. The lag truncation parameter used is 3. 
Figure 1: Hurricane Incidence

Annual Storm Incidence in the North Atlantic and Caribbean 1960-2003, Quintennial Totals

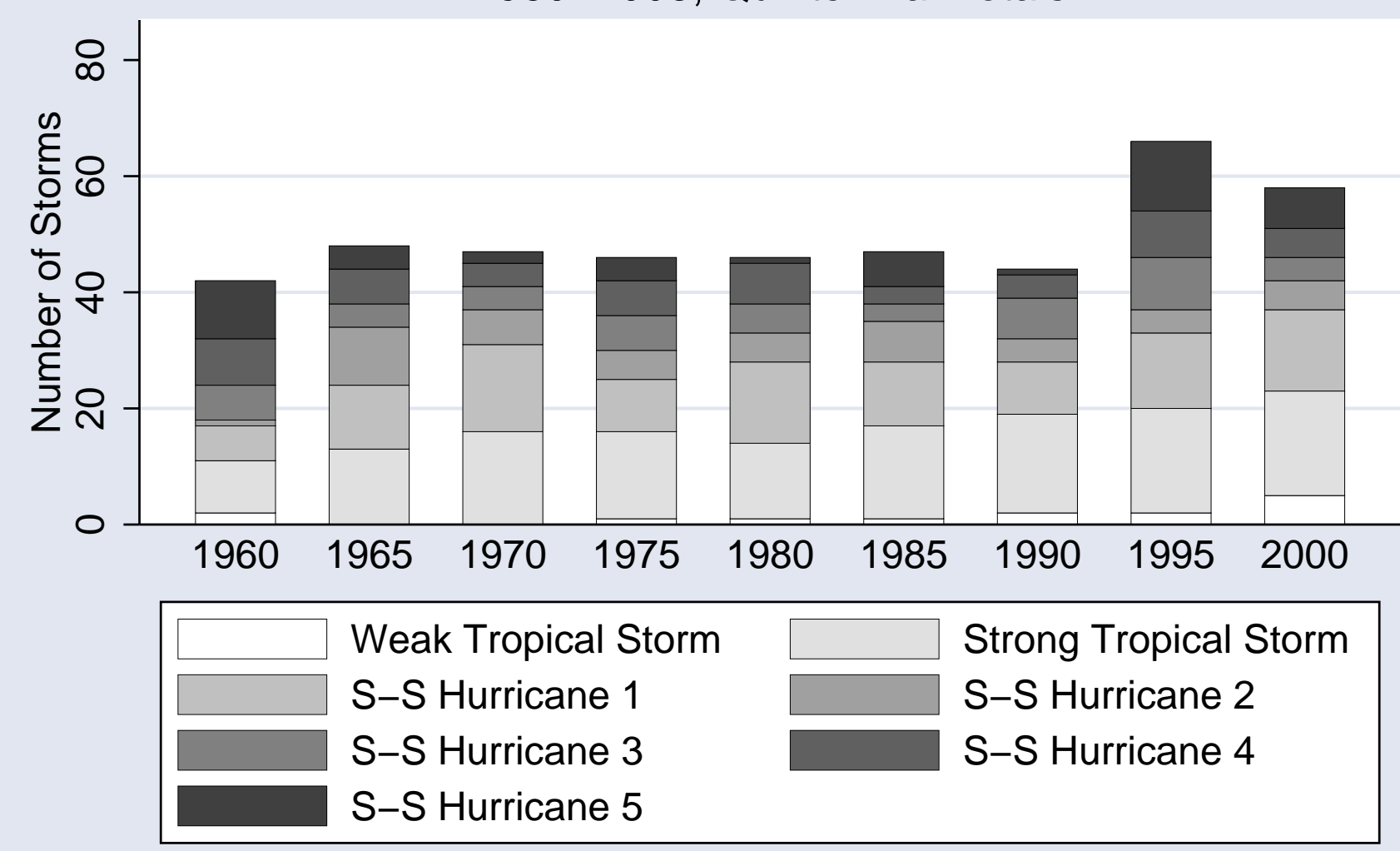

Source: US National Hurricane Center Historic Storm Tracks Database 
Figure 2: Hurricanes Georges (top) and Luis (bottom) over Puerto Rico and Barbuda respectively. (Source: Pasch et al., 2001 and Lawrence et al., 1998)
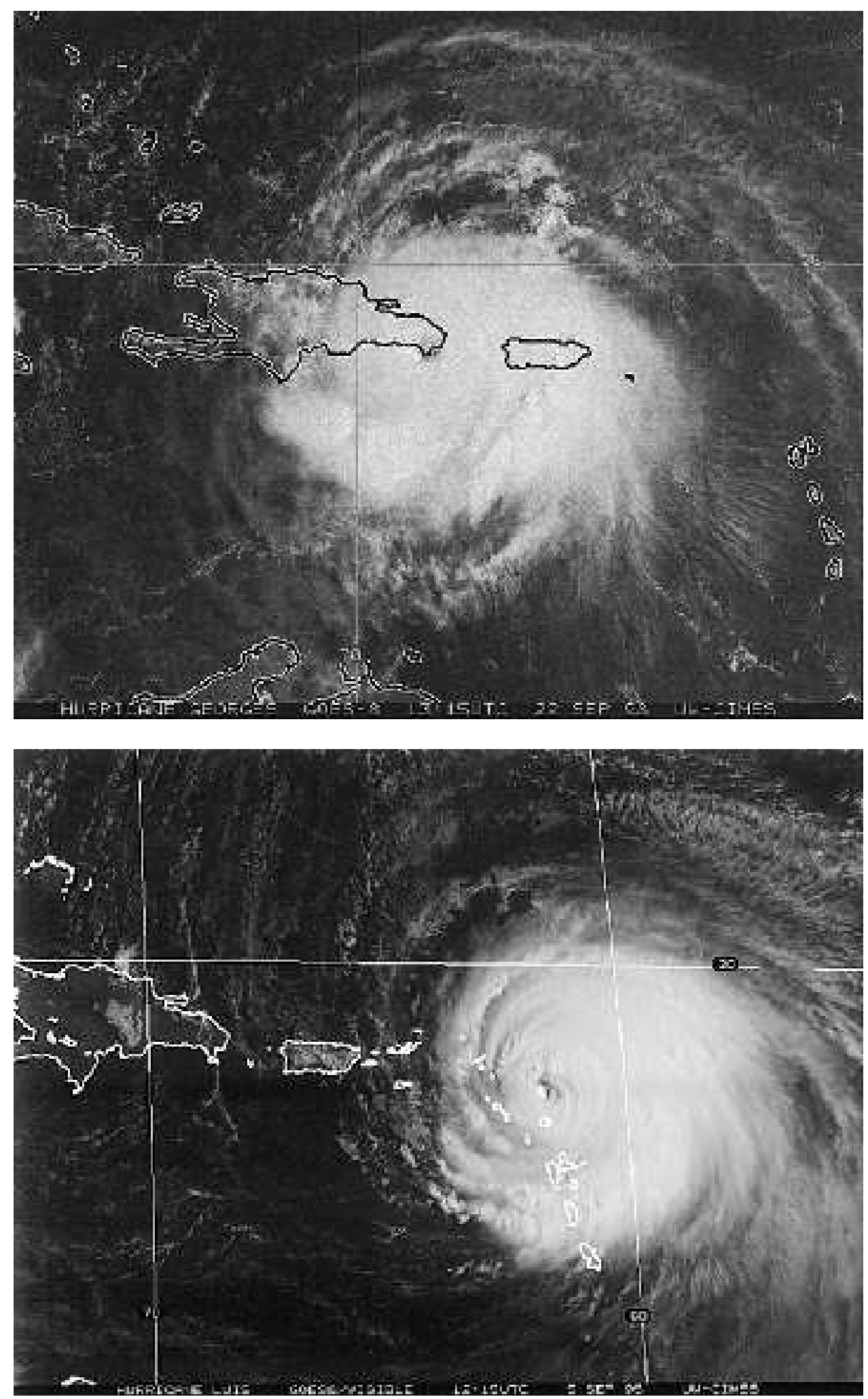
Figure 3: Simulated Impulse Response - Current Account over Output

\section{Current Account to GDP Ratio Response}

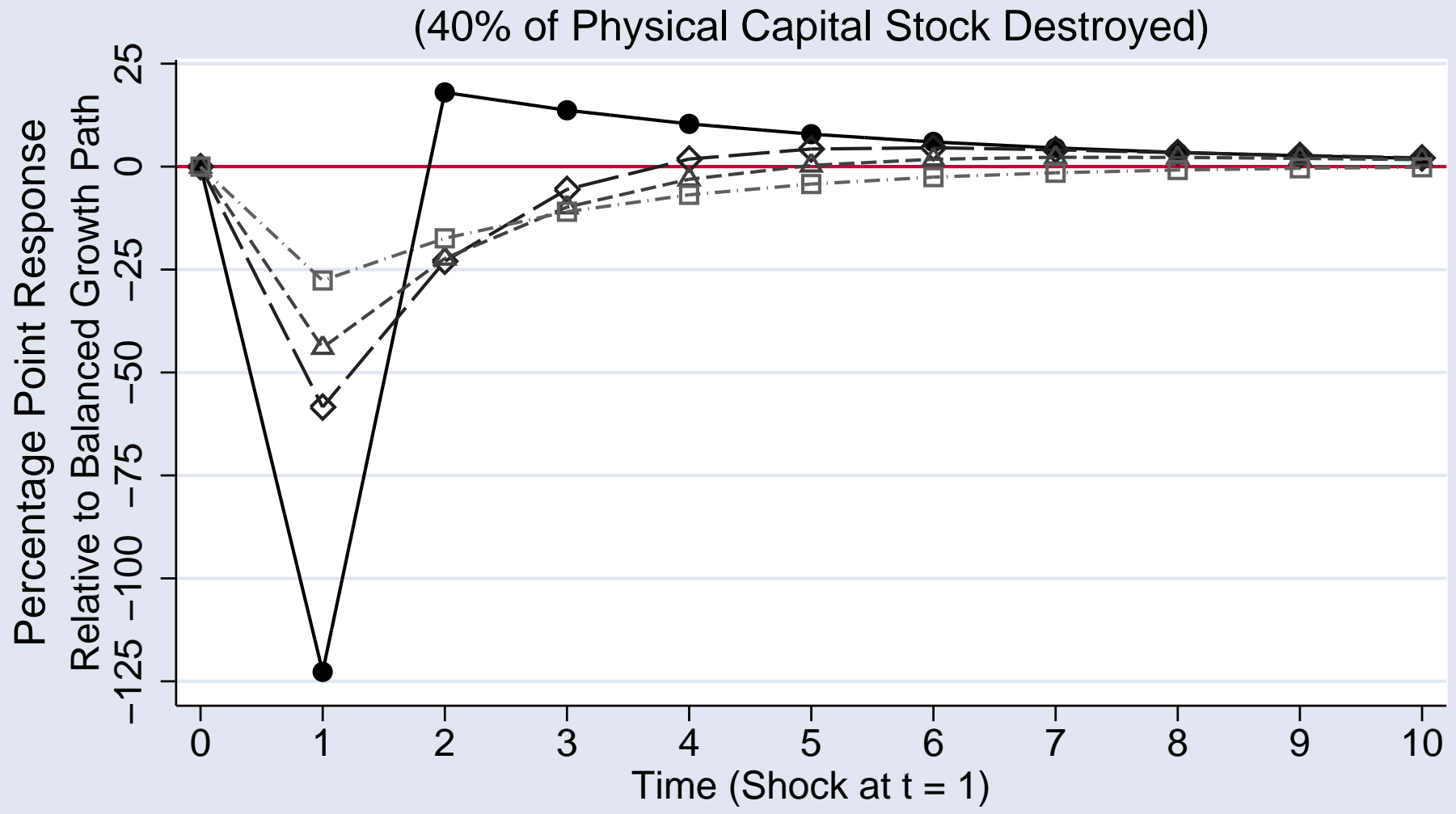

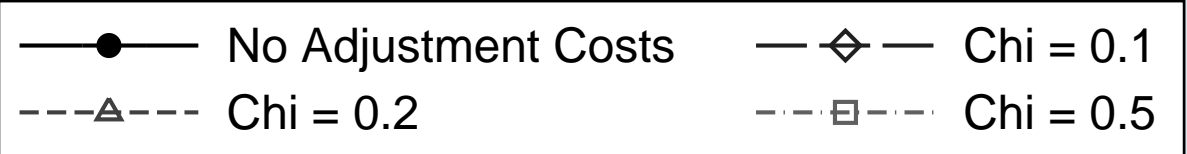

The deep parameter values underlying the above simulation are: real foreign interest rate $r=0.10$; time discount factor $\beta=0.80$; intertemporal elasticity of substitution $\sigma=2$; Cobb-Douglas capital exponent $\alpha=0.25$; and exogenous rate of productivity growth $g=0.02$. The parameter $\chi$ determines how large capital adjustment costs are, with higher values implying larger costs $(\chi=0$ with no adjustment costs) 
Figure 4: Simulated Impulse Responses - Output and Consumption Growth
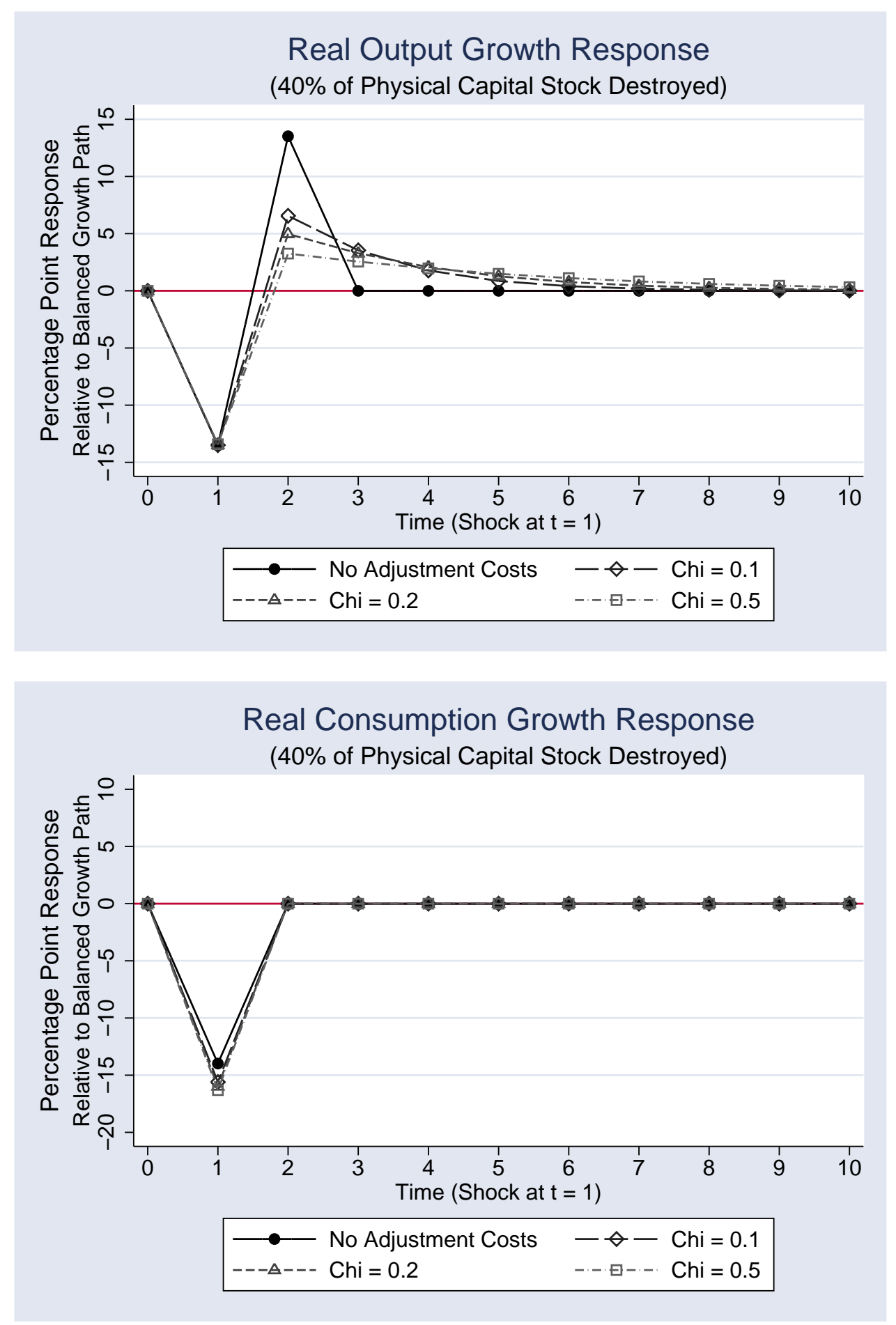

The deep parameter values underlying the above simulation are: real foreign interest rate $r=0.10$; time discount factor $\beta=0.80$; intertemporal elasticity of substitution $\sigma=2$; Cobb-Douglas capital exponent $\alpha=0.25$; and exogenous rate of productivity growth $g=0.02$. The parameter $\chi$ determines how large capital adjustment costs are, with higher values implying larger costs $(\chi=0$ with no adjustment costs). 
Figure 5: Caribbean and Central American Hurricane Damages Map

\section{HURRICANE ECONOMIC DAMAGES BY COUNTRY:}

1960-2003

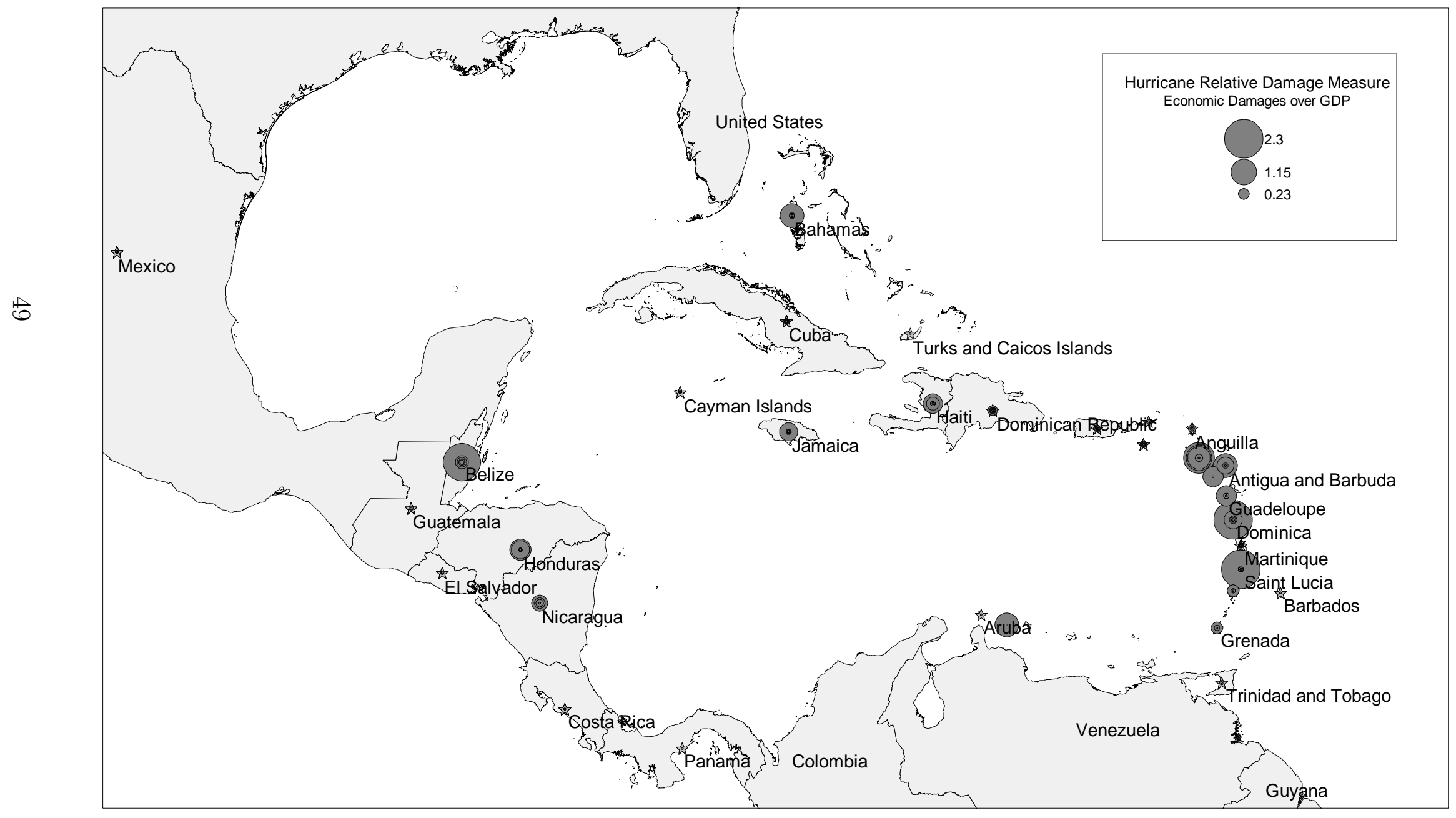


Figure 6: Hurricane Damage Measure Distribution

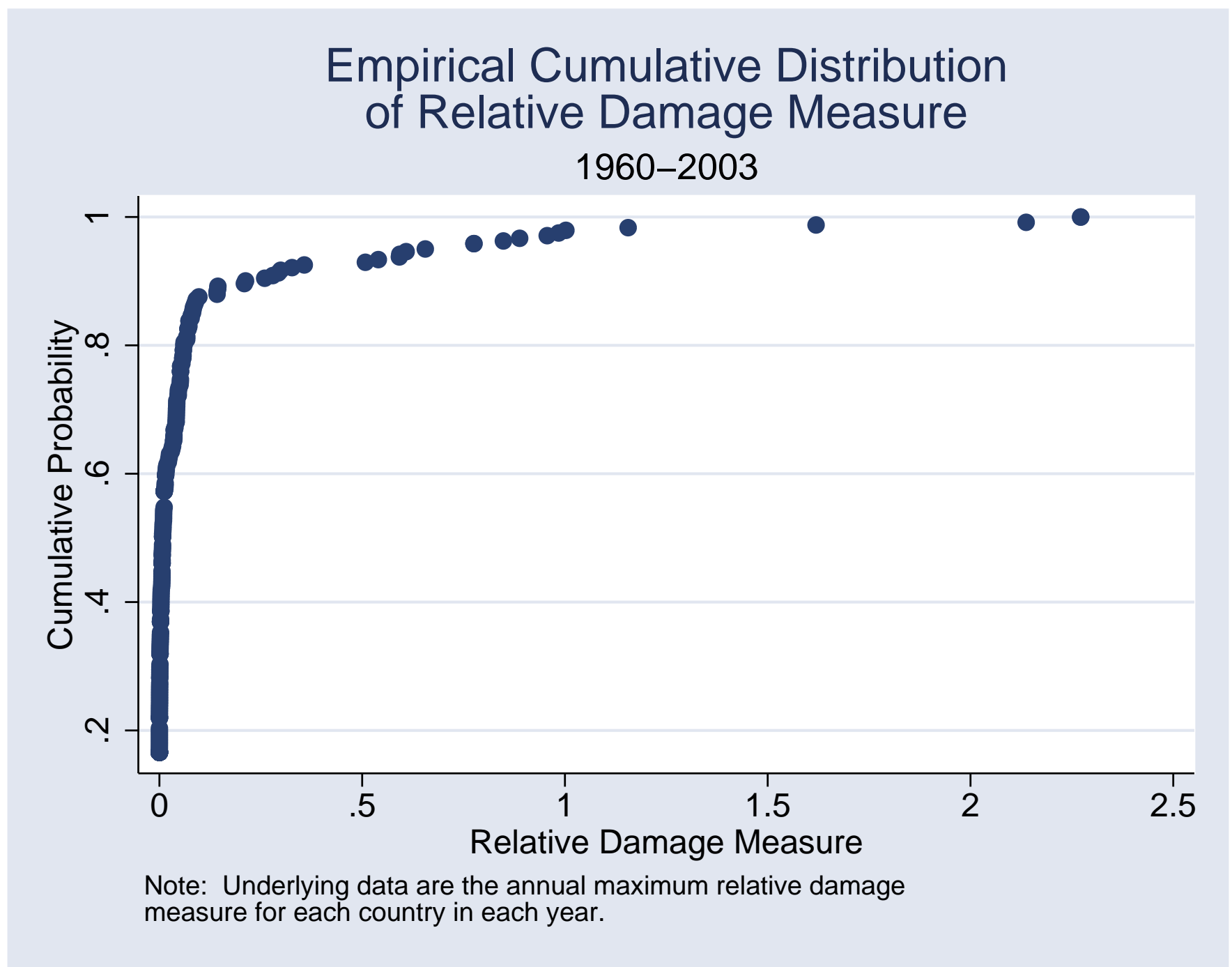




\section{Appendix (NOT FOR PUBLICATION)}

\section{A Intertemporal Current Account Model Solution}

Let Home's small, open economy be characterized by a representative agent, who faces the following problem:

$$
\begin{gathered}
\max _{C_{s}, I_{s}} U=E_{t}\left[\sum_{s=t}^{\infty} \beta^{s-t} u\left(C_{s}\right)\right] \\
\text { s.t. } C_{s}=(1+r) B_{s}+Y_{s}+N_{s}-I_{s}-C\left(I_{s}, K_{s}\right)-G_{s}-B_{s+1} \text { for all } s, \\
K_{s+1}=\left(1-\varepsilon_{s+1}\right)\left[K_{s}+I_{s}\right], \tilde{K}_{s+1}=K_{s}+I_{s}, Y_{s} \equiv F\left(A_{s}, K_{s}\right) \text { and } A_{s+1}=(1+g) A_{s} .
\end{gathered}
$$

Assume that the government budget is balanced (expenditures equal lump-sum tax receipts). The components of the problem are:

1. $\beta$ is the time preference discount factor and $\beta \in(0,1)$.

2. $u(\cdot)$ is a concave, period utility function.

3. $C$ is period consumption.

4. $B$ is net foreign asset holdings.

5. $r$ is the exogenous constant foreign rate of return on foreign assets.

6. $Y$ is output.

7. $N$ is exogenous net transfers from abroad.

8. $A$ is exogenous total factor productivity, which grows at rate $g$.

9. $F(\cdot)$ is a concave, linearly homogenous production function with $F_{A}>0, F_{K}>0$, $F_{A K}>0, F_{A A}<0, F_{K K}<0$.

10. $K$ is the physical capital stock (which is non-tradeable). 
11. $I$ is physical capital investment.

12. $\tilde{K}$ is next period's planned physical capital stock.

13. $\varepsilon$ is the proportion of the planned physical capital stock that is destroyed in a period, before it can be used in production.

14. $C(I, K)$ is a convex, linearly homogenous physical capital adjustment cost function with $C_{I}>0, C_{K}<0, C_{I I}>0, C_{K K}>0, C\left(0, K_{s}\right)=0$.

15. $G$ is exogenous government spending.

The above represents the most general formulation of the intertemporal current account model I will investigate. The general model implicitly assumes that international asset markets are incomplete (a complete set of state-contingent assets does not exist), while the domestic asset market is complete, in the sense that a representative agent exists for the domestic economy. Preferences are time-additive and separable (habit formation in consumption is not considered here). Discounting is exponential and the risk-free world real interest rate is assumed to be constant. Expectations are formed rationally. After exploring the implications of the above ICA model, I will impose some assumptions on particular functional forms of the components of the model in order to generate sharper predictions. $^{1}$

There is a single source of uncertainty in the agent's problem: the actual level of capital stock available to use in production. ${ }^{2} \quad \tilde{K}_{s+1}$ denotes the planned capital stock in the absence of any shocks. The capital stock shock affects the capital stock multiplicatively, acting as a kind of stochastic linear depreciation rate. The capital stock shock is given

\footnotetext{
${ }^{1}$ Given that there is exogenous and persistent productivity growth, an additional assumption regarding the relationship of growth, the real interest rate, and the time preference discount factor are required to ensure that the problem is well-defined. Carroll [2004] presents a discussion of such an assumption. Essentially, the agent must not be too patient for the problem to be well-defined. I will revisit this requirement more formally later.

${ }^{2}$ There are potentially two other sources of uncertainty. These are the level of net transfers from abroad $N$ and domestic government spending $G$, which may respond to the local capital shock (or may not). For example, if foreign aid flows into the country after a shock, then $\operatorname{Corr}\left(\varepsilon_{s}, N_{s}\right)>0 \Rightarrow$ $\operatorname{Corr}\left(\left[1-\varepsilon_{s}\right], N_{s}\right)<0$. I will discuss this possibility later.
} 
by $\varepsilon_{s+1} \in[0,1]$, which is a random, i.i.d. shock and is unknown before time $s+1$. $^{3}$ From this, we can see that $K_{s+1} \in\left[0, \tilde{K}_{s+1}\right]$, as the resulting capital stock cannot be negative. Since the capital stock is uncertain, output is uncertain.

The following variables are chosen at time $s: C_{s}$ (equivalently $B_{s+1}$ ) and $I_{s}$ (equivalently $\left.\tilde{K}_{s+1}\right)$. Once these are chosen, then $\varepsilon_{s+1}$ is drawn, and period $s+1$ commences. All other variables occur exactly at the time indicated by their subscript.

There are two state variable at work here: $K_{s}$ and $B_{s} \cdot{ }^{4}$ Notice that although $B_{s}$ appears to be a state variable, it is in fact a choice variable. The evolution of $B_{s}$ is given by the intertemporal budget constraint:

$$
B_{s+1}=(1+r) B_{s}+Y_{s}+N_{s}-I_{s}-C\left(I_{s}, K_{s}\right)-G_{s}-C_{s},
$$

while the evolution of $K_{s}$ is given by the equation $K_{s+1}=\left(1-\varepsilon_{s+1}\right)\left[K_{s}+I_{s}\right]=\left(1-\varepsilon_{s+1}\right) \tilde{K}_{s+1}$. Let $\delta_{s+1}=\left(1-\varepsilon_{s+1}\right)$. The one-period ahead capital stock is uncertain at any moment in time, due to the capital shock. The agent is however able to chose the planned capital stock, $\tilde{K}_{s+1}$. This is equivalent to choosing the level of investment. One-period ahead net foreign asset holdings are certain, since it is a choice variable at the current moment of time.

Since the capital stock is stochastic, the problem is amenable to dynamic programming. The Bellman equation for the agent's optimization problem will be:

$$
\begin{aligned}
\mathcal{V}\left(K_{t}, B_{t}, A_{t}\right) & =\max _{B_{s+1}, \tilde{K}_{s+1}} E_{t}\left[\sum_{s=t}^{\infty} \beta^{s-t} u\left[C_{s}\right]\right] \\
& =\max _{B_{s+1}, \tilde{K}_{s+1}}\left\{u\left[C_{t}\right]+\beta E_{t}\left[\sum_{s=t+1}^{\infty} \beta^{s-t+1} u\left[C_{s}\right]\right]\right\} \\
& =\max _{B_{s+1}, \tilde{K}_{s+1}}\left\{u \left[(1+r) B_{t}+Y_{t}+N_{t}-\left(\tilde{K}_{t+1}-K_{t}\right)\right.\right.
\end{aligned}
$$

\footnotetext{
${ }^{3}$ Note that the limited range of $\varepsilon$ implies that its mean is generally non-zero (and between zero and one).

${ }^{4}$ There is a trivial third state variable $A_{s}$, which evolves in a deterministic manner and is not influenced by the control variables.
} 


$$
\begin{aligned}
& \left.\left.-C\left(\left(\tilde{K}_{t+1}-K_{t}\right), K_{t}\right)-G_{t}-B_{t+1}\right]+\beta E_{t}\left[\sum_{s=t+1}^{\infty} \beta^{s-t+1} u\left[C_{s}\right]\right]\right\} \\
= & \max _{B_{t+1}, \tilde{K}_{t+1}}\left\{u \left[(1+r) B_{t}+Y_{t}+N_{t}-\left(\tilde{K}_{t+1}-K_{t}\right)\right.\right. \\
& \left.-C\left(\left(\tilde{K}_{t+1}-K_{t}\right), K_{t}\right)-G_{t}-B_{t+1}\right] \\
& \left.+\beta E_{t}\left[\max _{B_{s+1}, \tilde{K}_{s}} E_{t+1}\left[\sum_{s=t+1}^{\infty} \beta^{s-t+1} u\left[C_{s}\right]\right]\right]\right\} \\
= & \max _{B_{t+1}, \tilde{K}_{t+1}}\left\{u \left[(1+r) B_{t}+Y_{t}+N_{t}-\left(\tilde{K}_{t+1}-K_{t}\right)\right.\right. \\
& \left.\left.-C\left(\left(\tilde{K}_{t+1}-K_{t}\right), K_{t}\right)-G_{t}-B_{t+1}\right]+\beta E_{t}\left[\mathcal{V}\left(K_{t+1}, B_{t+1}, A_{t+1}\right)\right]\right\} .
\end{aligned}
$$

The first order conditions on the righthand side of the equation are:

$$
\begin{aligned}
\frac{\partial U}{\partial B_{t+1}} & =u^{\prime}\left(C_{t}\right)(-1)+\beta E_{t}\left[\mathcal{V}_{B}\left(K_{t+1}, B_{t+1}, A_{t+1}\right)\right]=0 \\
& \Rightarrow u^{\prime}\left(C_{t}\right)=\beta E_{t}\left[\mathcal{V}_{B}\left(K_{t+1}, B_{t+1}, A_{t+1}\right)\right] \\
\frac{\partial U}{\partial \tilde{K}_{t+1}} & =u^{\prime}\left(C_{t}\right)\left(-1-C_{I}\left(I_{t}, K_{t}\right)\right)+\beta E_{t}\left[\mathcal{V}_{K}\left(K_{t+1}, B_{t+1}, A_{t+1}\right) \delta_{t+1}\right]=0 \\
& \Rightarrow u^{\prime}\left(C_{t}\right)\left(1+C_{I}\left(I_{t}, K_{t}\right)\right)=\beta E_{t}\left[\mathcal{V}_{K}\left(K_{t+1}, B_{t+1}, A_{t+1}\right) \delta_{t+1}\right] .
\end{aligned}
$$

Together, these first order conditions imply that:

$$
E_{t}\left[\mathcal{V}_{B}\left(K_{t+1}, B_{t+1}, A_{t+1}\right)\right]=E_{t}\left[\frac{\mathcal{V}_{K}\left(K_{t+1}, B_{t+1}, A_{t+1}\right)}{\left(1+C_{I}\left(I_{t}, K_{t}\right)\right)} \delta_{t+1}\right]=\frac{1}{\beta} u^{\prime}\left(C_{t}\right)
$$

Essentially, the choice between investing in physical capital and increasing foreign asset holdings must be such that the expected returns on either state variable are equalized. The envelope theorem implies that the first derivative of the value function at the interior 
optimum is: ${ }^{5}$

$$
\begin{aligned}
{\left[\begin{array}{c}
\frac{\partial \mathcal{V}}{\partial K} \\
\frac{\partial \mathcal{V}}{\partial B} \\
\frac{\partial \mathcal{V}}{\partial A}
\end{array}\right] } & =\left[\begin{array}{c}
u^{\prime}\left(C_{t}\right)\left(F_{K}\left(A_{t}, K_{t}\right)+1+C_{I}\left(I_{t}, K_{t}\right)-C_{K}\left(I_{t}, K_{t}\right)\right) \\
u^{\prime}\left(C_{t}\right)(1+r) \\
u^{\prime}\left(C_{t}\right)\left(F_{A}\left(A_{t}, K_{t}\right)\right)
\end{array}\right] \\
& +\beta E_{t}\left\{\left[\begin{array}{c}
\left(\frac{\partial \mathcal{V}}{\partial K}\right)_{t+1} \delta_{t+1} \\
0 \\
\left(\frac{\partial \mathcal{V}}{\partial A}\right)_{t+1}(1+g)
\end{array}\right]\right\}
\end{aligned}
$$

From this, we can see that the first order condition for foreign bond holdings gives:

$$
\begin{aligned}
u^{\prime}\left(C_{t}\right) & =\beta E_{t}\left[\mathcal{V}_{B}\left(K_{t+1}, B_{t+1}, A_{t+1}\right)\right] \\
& =\beta E_{t}\left[u^{\prime}\left(C_{t+1}\right)(1+r)\right] \\
& =\beta(1+r) E_{t}\left[u^{\prime}\left(C_{t+1}\right)\right],
\end{aligned}
$$

which is the standard bond Euler equation under uncertainty. The physical capital Euler equation is given by:

$$
\begin{aligned}
u^{\prime}\left(C_{t}\right)\left(1+C_{I}\left(I_{t}, K_{t}\right)\right)= & \beta E_{t}\left[\mathcal{V}_{K}\left(K_{t+1}, B_{t+1}, A_{t+1}\right) \delta_{t+1}\right] \\
= & \beta E_{t}\left\{\left[u ^ { \prime } ( C _ { t + 1 } ) \left(F_{K}\left(A_{t+1}, K_{t+1}\right)+1+C_{I}\left(I_{t+1}, K_{t+1}\right)\right.\right.\right. \\
& \left.\left.\left.\quad-C_{K}\left(I_{t+1}, K_{t+1}\right)\right)+\beta E_{t+1}\left[\left(\frac{\partial \mathcal{V}}{\partial K}\right)_{t+2} \delta_{t+2}\right]\right] \delta_{t+1}\right\}
\end{aligned}
$$

Notice that the left-hand side of this equation is the marginal value of reducing consumption enough to make one unit of investment $\left(d C_{t}=1+C_{I}\left(I_{t}, K_{t}\right)\right.$ so that $\left.d I_{t}=1\right)$. The right-hand side of the equation is then the marginal value (time-discounted) of the increased consumption allowed by the one unit increase in investment. Output rises due to the capital stock being higher, while capital adjustment costs fall with a larger capital

\footnotetext{
${ }^{5}$ This is also sometimes referred to as the Benveniste-Scheinkman formula (Ljungqvist and Sargent, 2000).
} 
stock (since $C_{K}$ is negative). The last term is the effect of the higher capital stock on future value.

Further simplifying reveals that:

$$
\begin{aligned}
\left(1+C_{I}\left(I_{t}, K_{t}\right)\right) & =E_{t}\left\{\left[\frac { \beta u ^ { \prime } ( C _ { t + 1 } ) } { u ^ { \prime } ( C _ { t } ) } \left(F_{K}\left(A_{t+1}, K_{t+1}\right)+1+C_{I}\left(I_{t+1}, K_{t+1}\right)\right.\right.\right. \\
& \left.\left.\left.-C_{K}\left(I_{t+1}, K_{t+1}\right)\right)+\beta^{2} E_{t+1}\left[\frac{\left(\frac{\partial \mathcal{V}}{\partial K}\right)_{t+2}}{u^{\prime}\left(C_{t}\right)} \delta_{t+2}\right]\right] \delta_{t+1}\right\}
\end{aligned}
$$

Here, we can use a recursive substitution of the envelope condition to eliminate the derivatives of the value function from the Euler equation. We then have that:

$$
\begin{aligned}
\left(1+C_{I}\left(I_{t}, K_{t}\right)\right) & =\sum_{s=1}^{\infty} E_{t}\left\{\left[\frac { \beta ^ { s } u ^ { \prime } ( C _ { t + s } ) } { u ^ { \prime } ( C _ { t } ) } \left(F_{K}\left(A_{t+s}, K_{t+s}\right)+1+C_{I}\left(I_{t+s}, K_{t+s}\right)\right.\right.\right. \\
& \left.\left.\left.-C_{K}\left(I_{t+s}, K_{t+s}\right)\right) \prod_{i=1}^{s} \delta_{t+i}\right]\right\} \\
& +E_{t}\left\{\lim _{s \rightarrow \infty} \beta^{s} \prod_{i=1}^{s} \delta_{s+i} \frac{\mathcal{V}_{K}\left(K_{t+s}, B_{t+s}, A_{t+s}\right)}{u^{\prime}\left(C_{t}\right)}\right\}
\end{aligned}
$$

As long as the discount factor and shock terms dominate the marginal valuation of capital in the limit, the last term will go to zero (since $\beta \in(0,1)$ and $\delta_{s} \in[0,1]$ ). This is also required for the infinite series in the first term to converge. Assume that these conditions hold. 
We then have that:

$$
\begin{aligned}
\left(1+C_{I}\left(I_{t}, K_{t}\right)\right)= & \sum_{s=1}^{\infty} E_{t}\left\{\left[\frac { \beta ^ { s } u ^ { \prime } ( C _ { t + s } ) } { u ^ { \prime } ( C _ { t } ) } \left(F_{K}\left(A_{t+s}, K_{t+s}\right)+1+C_{I}\left(I_{t+s}, K_{t+s}\right)\right.\right.\right. \\
& \left.\left.\left.-C_{K}\left(I_{t+s}, K_{t+s}\right)\right) \prod_{i=1}^{s} \delta_{t+i}\right]\right\} \\
= & \sum_{s=1}^{\infty} E_{t}\left\{\frac{\beta^{s} u^{\prime}\left(C_{t+s}\right)}{u^{\prime}\left(C_{t}\right)}\right\} E_{t}\left\{\left(F_{K}\left(A_{t+s}, K_{t+s}\right)+1+C_{I}\left(I_{t+s}, K_{t+s}\right)\right.\right. \\
& \left.\left.-C_{K}\left(I_{t+s}, K_{t+s}\right)\right) \prod_{i=1}^{s} \delta_{t+i}\right\} \\
+ & \operatorname{Cov}_{t}\left\{\frac{\beta^{s} u^{\prime}\left(C_{t+s}\right)}{u^{\prime}\left(C_{t}\right)},\left(F_{K}\left(A_{t+s}, K_{t+s}\right)+1+C_{I}\left(I_{t+s}, K_{t+s}\right)\right.\right. \\
& \left.\left.-C_{K}\left(I_{t+s}, K_{t+s}\right)\right) \prod_{i=1}^{s} \delta_{t+i}\right\}
\end{aligned}
$$

We will now make use of the earlier bond Euler equation. From it, we know that:

$$
\begin{aligned}
E_{t}\left\{\frac{\beta^{s} u^{\prime}\left(C_{t+s}\right)}{u^{\prime}\left(C_{t}\right)}\right\} & =E_{t}\left\{\frac{\beta u^{\prime}\left(C_{t+1}\right)}{u^{\prime}\left(C_{t}\right)} \frac{\beta u^{\prime}\left(C_{t+2}\right)}{u^{\prime}\left(C_{t+1}\right)} \cdots \frac{\beta u^{\prime}\left(C_{t+s}\right)}{u^{\prime}\left(C_{t+s-1}\right)}\right\} \\
& =E_{t}\left\{\frac{\beta u^{\prime}\left(C_{t+1}\right)}{u^{\prime}\left(C_{t}\right)} E_{t+1}\left[\frac{\beta u^{\prime}\left(C_{t+2}\right)}{u^{\prime}\left(C_{t+1}\right)}\right] \cdots E_{t+s-1}\left[\frac{\beta u^{\prime}\left(C_{t+s}\right)}{u^{\prime}\left(C_{t+s-1}\right)}\right]\right\} \\
& =E_{t}\left\{\frac{\beta u^{\prime}\left(C_{t+1}\right)}{u^{\prime}\left(C_{t}\right)} E_{t+1}\left[\frac{\beta u^{\prime}\left(C_{t+2}\right)}{u^{\prime}\left(C_{t+1}\right)}\right] \cdots \frac{1}{1+r}\right\} \\
& =E_{t}\left\{\frac{\beta u^{\prime}\left(C_{t+1}\right)}{u^{\prime}\left(C_{t}\right)} \frac{1}{1+r} \cdots \frac{1}{1+r}\right\} \\
& =\left(\frac{1}{1+r}\right)^{s}
\end{aligned}
$$


Substituting it, we have:

$$
\begin{gathered}
\left(1+C_{I}\left(I_{t}, K_{t}\right)\right)=\sum_{s=1}^{\infty}\left(\frac{1}{1+r}\right)^{s} E_{t}\left\{\left(F_{K}\left(A_{t+s}, K_{t+s}\right)+1+C_{I}\left(I_{t+s}, K_{t+s}\right)\right.\right. \\
\left.\left.-C_{K}\left(I_{t+s}, K_{t+s}\right)\right) \prod_{i=1}^{s} \delta_{t+i}\right\} \\
+\sum_{s=1}^{\infty} \operatorname{Cov}_{t}\left\{\frac{\beta^{s} u^{\prime}\left(C_{t+s}\right)}{u^{\prime}\left(C_{t}\right)},\left(F_{K}\left(A_{t+s}, K_{t+s}\right)+1+C_{I}\left(I_{t+s}, K_{t+s}\right)\right.\right. \\
\left.\left.-C_{K}\left(I_{t+s}, K_{t+s}\right)\right) \prod_{i=1}^{s} \delta_{t+i}\right\}
\end{gathered}
$$

This is analogous to the classic consumption capital asset pricing equation, where the asset in question here is physical capital. An alternative formulation of the above physical capital Euler equation reveals its links to Tobin's $q$. Let $q_{t}=1+C_{I}\left(I_{t}, K_{t}\right)$ and $\gamma_{t+s}=$ $\prod_{i=1}^{s} \delta_{t+i}$. The physical capital Euler equation can be written as:

$$
\begin{aligned}
E_{t}\left\{u^{\prime}\left(C_{t}\right) q_{t}\right\}=E_{t} & \left\{\sum _ { s = 1 } ^ { \infty } ( \beta L ^ { - 1 } ) ^ { s } \left[u ^ { \prime } ( C _ { t } ) \left(F_{K}\left(A_{t}, K_{t}\right)+q_{t}\right.\right.\right. \\
& \left.\left.\left.-C_{K}\left(I_{t}, K_{t}\right)\right) \gamma_{t}\right]\right\} \\
E_{t}\left\{u^{\prime}\left(C_{t}\right) q_{t}\right\}=E_{t}\left\{\frac { \beta L ^ { - 1 } } { 1 - \beta L ^ { - 1 } } \left[u ^ { \prime } ( C _ { t } ) \left(F_{K}\left(A_{t}, K_{t}\right)+q_{t}\right.\right.\right. & \left.\left.\left.-C_{K}\left(I_{t}, K_{t}\right)\right) \gamma_{t}\right]\right\} \\
E_{t}\left\{\left(1-\beta L^{-1}\right)\left[u^{\prime}\left(C_{t}\right) q_{t}\right]\right\}=E_{t}\left\{\beta L^{-1}\left[u^{\prime}\left(C_{t}\right)\left(F_{K}\left(A_{t}, K_{t}\right)+q_{t}-C_{K}\left(I_{t}, K_{t}\right)\right) \gamma_{t}\right]\right\} & \\
u^{\prime}\left(C_{t}\right) q_{t}-\beta E_{t}\left\{u^{\prime}\left(C_{t+1}\right) q_{t+1}\right\}=\beta & E_{t}\left\{u ^ { \prime } ( C _ { t + 1 } ) \left(F_{K}\left(A_{t+1}, K_{t+1}\right)+q_{t+1}\right.\right. \\
& \left.\left.-C_{K}\left(I_{t+1}, K_{t+1}\right)\right) \gamma_{t+1}\right\} \\
q_{t}=E_{t} & \left\{\frac { \beta u ^ { \prime } ( C _ { t + 1 } ) } { u ^ { \prime } ( C _ { t } ) } \left[\delta_{t+1} F_{K}\left(A_{t+1}, K_{t+1}\right)+\left(1+\delta_{t+1}\right) q_{t+1}\right.\right. \\
& \left.\left.-\delta_{t+1} C_{K}\left(I_{t+1}, K_{t+1}\right)\right]\right\} .
\end{aligned}
$$

\section{A.1 A Specific Intertemporal Current Account Model}

Sharper predictions require sharper assumptions. Accordingly, I will consider a specific set of functional forms for the general ICA model and consider the consequences for the 
current account in light of physical capital shocks. The following functional forms are assumed:

1. the production function is Cobb-Douglas, with $F\left(A_{t}, K_{t}\right)=A_{t}^{1-\alpha} K_{t}^{\alpha}$, where $\alpha \in$ $(0,1)$.

2. the capital adjustment cost function is linearly homogenous, with $C\left(I_{t}, K_{t}\right)=$ $\frac{\chi}{2}\left(\frac{I_{t}^{2}}{K_{t}}\right)$, where $\chi>0$.

3. the period utility function is isoelastic, with $u\left(C_{t}\right)=\frac{C_{t}^{1-\frac{1}{\sigma}}}{1-\frac{1}{\sigma}}-1$, for $\sigma>0$, and $u\left(C_{t}\right)=\ln \left(C_{t}\right)$, for $\sigma=1 . \quad \sigma$ is the elasticity of intertemporal substitution of consumption.

For the problem to be well-defined under these functional forms, it is necessary that $\beta(1+g)^{\frac{\sigma-1}{\sigma}} \in(0,1)$ and $\beta(1+r)^{\frac{\sigma-1}{\sigma}} \in(0,1)$. These parameter restrictions ensure that the agent is not too patient; they will not choose to accumulate an infinite amount of assets.

Under perfect foresight, the bond Euler equation implies:

$$
\begin{aligned}
& C_{t}^{-\frac{1}{\sigma}}=\beta(1+r) C_{t+1}^{-\frac{1}{\sigma}} \\
& C_{t+1}=\beta^{\sigma}(1+r)^{\sigma} C_{t} .
\end{aligned}
$$

Recursive substitution reveals that:

$$
C_{t+s}=\left[\beta^{\sigma}(1+r)^{\sigma}\right]^{s} C_{t} .
$$

An explicit equation for consumption can be found using this expression for consumption and the intertemporal budget constraint. The budget constraint implies:

$$
\begin{aligned}
B_{t+1}-(1+r) B_{t} & =Y_{t}+N_{t}-I_{t}-C\left(I_{t}, K_{t}\right)-G_{t}-C_{t} \\
(1-(1+r) L) B_{t+1} & =Y_{t}+N_{t}-I_{t}-C\left(I_{t}, K_{t}\right)-G_{t}-C_{t}
\end{aligned}
$$




$$
\begin{aligned}
B_{t+1} & =(1-(1+r) L)^{-1}\left[Y_{t}+N_{t}-I_{t}-C\left(I_{t}, K_{t}\right)-G_{t}-C_{t}\right] \\
& =\left(\frac{-(1+r)^{-1} L^{-1}}{1-(1+r)^{-1} L^{-1}}\right)\left[Y_{t}+N_{t}-I_{t}-C\left(I_{t}, K_{t}\right)-G_{t}-C_{t}\right] \\
& =\left(1-\frac{1}{1-(1+r)^{-1} L^{-1}}\right)\left[Y_{t}+N_{t}-I_{t}-C\left(I_{t}, K_{t}\right)-G_{t}-C_{t}\right] \\
& =\left(1-\sum_{s=0}^{\infty}\left(\frac{L^{-1}}{1+r}\right)^{s}\right)\left[Y_{t}+N_{t}-I_{t}-C\left(I_{t}, K_{t}\right)-G_{t}-C_{t}\right] \\
& =-\sum_{s=1}^{\infty}\left(\frac{1}{1+r}\right)^{s} L^{-s}\left[Y_{t}+N_{t}-I_{t}-C\left(I_{t}, K_{t}\right)-G_{t}-C_{t}\right] \\
& =-\sum_{s=1}^{\infty}\left(\frac{1}{1+r}\right)^{s}\left[Y_{t+s}+N_{t+s}-I_{t+s}-C\left(I_{t+s}, K_{t+s}\right)-G_{t+s}-C_{t+s}\right]
\end{aligned}
$$

Substituting this expression back into the period budget constraint, we can see that:

$$
\sum_{s=0}^{\infty}\left(\frac{1}{1+r}\right)^{s} C_{t+s}=(1+r) B_{t}+\sum_{s=0}^{\infty}\left(\frac{1}{1+r}\right)^{s}\left[Y_{t+s}+N_{t+s}-I_{t+s}-C\left(I_{t+s}, K_{t+s}\right)-G_{t+s}\right]
$$

Denote lifetime wealth at time $t$ by:

$$
W_{t}=(1+r) B_{t}+\sum_{s=0}^{\infty}\left(\frac{1}{1+r}\right)^{s}\left[Y_{t+s}+N_{t+s}-I_{t+s}-C\left(I_{t+s}, K_{t+s}\right)-G_{t+s}\right]
$$

The lifetime budget constraint is now:

$$
\begin{gathered}
\sum_{s=0}^{\infty}\left(\frac{1}{1+r}\right)^{s}\left[\beta^{\sigma}(1+r)^{\sigma}\right]^{s} C_{t}=W_{t} \\
C_{t}=\left\{\sum_{s=0}^{\infty}\left[\beta^{\sigma}(1+r)^{\sigma-1}\right]^{s}\right\}^{-1} W_{t}
\end{gathered}
$$

Under the restriction that $\beta(1+r)^{\frac{\sigma-1}{\sigma}} \in(0,1)$, consumption is well-defined. Consumption is then given by:

$$
\begin{aligned}
C_{t} & =\left\{\frac{1}{1-\beta^{\sigma}(1+r)^{\sigma-1}}\right\}^{-1} W_{t} \\
& =\left\{\frac{1+r-\beta^{\sigma}(1+r)^{\sigma}}{1+r}\right\} W_{t}
\end{aligned}
$$




$$
=\frac{r+v}{1+r} W_{t}
$$

where $v \equiv 1-\beta^{\sigma}(1+r)^{\sigma}$. The restriction on $\beta(1+r)^{\frac{\sigma-1}{\sigma}}$ implies that $v \in(-r, 1)$. It is implicitly a measure of impatience (the difference between the time preference factor $\beta$ and the world market discount factor $\left.\frac{1}{1+r}\right)$. If $v<0$, then the agent is patient $\left(\beta>\frac{1}{1+r}\right)$, while if $v>0$ the agent is impatient $\left(\beta<\frac{1}{1+r}\right)$.

It remains for the optimal investment path to be found. The physical capital Euler equation implies that:

$$
\begin{aligned}
1+\chi \frac{I_{t}}{K_{t}} & =\sum_{s=1}^{\infty} \beta^{s}\left(\frac{C_{t+s}}{C_{t}}\right)^{-\frac{1}{\sigma}}\left(\alpha A_{t+s}^{1-\alpha} K_{t+s}^{\alpha-1}+\frac{\chi}{2}\left(\frac{I_{t+s}}{K_{t+s}}\right)^{2}\right) \\
& =\sum_{s=1}^{\infty} \beta^{s}\left(\frac{\left[\beta^{\sigma}(1+r)^{\sigma}\right]^{s} C_{t}}{C_{t}}\right)^{-\frac{1}{\sigma}}\left(\alpha A_{t+s}^{1-\alpha} K_{t+s}^{\alpha-1}+\frac{\chi}{2}\left(\frac{I_{t+s}}{K_{t+s}}\right)^{2}\right) \\
& =\sum_{s=1}^{\infty} \beta^{s} \beta^{-s}(1+r)^{-s}\left(\alpha A_{t+s}^{1-\alpha} K_{t+s}^{\alpha-1}+\frac{\chi}{2}\left(\frac{I_{t+s}}{K_{t+s}}\right)^{2}\right) \\
& =\sum_{s=1}^{\infty}\left(\frac{1}{1+r}\right)^{s}\left(\alpha A_{t+s}^{1-\alpha} K_{t+s}^{\alpha-1}+\frac{\chi}{2}\left(\frac{I_{t+s}}{K_{t+s}}\right)^{2}\right) .
\end{aligned}
$$

This basic equation can actually be further simplified by using lag polynomials (denoted $L)$. Note that an equivalent expression is:

$$
1+\chi \frac{I_{t}}{K_{t}}=\sum_{s=1}^{\infty}\left(\left(\frac{1}{1+r}\right) L^{-1}\right)^{s}\left[\alpha A_{t}^{1-\alpha} K_{t}^{\alpha-1}+\frac{\chi}{2}\left(\frac{I_{t}}{K_{t}}\right)^{2}\right]
$$

Further, note that the lag polynomial $\sum_{s=1}^{\infty}\left(\left(\frac{1}{1+r}\right) L^{-1}\right)^{s}=\frac{1}{1-\gamma L^{-1}}-1=\frac{1-1+\left(\frac{1}{1+r}\right) L^{-1}}{1-\left(\frac{1}{1+r}\right) L^{-1}}=$ $\frac{\left(\frac{1}{1+r}\right) L^{-1}}{1-\left(\frac{1}{1+r}\right) L^{-1}}$. Let $q_{t}=1+\chi \frac{I_{t}}{K_{t}}$. The above equation can be rewritten as:

$$
\begin{aligned}
q_{t} & =\frac{\left(\frac{1}{1+r}\right) L^{-1}}{1-\left(\frac{1}{1+r}\right) L^{-1}}\left[\alpha A_{t}^{1-\alpha} K_{t}^{\alpha-1}+\frac{\chi}{2}\left(\frac{I_{t}}{K_{t}}\right)^{2}\right] \\
\left(1-\left(\frac{1}{1+r}\right) L^{-1}\right) q_{t} & =\left(\frac{1}{1+r}\right) L^{-1}\left[\alpha A_{t}^{1-\alpha} K_{t}^{\alpha-1}+\frac{\chi}{2}\left(\frac{I_{t}}{K_{t}}\right)^{2}\right] \\
q_{t}-\left(\frac{1}{1+r}\right) q_{t+1} & =\left(\frac{1}{1+r}\right) \alpha A_{t+1}^{1-\alpha} K_{t+1}^{\alpha-1}+\left(\frac{1}{1+r}\right) \frac{\chi}{2}\left(\frac{I_{t+1}}{K_{t+1}}\right)^{2}
\end{aligned}
$$




$$
q_{t}=\frac{1}{1+r}\left[\alpha A_{t+1}^{1-\alpha} K_{t+1}^{\alpha-1}+\frac{\chi}{2}\left(\frac{I_{t+1}}{K_{t+1}}\right)^{2}+q_{t+1}\right]
$$

This states that the level of investment today should be chosen so that the marginal cost of investing in physical capital today equals the present value of next period's marginal product of physical capital minus the marginal change in capital adjustment costs from the capital stock (which is negative) plus the marginal cost of investing in physical capital tomorrow. It implicitly defines the optimal investment choice. Later, I will derive an explicit optimal investment function.

What will the current account be under these conditions? Define net income $Q_{t}=$ $Y_{t}+N_{t}-I_{t}-C\left(I_{t}, K_{t}\right)-G_{t}$. The current account is defined to be:

$$
\begin{aligned}
C A_{t} & =B_{t+1}-B_{t} \\
& =(1+r) B_{t}+Y_{t}+N_{t}-I_{t}-C\left(I_{t}, K_{t}\right)-G_{t}-C_{t}-B_{t} \\
& =r B_{t}+Y_{t}+N_{t}-I_{t}-C\left(I_{t}, K_{t}\right)-G_{t}-C_{t} \\
& =r B_{t}+Q_{t}-\frac{r+v}{1+r} W_{t} \\
& =r B_{t}+Q_{t}-\frac{r+v}{1+r}\left[(1+r) B_{t}+\sum_{s=0}^{\infty}\left(\frac{1}{1+r}\right)^{s} Q_{t+s}\right] \\
& =-v B_{t}+Q_{t}-\left(\frac{r+v}{1+r}\right)\left[\sum_{s=0}^{\infty}\left(\frac{1}{1+r}\right)^{s} Q_{t+s}\right] .
\end{aligned}
$$

Hence, the model solution is characterized by the following equations:

$$
\begin{aligned}
Y_{t} & =A_{t}^{1-\alpha} K_{t}^{\alpha} \\
A_{t+1} & =(1+g) A_{t} \\
W_{t} & =(1+r) B_{t}+\sum_{s=0}^{\infty}\left(\frac{1}{1+r}\right)^{s}\left[Y_{t+s}+N_{t+s}-I_{t+s}-C\left(I_{t+s}, K_{t+s}\right)-G_{t+s}\right] \\
& =(1+r) B_{t}+\sum_{s=0}^{\infty}\left(\frac{1}{1+r}\right)^{s} Q_{t+s} \\
C_{t} & =\frac{r+v}{1+r} W_{t}
\end{aligned}
$$




$$
\begin{aligned}
q_{t} & =1+\chi \frac{I_{t}}{K_{t}} \\
& =\sum_{s=1}^{\infty}\left(\frac{1}{1+r}\right)^{s}\left(\alpha A_{t+s}^{1-\alpha} K_{t+s}^{\alpha-1}+\frac{\chi}{2}\left(\frac{I_{t+s}}{K_{t+s}}\right)^{2}\right) \\
& =\frac{1}{1+r}\left[\alpha A_{t+1}^{1-\alpha} K_{t+1}^{\alpha-1}+\frac{\chi}{2}\left(\frac{I_{t+1}}{K_{t+1}}\right)^{2}+q_{t+1}\right] \\
C A_{t} & =-v B_{t}+Q_{t}-\left(\frac{r+v}{1+r}\right)\left[\sum_{s=0}^{\infty}\left(\frac{1}{1+r}\right)^{s} Q_{t+s}\right]
\end{aligned}
$$

\section{A.1.1 Characterizing the Balanced Growth Path and Optimal Investment}

What occurs on a balanced growth path (BGP)? Let overbars denote BGP quantities. In general, the growth rate of $Y$ is given by:

$$
\begin{aligned}
g_{Y} & =\ln \left(Y_{t+1}\right)-\ln \left(Y_{t}\right) \\
& =(1-\alpha) \ln (1+g)+(1-\alpha) \ln A_{t}+\alpha \ln K_{t+1}-(1-\alpha) \ln A_{t}-\alpha \ln K_{t} \\
& =(1-\alpha) \ln (1+g)+\alpha \ln \left(\frac{K_{t+1}}{K_{t}}\right) \\
& =(1-\alpha) \ln (1+g)+\alpha \ln \left(1+\frac{I_{t}}{K_{t}}\right) .
\end{aligned}
$$

Thus, on a BGP where $g_{Y}=\bar{g}_{Y}$ is a constant, then $\left(\frac{\bar{I}}{K}\right)$ must be a constant. We know then that $\bar{q}=1+\chi\left(\frac{\bar{I}}{K}\right)$ is a constant. The capital Euler equation tells us that:

$$
\begin{aligned}
q_{t} & =\frac{1}{1+r}\left[\alpha A_{t+1}^{1-\alpha} K_{t+1}^{\alpha-1}+\frac{1}{2 \chi}\left(q_{t+1}-1\right)^{2}+q_{t+1}\right] \\
q_{t}+r q_{t} & =\alpha A_{t+1}^{1-\alpha} K_{t+1}^{\alpha-1}+\frac{1}{2 \chi}\left(q_{t+1}-1\right)^{2}+q_{t+1} \\
\Delta q_{t+1} & =r q_{t}-\alpha \frac{Y_{t+1}}{K_{t+1}}-\frac{1}{2 \chi}\left(q_{t+1}-1\right)^{2} \\
-\alpha \frac{Y_{t+1}}{K_{t+1}} & =\frac{1}{2 \chi}(\bar{q}-1)^{2}-r \bar{q}, \text { if } \Delta q_{t+1}=0 .
\end{aligned}
$$


A phase diagram analysis in $\left(\frac{Y}{K}, q\right)$-space can help us understand possible equilibria for the system and their stability properties. The relevant nullclines are:

$$
\begin{aligned}
\Delta q & =0: \quad[q-(1+r \chi)]^{2}=4\left[-\frac{\alpha \chi}{2}\right]\left[\left(\frac{Y}{K}\right)-\frac{r(2+r \chi)}{2 \alpha}\right] \\
\Delta\left(\frac{Y}{K}\right) & =0: \quad q=1+\chi g .
\end{aligned}
$$

The second nullcline arises due to the fact that $g_{Y}=g_{K}=\ln \left(1+\frac{I}{K}\right)=\ln (1+g) \approx g$ (for small $g$ ) in order for $\left(\frac{Y}{K}\right)$ to be constant. The $q$-nullcline is a parabola opening to the left with vertex at $\left(\frac{r(2+r \chi)}{2 \alpha},(1+\chi r)\right)$ and latus rectum (chord parallel to the tangent at the vertex going through the focus) with length $2 \alpha \chi$. There is exactly one equilibrium, which occurs when $\bar{q}=1+\chi g$. The corresponding level of $\left(\frac{Y}{K}\right)$ is given by:

$$
\begin{aligned}
-\alpha(\bar{Y}) & =\frac{1}{2 \chi}(\bar{q}-1)^{2}-r \bar{q} \\
(\bar{Y} \bar{K}) & =\left[r \bar{q}-\frac{1}{2 \chi}(\bar{q}-1)^{2}\right] \frac{1}{\alpha} \\
& =\left[r(1+\chi g)-\frac{1}{2 \chi}(1+\chi g-1)^{2}\right] \frac{1}{\alpha} \\
& =\left[r+r \chi g-\frac{1}{2} \chi g^{2}\right] \frac{1}{\alpha} x \\
& =\zeta, \text { by definition. }
\end{aligned}
$$

Note that $\zeta>0$ only if $g<r+\sqrt{r^{2}+\frac{2}{\chi} r}$, for $r, g>0$. We impose this condition for all that follows. See figure A.1 for a graph of the phase space.

To understand the stability properties of the equilibrium, the original system of difference equations must be analysed. The system is:

$$
\begin{aligned}
\Delta q_{t+1} & =r q_{t}-\alpha \frac{Y_{t+1}}{K_{t+1}}-\frac{1}{2 \chi}\left(q_{t+1}-1\right)^{2} \\
\Delta\left(\frac{Y_{t+1}}{K_{t+1}}\right) & =(1-\alpha) \ln \left(\frac{1+g}{1+\left(\frac{q_{t}-1}{\chi}\right)}\right)\left(\frac{Y_{t}}{K_{t}}\right) \\
& \approx(1-\alpha)\left[g-\left(\frac{q_{t}-1}{\chi}\right)\right]\left(\frac{Y_{t}}{K_{t}}\right) .
\end{aligned}
$$


The equation of motion for $\left(\frac{Y}{K}\right)$ comes from considering its growth rate (i.e., the $\log$ difference of $\left.\left(\frac{Y}{K}\right)\right)$. Since the equations of motion are twice differentiable with respect to $q_{t}$ and $\frac{Y_{t}}{K_{t}}$, the nonlinear system of difference equations is almost linear. Essentially, the higher order terms in a Taylor expansion around the equilibrium of the equations of motion all go to zero extremely quickly in the neighborhood of the equilibrium. The first order Taylor approximation is sufficient to characterize the stability properties of the equilibrium. Setting the system back one-period, the Taylor approximation of the system is:

$$
\begin{gathered}
{\left[\begin{array}{c}
q_{t}-\bar{q} \\
\left(\frac{Y_{t}}{K_{t}}\right)-\zeta
\end{array}\right]=\left[\begin{array}{cc}
(1+r)+\left(\frac{\alpha(1-\alpha)}{\chi(1+g)}\right) \zeta & -\alpha \\
-\left(\frac{(1-\alpha)}{\chi(1+g)}\right) \zeta & 1
\end{array}\right]\left[\begin{array}{c}
q_{t-1}-\bar{q} \\
\left(\frac{Y_{t-1}}{K_{t-1}}\right)-\zeta
\end{array}\right]} \\
\Rightarrow z_{t}=A z_{t-1}, \text { where } z_{t}=\left[\begin{array}{c}
q_{t}-\bar{q} \\
\left(\frac{Y_{t}}{K_{t}}\right)-\zeta
\end{array}\right] \text { and } A \text { is the above coefficient matrix. }
\end{gathered}
$$

The corresponding characteristic equation of the above system, where $\lambda$ denotes an eigenvalue, is:

$$
\begin{aligned}
(1-\lambda)\left[(1+r)+\left(\frac{\alpha(1-\alpha)}{\chi(1+g)}\right) \zeta-\lambda\right]-\left(\frac{\alpha(1-\alpha)}{\chi(1+g)}\right) \zeta & =0 \\
\lambda^{2}-\left(2+r+\frac{\alpha(1-\alpha)}{\chi(1+g)} \zeta\right) \lambda+(1+r) & =0
\end{aligned}
$$

The quadratic formula reveals the two roots associated with the characteristic equation, which are both real and distinct (since the discriminant is positive). They are:

$$
\lambda=\frac{\left(2+r+\frac{\alpha(1-\alpha)}{\chi(1+g)} \zeta\right) \pm \sqrt{\left(2+r+\frac{\alpha(1-\alpha)}{\chi(1+g)} \zeta\right)^{2}-4(1+r)}}{2}
$$

Denote the roots $\lambda_{1}$ and $\lambda_{2}$, with $\lambda_{1}>\lambda_{2}$. Furthermore, note that $\lambda_{1}>1+\frac{r}{2}+\frac{\alpha(1-\alpha)}{2 \chi(1+g)} \zeta>$ 1 , since $r$ is positive (among other parameters). Since $\operatorname{det} A=\lambda_{1} \lambda_{2}=(1+r)>0$, then we know that $\lambda_{2}>0$. We can place more bounds on $\lambda_{2}$ by determining what parameter 
values generate $\lambda_{2}<1$ (i.e., when is $\lambda_{2}$ a stable root?). Suppose that $\lambda_{2} \in(0,1)$, then:

$$
\begin{aligned}
r+\frac{\alpha(1-\alpha)}{\chi(1+g)} \zeta & <\sqrt{\left(2+r+\frac{\alpha(1-\alpha)}{\chi(1+g)} \zeta\right)^{2}-4(1+r)} \\
\left(r+\frac{\alpha(1-\alpha)}{\chi(1+g)} \zeta\right)^{2}< & \left(2+r+\frac{\alpha(1-\alpha)}{\chi(1+g)} \zeta\right)^{2}-4(1+r) \\
r^{2}+2 r \frac{\alpha(1-\alpha)}{\chi(1+g)} \zeta+\left(\frac{\alpha(1-\alpha)}{\chi(1+g)} \zeta\right)^{2}< & 4+4 r+4 \frac{\alpha(1-\alpha)}{\chi(1+g)} \zeta+r^{2} \\
& +2 r \frac{\alpha(1-\alpha)}{\chi(1+g)} \zeta+\left(\frac{\alpha(1-\alpha)}{\chi(1+g)} \zeta\right)^{2}-4-4 r \\
0< & 4 \frac{\alpha(1-\alpha)}{\chi(1+g)} \zeta .
\end{aligned}
$$

This is always true, since all of the parameters are positive and $\alpha \in(0,1)$. Hence, $\lambda_{1}, \lambda_{2}>0, \lambda_{1}>1$ and $\lambda_{2}<1$. There is one unstable root (associated with the jump variable $q$ or more correctly $\frac{I}{K}$ ) and one stable root (associated with $\frac{Y}{K}$ ). The associated eigenvectors are given by:

$$
\begin{aligned}
{\left[\begin{array}{cc}
(1+r)+\left(\frac{\alpha(1-\alpha)}{\chi(1+g)}\right) \zeta & -\alpha \\
-\left(\frac{(1-\alpha)}{\chi(1+g)}\right) \zeta & 1
\end{array}\right]\left[\begin{array}{c}
e_{i} \\
1
\end{array}\right] } & =\lambda_{i}\left[\begin{array}{c}
e_{i} \\
1
\end{array}\right] \\
{\left[\begin{array}{c}
\left.(1+r)+\left(\frac{\alpha(1-\alpha)}{\chi(1+g)}\right) \zeta\right\} e_{i}-\alpha \\
\left(-\left(\frac{(1-\alpha)}{\chi(1+g)}\right) \zeta\right) e_{i}+1
\end{array}\right] } & =\left[\begin{array}{c}
\lambda_{i} e_{i} \\
\lambda_{i}
\end{array}\right] \\
e_{i} & =\frac{\alpha}{\left\{(1+r)+\left(\frac{\alpha(1-\alpha)}{\chi(1+g)}\right) \zeta\right\}-\lambda_{i}}=\frac{1-\lambda_{i}}{\left(\frac{(1-\alpha)}{\chi(1+g)}\right) \zeta}>0 .
\end{aligned}
$$

Define the eigenvector and eigenvalue matrices to be:

$$
E=\left[\begin{array}{cc}
e_{1} & e_{2} \\
1 & 1
\end{array}\right], E^{-1}=\frac{1}{e_{1}-e_{2}}\left[\begin{array}{cc}
1 & -e_{2} \\
-1 & e_{1}
\end{array}\right] \text { and } \Lambda=\left[\begin{array}{cc}
\lambda_{1} & 0 \\
0 & \lambda_{2}
\end{array}\right]
$$

Since we know that $A E=E \Lambda$, then $A=E \Lambda E^{-1}$. We can thus transform the original system and recover two decoupled difference equations which can be solved in the standard 
manner. Let $\tilde{z}=E^{-1} z$. Recall that:

$$
\begin{aligned}
{\left[\begin{array}{c}
q_{t}-\bar{q} \\
\left(\frac{Y_{t}}{K_{t}}\right)-\zeta
\end{array}\right] } & =A\left[\begin{array}{c}
q_{t-1}-\bar{q} \\
\left(\frac{Y_{t-1}}{K_{t-1}}\right)-\zeta
\end{array}\right] \\
z_{t} z_{t} & =A z_{t-1} \\
\tilde{z}_{t} & =\Lambda E^{-1} z_{t-1} \\
\tilde{z}_{t} & =\tilde{z}_{t-1}^{t} \tilde{z}_{0} \\
E \tilde{z}_{t} & =E \Lambda^{t} \tilde{z}_{0} \\
E E^{-1} z_{t} & =E \Lambda^{t} \tilde{z}_{0} \\
z_{t} & =E \Lambda^{t} \tilde{z}_{0} \\
{\left[\begin{array}{c}
q_{t}-\bar{q} \\
\left(\frac{Y_{t}}{K_{t}}\right)-\zeta
\end{array}\right] } & =\left[\begin{array}{cc}
e_{1} & e_{2} \\
1 & 1
\end{array}\right]\left[\begin{array}{l}
\lambda_{1}^{t} \tilde{z}_{0,1} \\
\lambda_{2}^{t} \tilde{z}_{0,2}
\end{array}\right] \\
{\left[\begin{array}{c}
q_{t}-\bar{q} \\
\left(\frac{Y_{t}}{K_{t}}\right)-\zeta
\end{array}\right] } & =\left[\begin{array}{c}
e_{1} \lambda_{1}^{t} \tilde{z}_{0,1}+e_{2} \lambda_{2}^{t} \tilde{z}_{0,2} \\
\lambda_{1}^{t} \tilde{z}_{0,1}+\lambda_{2}^{t} \tilde{z}_{0,2}
\end{array}\right] .
\end{aligned}
$$

Since $q$ is a jump variable, it will jump to the level $q_{0}=\bar{q}+e_{2}\left[\left(\frac{Y}{K}\right)_{0}-\zeta\right]$, thus making $\tilde{z}_{0,1}=0$ and eliminating the unstable root $\lambda_{1}$ from the solution. Furthermore, it ends up that $\tilde{z}_{0,2}=\frac{e_{1}-e_{2}}{e_{1}-e_{2}}\left[\left(\frac{Y}{K}\right)_{0}-\zeta\right]=\left[\left(\frac{Y}{K}\right)_{0}-\zeta\right]$. Hence, the solution and corresponding saddle path are given by:

$$
\left[\begin{array}{c}
q_{t}-\bar{q} \\
\left(\frac{Y_{t}}{K_{t}}\right)-\zeta
\end{array}\right]=\left[\begin{array}{c}
e_{2} \lambda_{2}^{t} \tilde{z}_{0,2} \\
\lambda_{2}^{t} \tilde{z}_{0,2}
\end{array}\right]=\left[\begin{array}{c}
e_{2}\left[\left(\frac{Y_{t}}{K_{t}}\right)-\zeta\right] \\
\lambda_{2}^{t}\left[\left(\frac{Y}{K}\right)_{0}-\zeta\right]
\end{array}\right]
$$

Notice how the equilibrium ratio of output to capital is independent of the preferences of the representative agent, depending solely on the production and investment properties of the economy. With these results, we can establish specific BGP values for the components 
of national income. Note that:

$$
\begin{aligned}
\left(\overline{\frac{I}{K}}\right) & =g \\
\bar{I}_{t} & =g \bar{K}_{t} \\
& =\frac{g}{\zeta} \bar{Y}_{t} \\
(\bar{I} & =\frac{g}{\zeta},
\end{aligned}
$$

and:

$$
\begin{aligned}
C\left(\bar{I}_{t}, \bar{K}_{t}\right) & =\frac{\chi}{2}\left(\frac{\bar{I}_{t}^{2}}{\bar{K}_{t}}\right) \\
& =\frac{\chi}{2} g^{2} \bar{K}_{t} \\
\left(\overline{\left.\frac{C(I, K)}{Y}\right)}\right) & =\frac{\chi g^{2}}{2 \zeta} .
\end{aligned}
$$

Assume that government spending is a constant proportion of national income in the steady-state, denoted $\xi$, and that net transfers are zero on the BGP. On the BGP, the future time path of $Q$ is known. It is:

$$
\begin{aligned}
(\overline{\bar{Q}}) & =1-\left(\overline{\frac{I}{Y}}\right)-\left(\overline{\frac{C(I, K)}{Y}}\right)-(\overline{\bar{G}}) \\
& =1-\frac{g}{\zeta}-\frac{\chi g^{2}}{2 \zeta}-\xi
\end{aligned}
$$

Hence, the ratio of net foreign asset holdings to current income on the BGP is given by:

$$
\begin{aligned}
\frac{\overline{C A}_{t}}{\bar{Y}_{t}} & =\frac{\bar{B}_{t+1}}{\bar{Y}_{t}}-\frac{\bar{B}_{t}}{\bar{Y}_{t}}=-v \frac{\bar{B}_{t}}{\bar{Y}_{t}}+\frac{\bar{Q}_{t}}{\bar{Y}_{t}}-\left(\frac{r+v}{1+r}\right)\left[\sum_{s=0}^{\infty}\left(\frac{1}{1+r}\right)^{s}\left(\frac{\bar{Q}_{t+s}}{\bar{Y}_{t+s}}\right)\left(\frac{\bar{Y}_{t+s}}{\bar{Y}_{t}}\right)\right] \\
\frac{\bar{B}_{t+1}}{\bar{Y}_{t}} & =(1-v) \frac{\bar{B}_{t}}{\bar{Y}_{t}}+\frac{\bar{Q}_{t}}{\bar{Y}_{t}}-\left(\frac{r+v}{1+r}\right)\left[\sum_{s=0}^{\infty}\left(\frac{1}{1+r}\right)^{s}\left(\frac{\bar{Q}_{t+s}}{\bar{Y}_{t+s}}\right)\left(\frac{(1+g)^{s} \bar{Y}_{t}}{\bar{Y}_{t}}\right)\right] \\
\frac{\bar{B}_{t+1}}{\bar{Y}_{t+1}} & =\frac{(1-v)}{(1+g)} \frac{\bar{B}_{t}}{Y_{t}}+\left(\frac{1}{1+g}\right) \frac{\bar{Q}_{t}}{Y_{t}}-\left[\frac{r+v}{(1+r)(1+g)}\right]\left[\sum_{s=0}^{\infty}\left(\frac{1+g}{1+r}\right)^{s}\left(\frac{\bar{Q}_{t+s}}{Y_{t+s}}\right)\right]
\end{aligned}
$$




$$
(\bar{B})=\frac{(1-v)}{(1+g)}(\bar{B})+\left(\frac{1}{1+g}\right)\left(\frac{\bar{Q}}{Y}\right)-\left[\frac{r+v}{(1+r)(1+g)}\right]\left(\frac{\bar{Q}}{Y}\right)\left[\sum_{s=0}^{\infty}\left(\frac{1+g}{1+r}\right)^{s}\right]
$$

For the ratio of net foreign assets to output on the BGP to be bounded, it is necessary that $g<r$ (else the infinite series in the above expression will not converge). The BGP ratio of net foreign assets to output is then determined by:

$$
\begin{aligned}
{\left[1-\frac{(1-v)}{(1+g)}\right]\left(\frac{\bar{B}}{Y}\right) } & =\left(\frac{1}{1+g}\right)\left(\frac{\bar{Q}}{Y}\right)-\left[\frac{r+v}{(1+r)(1+g)}\right]\left(\frac{1+r}{r-g}\right)\left(\frac{\bar{Q}}{Y}\right) \\
{\left[\frac{g+v}{1+g}\right]\left(\frac{\bar{B}}{\bar{Y}}\right) } & =\left(\frac{1}{1+g}\right)\left(\frac{\bar{Q}}{Y}\right)-\left[\frac{r+v}{1+g}\right]\left(\frac{1}{r-g}\right)\left(\frac{\bar{Q}}{Y}\right) \\
(g+v)\left(\frac{\bar{B}}{Y}\right) & =\left[1-\left(\frac{r+v}{r-g}\right)\right]\left(\frac{\bar{Q}}{Y}\right) \\
(g+v)\left(\frac{B}{Y}\right) & =\left[\frac{-g-v}{r-g}\right]\left(\frac{\bar{Q}}{Y}\right) \\
(\bar{B} & =\left[\frac{-1}{r-g}\right]\left(\frac{\bar{Q}}{Y}\right)
\end{aligned}
$$

Notice that this implies that $\left(\frac{\overline{C A}}{Y}\right)=g\left(\frac{\bar{B}}{Y}\right)$ on the BGP (the ratio is stationary), while $\overline{C A}$ on the BGP is growing (the level is nonstationary). ${ }^{6}$

\section{A.1.2 Response to A Physical Capital Shock}

What is the response of the current account and other measures at the time of an unanticipated negative physical capital shock in the perfect foresight model? For now, assume that $\frac{\partial T}{\partial K}=\frac{\partial G}{\partial K}=0$ at all times. The components of the current account response are given by:

$$
\frac{\partial C A_{t}}{\partial K_{t}}=-v \frac{\partial B_{t}}{\partial K_{t}}+\frac{\partial Q_{t}}{\partial K_{t}}-\left(\frac{r+v}{1+r}\right)\left[\sum_{s=0}^{\infty}\left(\frac{1}{1+r}\right)^{s} \frac{\partial Q_{t+s}}{\partial K_{t}}\right]
$$

\footnotetext{
${ }^{6}$ The derivation is:

$$
\begin{aligned}
\left(\overline{\frac{C A}{Y}}\right) & =(\overline{\bar{B}})(1+g)-(\overline{\bar{B}}) \\
& =g\left(\overline{\frac{B}{Y}}\right)
\end{aligned}
$$
}




$$
\begin{aligned}
& \frac{\partial B_{t}}{\partial K_{t}}=0 \text {, since } B_{t} \text { is chosen in the prior period. } \\
& \frac{\partial Q_{t}}{\partial K_{t}}=\frac{\partial Y_{t}}{\partial K_{t}}-\left(1+C_{I}\left(I_{t}, K_{t}\right)\right) \frac{\partial I_{t}}{\partial K_{t}}-C_{K}\left(I_{t}, K_{t}\right) \\
& \frac{\partial Y_{t}}{\partial K_{t}}=\alpha \frac{Y_{t}}{K_{t}}=\alpha A_{t}^{1-\alpha} K_{t}^{\alpha-1}>0 \\
& 1+\chi \frac{I_{t}}{K_{t}}=q_{t}=e_{2}\left(\frac{Y_{t}}{K_{t}}-\zeta\right)+\bar{q}>0, \text { for } Z_{t}=\left(\frac{Y_{t}}{K_{t}}-\zeta\right)>-\left(\frac{1+\chi g}{e_{2}}\right) . \Rightarrow \\
& \frac{\partial I_{t}}{\partial K_{t}}=\frac{\partial\left[\frac{e_{2}}{\chi}\left(Y_{t}-\zeta K_{t}\right)+g K_{t}\right]}{\partial K_{t}}=\frac{e_{2}}{\chi}\left(\alpha \frac{Y_{t}}{K_{t}}-\zeta\right)+g<0, \text { for } Z_{t}<\frac{(1-\alpha)}{\alpha} \zeta-\frac{\chi g}{\alpha e_{2}} . \\
& C_{K}\left(I_{t}, K_{t}\right)=-\frac{\chi}{2}\left(\frac{I_{t}}{K_{t}}\right)^{2}=-\frac{\chi}{2}\left(\frac{q_{t}-1}{\chi}\right)^{2}=-\frac{\left(e_{2}\left(\frac{Y_{t}}{K_{t}}-\zeta\right)+\chi g\right)^{2}}{2 \chi}<0 \Rightarrow \\
& \frac{\partial Q_{t}}{\partial K_{t}}=\alpha \frac{Y_{t}}{K_{t}}-\left[e_{2}\left(\frac{Y_{t}}{K_{t}}-\zeta\right)+\bar{q}\right]\left[\frac{e_{2}}{\chi}\left(\alpha \frac{Y_{t}}{K_{t}}-\zeta\right)+g\right]+\frac{\left(e_{2}\left(\frac{Y_{t}}{K_{t}}-\zeta\right)+\chi g\right)^{2}}{2 \chi}>0 . \\
& \frac{\partial Q_{t+s}}{\partial K_{t}}=\frac{\partial Y_{t+s}}{\partial K_{t}}-\left(1+\chi \frac{I_{t+s}}{K_{t+s}}\right) \frac{\partial I_{t+s}}{\partial K_{t}}+\frac{\chi}{2}\left(\frac{I_{t+s}}{K_{t+s}}\right)^{2} \frac{\partial K_{t+s}}{\partial K_{t}} \\
& \frac{\partial Y_{t+s}}{\partial K_{t}}=\alpha A_{t+s}^{1-\alpha} K_{t+s}^{\alpha-1} \frac{\partial K_{t+s}}{\partial K_{t}}=\alpha \frac{Y_{t+s}}{K_{t+s}} \frac{\partial K_{t+s}}{\partial K_{t}} \\
& \frac{\partial I_{t+s}}{\partial K_{t}}=\frac{\partial\left[\frac{e_{2}}{\chi}\left(Y_{t+s}-\zeta K_{t+s}\right)+g K_{t+s}\right]}{\partial K_{t}}=\left\{\frac{e_{2}}{\chi}\left(\alpha \frac{Y_{t+s}}{K_{t+s}}-\zeta\right)+g\right\} \frac{\partial K_{t+s}}{\partial K_{t}}<0, \\
& \text { for } Z_{t} \text { restricted as above. } \\
& K_{t+s}=K_{t}+\sum_{j=0}^{s-1} I_{t+j} \\
& \frac{\partial K_{t+s}}{\partial K_{t}}=1+\sum_{j=0}^{s-1} \frac{\partial I_{t+j}}{\partial K_{t}}
\end{aligned}
$$

A recursion can then be set up by noting that:

$$
\begin{aligned}
\frac{\partial K_{t+1}}{\partial K_{t}} & =1+\frac{\partial I_{t}}{\partial K_{t}} \\
& =1+\left\{\frac{e_{2}}{\chi}\left(\alpha \frac{Y_{t}}{K_{t}}-\zeta\right)+g\right\}>0, \text { given that } Z_{t}>\frac{(1-\alpha)}{\alpha} \zeta-\frac{(\chi+\chi g)}{\alpha e_{2}} . \\
\frac{\partial I_{t+1}}{\partial K_{t}} & =\left\{\frac{e_{2}}{\chi}\left(\alpha \frac{Y_{t+1}}{K_{t+1}}-\zeta\right)+g\right\} \frac{\partial K_{t+1}}{\partial K_{t}} \\
& =\left\{\frac{e_{2}}{\chi}\left(\alpha \frac{Y_{t+1}}{K_{t+1}}-\zeta\right)+g\right\}\left[1+\left\{\frac{e_{2}}{\chi}\left(\alpha \frac{Y_{t}}{K_{t}}-\zeta\right)+g\right\}\right]<0 \\
\frac{\partial K_{t+2}}{\partial K_{t}} & =1+\frac{\partial I_{t}}{\partial K_{t}}+\frac{\partial I_{t+1}}{\partial K_{t}}
\end{aligned}
$$




$$
\begin{aligned}
& =1+\left\{\frac{e_{2}}{\chi}\left(\alpha \frac{Y_{t}}{K_{t}}-\zeta\right)+g\right\}+\left\{\frac{e_{2}}{\chi}\left(\alpha \frac{Y_{t+1}}{K_{t+1}}-\zeta\right)+g\right\} \\
& \cdot\left[1+\left\{\frac{e_{2}}{\chi}\left(\alpha \frac{Y_{t}}{K_{t}}-\zeta\right)+g\right\}\right] \\
& =\left[1+\left\{\frac{e_{2}}{\chi}\left(\alpha \frac{Y_{t}}{K_{t}}-\zeta\right)+g\right\}\right]\left[1+\left\{\frac{e_{2}}{\chi}\left(\alpha \frac{Y_{t+1}}{K_{t+1}}-\zeta\right)+g\right\}\right]>0 \\
& \frac{\partial I_{t+2}}{\partial K_{t}}=\left\{\frac{e_{2}}{\chi}\left(\alpha \frac{Y_{t+2}}{K_{t+2}}-\zeta\right)+g\right\} \frac{\partial K_{t+2}}{\partial K_{t}} \\
& =\left\{\frac{e_{2}}{\chi}\left(\alpha \frac{Y_{t+2}}{K_{t+2}}-\zeta\right)+g\right\}\left[1+\left\{\frac{e_{2}}{\chi}\left(\alpha \frac{Y_{t}}{K_{t}}-\zeta\right)+g\right\}\right] \\
& \cdot\left[1+\left\{\frac{e_{2}}{\chi}\left(\alpha \frac{Y_{t+1}}{K_{t+1}}-\zeta\right)+g\right\}\right]<0 \\
& \frac{\partial K_{t+3}}{\partial K_{t}}=1+\frac{\partial I_{t}}{\partial K_{t}}+\frac{\partial I_{t+1}}{\partial K_{t}}+\frac{\partial I_{t+2}}{\partial K_{t}} \\
& =\left[1+\left\{\frac{e_{2}}{\chi}\left(\alpha \frac{Y_{t}}{K_{t}}-\zeta\right)+g\right\}\right]\left[1+\left\{\frac{e_{2}}{\chi}\left(\alpha \frac{Y_{t+1}}{K_{t+1}}-\zeta\right)+g\right\}\right] \\
& +\left\{\frac{e_{2}}{\chi}\left(\alpha \frac{Y_{t+2}}{K_{t+2}}-\zeta\right)+g\right\}\left[1+\left\{\frac{e_{2}}{\chi}\left(\alpha \frac{Y_{t}}{K_{t}}-\zeta\right)+g\right\}\right] \\
& \cdot\left[1+\left\{\frac{e_{2}}{\chi}\left(\alpha \frac{Y_{t+1}}{K_{t+1}}-\zeta\right)+g\right\}\right] \\
& =\left[1+\left\{\frac{e_{2}}{\chi}\left(\alpha \frac{Y_{t}}{K_{t}}-\zeta\right)+g\right\}\right]\left[1+\left\{\frac{e_{2}}{\chi}\left(\alpha \frac{Y_{t+1}}{K_{t+1}}-\zeta\right)+g\right\}\right] \\
& \cdot\left[1+\left\{\frac{e_{2}}{\chi}\left(\alpha \frac{Y_{t+2}}{K_{t+2}}-\zeta\right)+g\right\}\right]>0 \\
& \frac{\partial K_{t+s}}{\partial K_{t}}=\prod_{i=0}^{s-1}\left[1+\left\{\frac{e_{2}}{\chi}\left(\alpha \frac{Y_{t+i}}{K_{t+i}}-\zeta\right)+g\right\}\right]>0 \\
& \frac{\partial I_{t+s}}{\partial K_{t}}=\left\{\frac{e_{2}}{\chi}\left(\alpha \frac{Y_{t+s}}{K_{t+s}}-\zeta\right)+g\right\}\left\{\prod_{i=0}^{s-1}\left[1+\left\{\frac{e_{2}}{\chi}\left(\alpha \frac{Y_{t+i}}{K_{t+i}}-\zeta\right)+g\right\}\right]\right\}<0
\end{aligned}
$$

The model then means that:

$$
\begin{aligned}
\frac{\partial Q_{t+s}}{\partial K_{t}} & =\frac{\partial Y_{t+s}}{\partial K_{t}}-\left(1+C_{I}\left(I_{t+s}, K_{t+s}\right)\right) \frac{\partial I_{t+s}}{\partial K_{t}}-C_{K}\left(I_{t+s}, K_{t+s}\right) \frac{\partial K_{t+s}}{\partial K_{t}} \\
& =\alpha \frac{Y_{t+s}}{K_{t+s}} \frac{\partial K_{t+s}}{\partial K_{t}}-\left(1+x \frac{I_{t+s}}{K_{t+s}}\right)\left\{\frac{e_{2}}{\chi}\left(\alpha \frac{Y_{t+s}}{K_{t+s}}-\zeta\right)+g\right\} \frac{\partial K_{t+s}}{\partial K_{t}}+\chi\left(\frac{I_{t}}{K_{t}}\right)^{2} \frac{\partial K_{t+s}}{\partial K_{t}} \\
& =\left\{\alpha \frac{Y_{t+s}}{K_{t+s}}-\left(1+x \frac{I_{t+s}}{K_{t+s}}\right)\left\{\frac{e_{2}}{\chi}\left(\alpha \frac{Y_{t+s}}{K_{t+s}}-\zeta\right)+g\right\}+\chi\left(\frac{I_{t+s}}{K_{t+s}}\right)^{2}\right\} \frac{\partial K_{t+s}}{\partial K_{t}} \\
& =\left\{\alpha \frac{Y_{t+s}}{K_{t+s}}-\left(1+x \frac{I_{t+s}}{K_{t+s}}\right)\left\{\frac{e_{2}}{\chi}\left(\alpha \frac{Y_{t+s}}{K_{t+s}}-\zeta\right)+g\right\}+\chi\left(\frac{I_{t+s}}{K_{t+s}}\right)^{2}\right\}
\end{aligned}
$$




$$
\begin{gathered}
\cdot\left\{\prod_{i=0}^{s-1}\left[1+\left\{\frac{e_{2}}{\chi}\left(\alpha \frac{Y_{t+i}}{K_{t+i}}-\zeta\right)+g\right\}\right]\right\} \\
=\left\{\alpha \frac{Y_{t+s}}{K_{t+s}}-q_{t+s}\left\{\frac{e_{2}}{\chi}\left(\alpha \frac{Y_{t+s}}{K_{t+s}}-\zeta\right)+g\right\}+\chi\left(\frac{q_{t+s}-1}{\chi}\right)^{2}\right\} \\
\cdot\left\{\prod_{i=0}^{s-1}\left[1+\left\{\frac{e_{2}}{\chi}\left(\alpha \frac{Y_{t+i}}{K_{t+i}}-\zeta\right)+g\right\}\right]\right\}>0
\end{gathered}
$$

The current account response is then:

$$
\begin{aligned}
\frac{\partial C A_{t+s}}{\partial K_{t}}= & \frac{\partial Q_{t+s}}{\partial K_{t}}-\left(\frac{r+v}{1+r}\right)\left[\sum_{w=s}^{\infty}\left(\frac{1}{1+r}\right)^{w-s} \frac{\partial Q_{t+w}}{\partial K_{t}}\right] \\
= & \left\{\alpha \frac{Y_{t+s}}{K_{t+s}}-q_{t+s}\left\{\frac{e_{2}}{\chi}\left(\alpha \frac{Y_{t+s}}{K_{t+s}}-\zeta\right)+g\right\}+\chi\left(\frac{q_{t+s}-1}{\chi}\right)^{2}\right\} \\
- & \left(\frac{r+v}{1+r}\right)\left[\sum _ { w = s } ^ { \infty } ( \frac { 1 } { 1 + r } ) ^ { w - s } \left\{\alpha \frac{Y_{t+w}}{K_{t+w}}-q_{t+w}\left\{\frac{e_{2}}{\chi}\left(\alpha \frac{Y_{t+w}}{K_{t+w}}-\zeta\right)+g\right\}\right.\right. \\
& \left.\left.+\chi\left(\frac{q_{t+w}-1}{\chi}\right)^{2}\right\}\left\{\prod_{i=0}^{w-1}\left[1+\left\{\frac{e_{2}}{\chi}\left(\alpha \frac{Y_{t+i}}{K_{t+i}}-\zeta\right)+g\right\}\right]\right\}\right]
\end{aligned}
$$

Recall that:

$$
\left[\begin{array}{c}
q_{t+s}-\bar{q} \\
\left(\frac{Y_{t+s}}{K_{t+s}}\right)-\zeta
\end{array}\right]=\left[\begin{array}{c}
e_{2}\left[\left(\frac{Y_{t+s}}{K_{t+s}}\right)-\zeta\right] \\
\lambda_{2}^{s}\left[\left(\frac{Y}{K}\right)_{t}-\zeta\right]
\end{array}\right],
$$

along the linearized saddle path. By substituting the saddle path equations into the current account response, an explicit expression for the current account response can be found. The response is a function of the initial size of the physical capital shock (captured by $\left.\left(\frac{Y}{K}-\zeta\right)\right)$ and how far in the past the shock was (captured by $s$ ).

No Physical Capital Adjustment Costs Case Such a complicated current account response is difficult to interpret without simulating. In order to gain a better intuitive understanding of the dynamics, I simplify the model, by imposing the restriction that there are no physical capital adjustment $\operatorname{costs}(\chi=0)$. The underlying pattern of dynamics should be roughly similar to that of the more general model, but with responses occurring much quicker since there is no sluggishness in the model. In the absence of 
capital adjustment costs, the capital Euler equation implies:

$$
A_{s+1} F^{\prime}\left(K_{s}+I_{s}\right)=r
$$

The capital stock would jump to its BGP immediately after a physical capital shock. In response to an unforeseen negative physical capital shock, investment will thus be temporarily greater than its BGP level. Assuming that $\frac{\partial N}{\partial K}=\frac{\partial G}{\partial K}=0$, the model's dynamic response to a physical capital shock is described by:

$$
\begin{aligned}
& \frac{\partial I_{t}}{\partial K_{t}}=-1<0 \text {, by the implicit function theorem. } \\
& \frac{\partial I_{t+s}}{\partial K_{t}}=0, \text { for } s>0 \text {. } \\
& \frac{\partial K_{t}}{\partial K_{t}}=1>0 \text {. } \\
& \frac{\partial K_{t+s}}{\partial K_{t}}=\frac{\partial\left(K_{t}+\sum_{j=0}^{s-1} I_{t+j}\right)}{\partial K_{t}}=1-1=0 \text {, for } s>0 . \\
& \frac{\partial Y_{t+s}}{\partial K_{t}}=\alpha \frac{Y_{t+s}}{K_{t+s}} \frac{\partial K_{t+s}}{\partial K_{t}}=\left\{\begin{array}{c}
\alpha \frac{Y_{t}}{K_{t}}>0, \text { for } s=0 . \\
0, \text { for } s>0 .
\end{array}\right. \\
& \frac{\partial W_{t+s}}{\partial K_{t}}=(1+r) \frac{\partial B_{t+s}}{\partial K_{t}}+\sum_{i=0}^{\infty}\left(\frac{1}{1+r}\right)^{i}\left[\frac{\partial Y_{t+s+i}}{\partial K_{t}}-\frac{\partial I_{t+s+i}}{\partial K_{t}}\right] \\
& =\left\{\begin{array}{c}
\alpha \frac{Y_{t}}{K_{t}}+1, \text { for } s=0 . \\
(1+r) \frac{\partial B_{t+s}}{\partial K_{t}}, \text { for } s>0 .
\end{array}\right. \\
& \frac{\partial C_{t+s}}{\partial K_{t}}=\left(\frac{r+v}{1+r}\right) \frac{\partial W_{t+s}}{\partial K_{t}} \\
& =\left\{\begin{array}{c}
\left(\frac{r+v}{1+r}\right)\left(\alpha \frac{Y_{t}}{K_{t}}+1\right), \text { for } s=0 . \\
(r+v) \frac{\partial B_{t+s}}{\partial K_{t}}, \text { for } s>0 .
\end{array}\right. \\
& \frac{\partial Q_{t+s}}{\partial K_{t}}=\frac{\partial Y_{t+s}}{\partial K_{t}}-\frac{\partial I_{t+s}}{\partial K_{t}} \\
& =\left\{\begin{array}{c}
\alpha \frac{Y_{t}}{K_{t}}+1, \text { for } s=0 . \\
0, \text { for } s>0 .
\end{array}\right.
\end{aligned}
$$




$$
\begin{aligned}
\frac{\partial C A_{t+s}}{\partial K_{t}} & =\frac{\partial B_{t+s+1}}{\partial K_{t}}-\frac{\partial B_{t+s}}{\partial K_{t}} \\
& =-v \frac{\partial B_{t+s}}{\partial K_{t}}+\frac{\partial Q_{t+s}}{\partial K_{t}}-\left(\frac{r+v}{1+r}\right)\left[\sum_{i=0}^{\infty}\left(\frac{1}{1+r}\right)^{i} \frac{\partial Q_{t+s+i}}{\partial K_{t}}\right] \Rightarrow \\
\frac{\partial C A_{t}}{\partial K_{t}} & =\frac{\partial B_{t+1}}{\partial K_{t}}=\left(1-\frac{r+v}{1+r}\right)\left(\alpha \frac{Y_{t}}{K_{t}}+1\right)>0, \text { since } v \in(-r, 1) . \\
\frac{\partial C A_{t+s}}{\partial K_{t}} & =-v \frac{\partial B_{t+s}}{\partial K_{t}}=\frac{\partial B_{t+s+1}}{\partial K_{t}}-\frac{\partial B_{t+s}}{\partial K_{t}} \Rightarrow \frac{\partial B_{t+s+1}}{\partial K_{t}}=(1-v) \frac{\partial B_{t+s}}{\partial K_{t}}, \text { for } s>0 . \\
\frac{\partial B_{t+s}}{\partial K_{t}} & =(1-v)^{s-1} \frac{\partial B_{t+1}}{\partial K_{t}} \Rightarrow \\
\frac{\partial C A_{t+s}}{\partial K_{t}} & =-v(1-v)^{s-1} \frac{\partial B_{t+1}}{\partial K_{t}}\left\{\begin{array}{c}
>0, \text { if } v \in(-r, 0) . \\
=0, \text { if } v=0 . \\
<0, \text { if } v \in(0,1) .
\end{array}\right.
\end{aligned}
$$

Since $v \in(-r, 1)$, the recursive formula for net foreign assets reveals that future net foreign asset changes are of the same sign as the initial net foreign asset change, but shrinking in magnitude. Hence, the current account response for $s>0$ is given by:

$$
\frac{\partial C A_{t+s}}{\partial K_{t}}=-v(1-v)^{s} \frac{\partial B_{t+1}}{\partial K_{t}}<0, \text { for } s>0 \text { and } v \in(0,1)
$$

The current account has an S-shaped response if the country is impatient, with the initial sign of the response identical to the sign of the capital shock.

Stationary transformations of the above variables behave in a qualitatively similar fashion to their levels. The contemporaneous response of the ratio of the current account to national income is then:

$$
\begin{aligned}
\frac{\partial\left(\frac{C A_{t}}{Y_{t}}\right)}{\partial K_{t}}= & \frac{\frac{\partial C A_{t}}{\partial K_{t}}}{Y_{t}}-\frac{C A_{t}}{Y_{t}} \frac{\frac{\partial Y_{t}}{\partial K_{t}}}{Y_{t}} \\
= & \left(1-\frac{r+v}{1+r}\right)\left(\alpha \frac{1}{K_{t}}+\frac{1}{Y_{t}}\right)-\frac{C A_{t}}{Y_{t}}\left[\alpha \frac{1}{K_{t}}\right] \\
= & \left(1-\frac{r+v}{1+r}-\frac{C A_{t}}{Y_{t}}\right)\left[\alpha \frac{1}{K_{t}}\right]+\left(1-\frac{r+v}{1+r}\right)\left(\frac{1}{Y_{t}}\right)>0 \\
& \text { since } \frac{C A_{t}}{Y_{t}}<\left(1-\frac{r+v}{1+r}\right) .
\end{aligned}
$$


The future response of the ratio of the current account to national income is:

$$
\begin{aligned}
\frac{\partial\left(\frac{C A_{t+s}}{Y_{t+s}}\right)}{\partial K_{t}} & =\frac{\frac{\partial C A_{t+s}}{\partial K_{t}}}{Y_{t+s}}-\frac{C A_{t+s}}{Y_{t+s}} \frac{\frac{\partial Y_{t+s}}{\partial K_{t}}}{Y_{t+s}} \\
& =-v(1-v)^{s}\left(1-\frac{r+v}{1+r}\right)\left(\alpha \frac{1}{K_{t}} \cdot \frac{Y_{t}}{Y_{t+s}}+\frac{1}{Y_{t+s}}\right)<0 \text {, for } s>0 .
\end{aligned}
$$

Thus, the response of the ratio of the current account to national income depends on $\frac{d K_{t}}{K_{t}}$, $\frac{Y_{t}}{K_{t}}$, and $\frac{Y_{t}}{Y_{t+s}}$.

\section{A.2 An Alternative Atemporal Current Account Model}

A classic example of an atemporal current account model is the Mundell-Fleming extension of the Keynesian IS-LM model. Atemporal macroeconomic models are an amalgam of ad hoc functions of aggregate quantities which interact with each other. They do not rely on microeconomic foundations to generate aggregate behavior, and as such, do not take account of foresight in consumption and investment planning (which means that budget constraints are not addressed). Consider the following atemporal current account model as a simple alternative to an ICA model. The model is characterized by the following equations:

$$
\begin{aligned}
C_{t} & =C\left(Y_{t}+r B_{t}-T_{t}\right), \text { with } C^{\prime}\left(Y_{t}+r B_{t}\right) \in(0,1) \\
Y_{t} & =A_{t} F\left(K_{t}\right) \\
I_{t} & =I\left(A_{t} F^{\prime}\left(K_{t}\right)-r\right), \text { with } I^{\prime}\left(A_{t} F^{\prime}\left(K_{t}\right)-r\right) \geq 0 \\
K_{t+1} & =K_{t}+I_{t} \\
C A_{t} & =B_{t+1}-B_{t}=S_{t}-I_{t} \\
& =Y_{t}+r B_{t}+N_{t}-C_{t}-\left(G_{t}-T_{t}\right)-I_{t}
\end{aligned}
$$


Aggregate consumption, denoted by $C$, is thus a standard Keynesian consumption func-

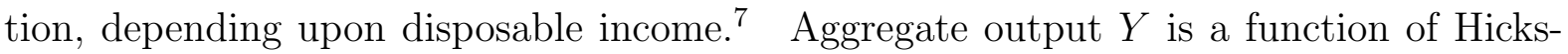
neutral total factor productivity $A$ and the physical capital stock $K$. Here, $F(\cdot)$ is a standard concave production function, with $F_{K}>0$ and $F_{K K}<0$. Aggregate investment $I$ is an increasing function of the difference between the current marginal product of capital and the world real interest rate $r . \quad B$ is net foreign asset holdings, yielding a risk-free rate of return of $r$, which is the constant world real interest rate. ${ }^{8} G, T$, and $N$ are respectively, government spending, lump-sum taxes, and net transfers from abroad. As usual, the current account is defined to be the difference in net foreign assets, or the difference between domestic saving and investment.

Further, suppose that:

$$
\begin{aligned}
\frac{d K_{t+1}}{d K_{t}} & =1+\frac{\partial I_{t}}{\partial K_{t}} \\
& =1+I^{\prime}\left(A_{t} F^{\prime}\left(K_{t}\right)-r\right) A_{t} F^{\prime \prime}\left(K_{t}\right)>0 \text {, by assumption. }
\end{aligned}
$$

This implies that $\frac{d K_{t+1}}{d K_{t}} \in(0,1)$. There is some persistence in the capital stock; capital adjusts sluggishly.

The model then has a transparent recursive structure. Define $\sigma_{t}=\left(1-C^{\prime}\left(Y_{t}+r B_{t}\right)\right)$. Ignoring changes in government spending, taxes, and net transfers from abroad, the contemporaneous and future current account responses are: ${ }^{9}$

$$
\begin{aligned}
\frac{\partial C A_{t}}{\partial K_{t}} & =\left[1-C^{\prime}\left(Y_{t}+r B_{t}\right)\right] A_{t} F^{\prime}\left(K_{t}\right)-I^{\prime}\left(A_{t} F^{\prime}\left(K_{t}\right)-r\right) A_{t} F^{\prime \prime}\left(K_{t}\right) \\
& =\left[1-C_{t}^{\prime}\right] A_{t} F_{t}^{\prime}-I_{t}^{\prime} A_{t} F_{t}^{\prime \prime} \equiv \Omega_{t}=\frac{\partial B_{t+1}}{\partial K_{t}}>0 \\
\frac{\partial C A_{t+1}}{\partial K_{t}} & =\frac{\partial S_{t+1}}{\partial K_{t}}-\frac{\partial I_{t+1}}{\partial K_{t}}
\end{aligned}
$$

\footnotetext{
${ }^{7}$ Consumers are assumed to hold net foreign assets, $B$.

${ }^{8}$ Recall that the timing convention for net foreign assets $B$ is such that $B_{t}$ is determined at time $t-1$. Thus, $B_{t}$ is unaffected by events at time $t$.

${ }^{9}$ Here, I will suppress the function arguments as they are understood, while maintaining the time subscripts.
} 


$$
\begin{aligned}
& =\left[1-C_{t+1}^{\prime}\right] A_{t+1} F_{t+1}^{\prime} \frac{d K_{t+1}}{d K_{t}}+\left[1-C_{t+1}^{\prime}\right] r \frac{\partial B_{t+1}}{\partial K_{t}}-I_{t+1}^{\prime} A_{t+1} F_{t+1}^{\prime \prime} \frac{d K_{t+1}}{d K_{t}}>0 \\
& =\left\{\left[1-C_{t+1}^{\prime}\right] A_{t+1} F_{t+1}^{\prime}-I_{t+1}^{\prime} A_{t+1} F_{t+1}^{\prime \prime}\right\} \frac{d K_{t+1}}{d K_{t}}+\left[1-C_{t+1}^{\prime}\right] r \Omega_{t} \\
& =\Omega_{t+1} \frac{d K_{t+1}}{d K_{t}}+\sigma_{t+1} r \frac{\partial B_{t+1}}{\partial K_{t}}>0 \\
& \Rightarrow \frac{\partial B_{t+2}}{\partial K_{t}}=\frac{\partial C A_{t+1}}{\partial K_{t}}+\frac{\partial B_{t+1}}{\partial K_{t}}>0 \\
& \frac{\partial C A_{t+2}}{\partial K_{t}}=\frac{\partial S_{t+2}}{\partial K_{t}}-\frac{\partial I_{t+2}}{\partial K_{t}} \\
& =\left[1-C_{t+2}^{\prime}\right] A_{t+2} F_{t+2}^{\prime} \frac{d K_{t+2}}{d K_{t+1}} \frac{d K_{t+1}}{d K_{t}}+\left[1-C_{t+2}^{\prime}\right] r \frac{\partial B_{t+2}}{\partial K_{t}} \\
& -I_{t+2}^{\prime} A_{t+2} F_{t+2}^{\prime \prime} \frac{d K_{t+2}}{d K_{t+1}} \frac{d K_{t+1}}{d K_{t}} \\
& =\Omega_{t+2} \frac{d K_{t+2}}{d K_{t+1}} \frac{d K_{t+1}}{d K_{t}}+\sigma_{t+2} r \frac{\partial B_{t+2}}{\partial K_{t}}>0 \\
& \Rightarrow \frac{\partial B_{t+3}}{\partial K_{t}}=\frac{\partial C A_{t+2}}{\partial K_{t}}+\frac{\partial B_{t+2}}{\partial K_{t}}>0 \\
& \frac{\partial C A_{t+3}}{\partial K_{t}}=\Omega_{t+3} \frac{d K_{t+3}}{d K_{t+2}} \frac{d K_{t+2}}{d K_{t+1}} \frac{d K_{t+1}}{d K_{t}}+\sigma_{t+3} r \frac{\partial B_{t+3}}{\partial K_{t}}>0 \\
& \frac{\partial C A_{t+s}}{\partial K_{t}}=\Omega_{t+s} \prod_{i=1}^{s} \frac{d K_{t+i}}{d K_{t+i-1}}+\sigma_{t+s} r \frac{\partial B_{t+s}}{\partial K_{t}}>0 \\
& \Rightarrow \frac{\partial B_{t+s+1}}{\partial K_{t}}=\Omega_{t+s} \prod_{i=1}^{s} \frac{d K_{t+i}}{d K_{t+i-1}}+\left(1+\sigma_{t+s} r\right) \frac{\partial B_{t+s}}{\partial K_{t}}
\end{aligned}
$$

The first term of the period $(t+s)$ current account response goes to zero, as $s \rightarrow \infty .^{10}$ Consider the expression for the change in net foreign assets as $s \rightarrow \infty$. A bound on the limiting change in net foreign assets can be found by setting $\sigma=1$ (this is the upper bound of $\sigma$ ), and solving the resulting limiting linear difference equation. ${ }^{11}$ In this case,

\footnotetext{
${ }^{10}$ For the response of the future capital stock to changes in the current capital stock to diminish over time, it is necessary that:

$$
\begin{aligned}
\frac{d K_{t+2}}{d K_{t+1}} \frac{d K_{t+1}}{d K_{t}}-\frac{d K_{t+1}}{d K_{t}} & <0 \\
\left(\frac{d K_{t+2}}{d K_{t+1}}-1\right) \frac{d K_{t+1}}{d K_{t}} & <0 \\
\frac{d K_{t+2}}{d K_{t+1}} & <1 .
\end{aligned}
$$

This is true by assumption. The derivative of the investment function and the second derivative of the production function must both be finite, and furthermore, cannot grow in magnitude overly quickly (else they would dominate the declining capital stock response).

${ }^{11} L$ denotes the standard lag operator.
} 
we have:

$$
\begin{aligned}
\frac{\partial B_{t+s+1}}{\partial K_{t}} & =(1+r) \frac{\partial B_{t+s}}{\partial K_{t}} \\
& \Rightarrow(1-(1+r) L) \frac{\partial B_{t+s+1}}{\partial K_{t}}=0 \\
\frac{\partial B_{t+s+1}}{\partial K_{t}} & \approx(1+r)^{s} \frac{\partial B_{t+1}}{\partial K_{t}}, \text { for } s \text { very large. }
\end{aligned}
$$

This implies that a bound on the limiting change in the current account is:

$$
\begin{aligned}
\frac{\partial C A_{t+s}}{\partial K_{t}} & =\frac{\partial B_{t+s+1}}{\partial K_{t}}-\frac{\partial B_{t+s}}{\partial K_{t}} \\
& \approx[(1+r)-1](1+r)^{s} \frac{\partial B_{t+1}}{\partial K_{t}} \\
& =r(1+r)^{s} \frac{\partial B_{t+1}}{\partial K_{t}}, \text { for } s \text { very large. }
\end{aligned}
$$

The upper bound on the current account response implies that there is a permanent and growing (in magnitude) change in the current account in the future as a result of a capital shock! More generally, as long as $\sigma r>0$, then such a result will occur in the limit (though somewhat more slowly than in the $\sigma=1$ case). Why does this occur in the atemporal model? Because the intertemporal budget constraint does not enter into the atemporal model, once debt or credit is accumulated, it stays accumulated and increases at rate $r$ in the limit. ${ }^{12}$ The atemporal model thus gives rise to current account response shaped like a wide $\mathrm{L}$, as initially the $\Omega$ term gives an additional push to the response. If an ad hoc transversality condition is imposed upon the atemporal model, it is still not clear when it will bind, as the model does not have a natural mechanism by which such a condition is communicated to the economy.

The response of the ratio of the current account to output is given by:

$$
\frac{\partial\left(\frac{C A_{t+s}}{Y_{t+s}}\right)}{\partial K_{t}}=\frac{\frac{\partial C A_{t+s}}{\partial K_{t}}}{Y_{t+s}}-\frac{C A_{t+s}}{Y_{t+s}} \frac{\frac{\partial Y_{t+s}}{\partial K_{t}}}{Y_{t+s}}
$$

\footnotetext{
${ }^{12}$ The essential condition which the intertemporal budget constraint requires is that the debt or credit principal must vanish in the limit.
} 


$$
\begin{gathered}
=\frac{\left\{\Omega_{t+s} \prod_{i=1}^{s} \frac{d K_{t+i}}{d K_{t+i-1}}+\sigma_{t+s} r \frac{\partial B_{t+s}}{\partial K_{t}}\right\}}{Y_{t+s}} \\
-\frac{C A_{t+s}}{Y_{t+s}} \frac{A_{t+s} F^{\prime}\left(K_{t+s}\right) \prod_{i=1}^{s} \frac{d K_{t+i}}{d K_{t+i-1}}}{Y_{t+s}}
\end{gathered}
$$

The first term here is positive, while the sign of the second term depends upon the sign of $\frac{C A_{t+s}}{Y_{t+s}}$. If $\frac{C A_{t+s}}{Y_{t+s}}<0$, then the future response of the current account over output is unambiguously positive. In the case where $\frac{C A_{t+s}}{Y_{t+s}}>0$, a sufficient condition for the future response to be positive is that $\frac{C A_{t+s}}{Y_{t+s}}<\frac{\Omega_{t+s}}{A_{t+s} F_{t+s}^{\prime}}+\frac{\sigma_{t+s} r \frac{\partial B_{t+s}}{\partial K_{t}}}{A_{t+s} F_{t+s}^{\prime}{ }_{i=1}^{s} \frac{d K_{t+i}}{d K_{t+i-1}}}$, which occurs almost surely in the limit as the denominator on the second term goes to zero. Thus, the response of the current account to output ratio is also L-shaped. 
Figure A.1: Phase Diagram Dynamics - Output:capital Ratio and Tobin's q

CAPITAL ADJUSTMENT COST MODEL DYNAMICS

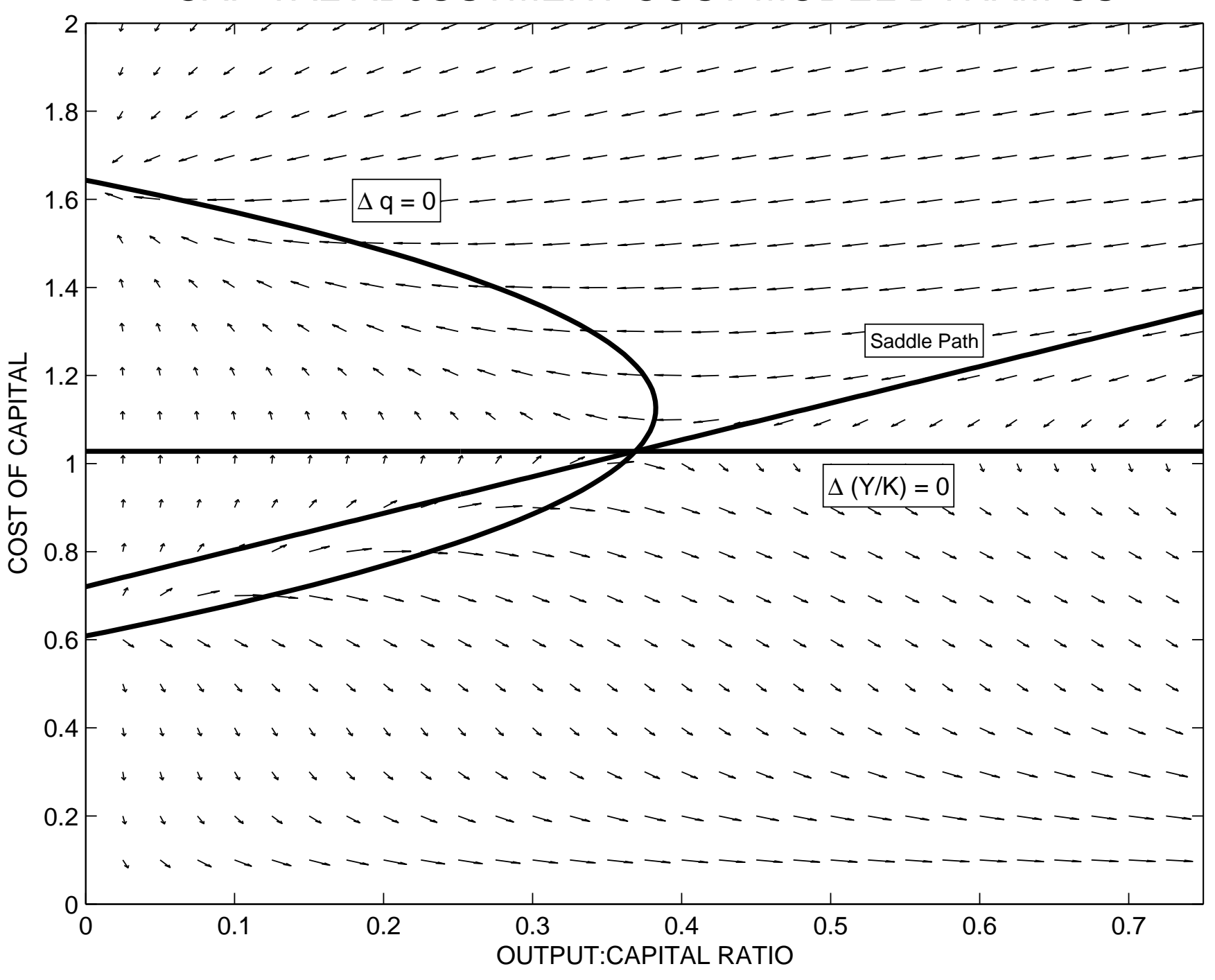

